International Scientific-Technical and Production Journal

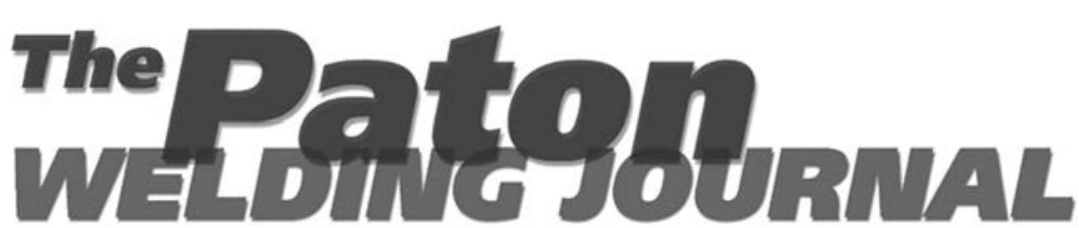

December 2015

English translation of the monthly «Avtomaticheskaya Svarka» (Automatic Welding) journal published in Russian since 1948

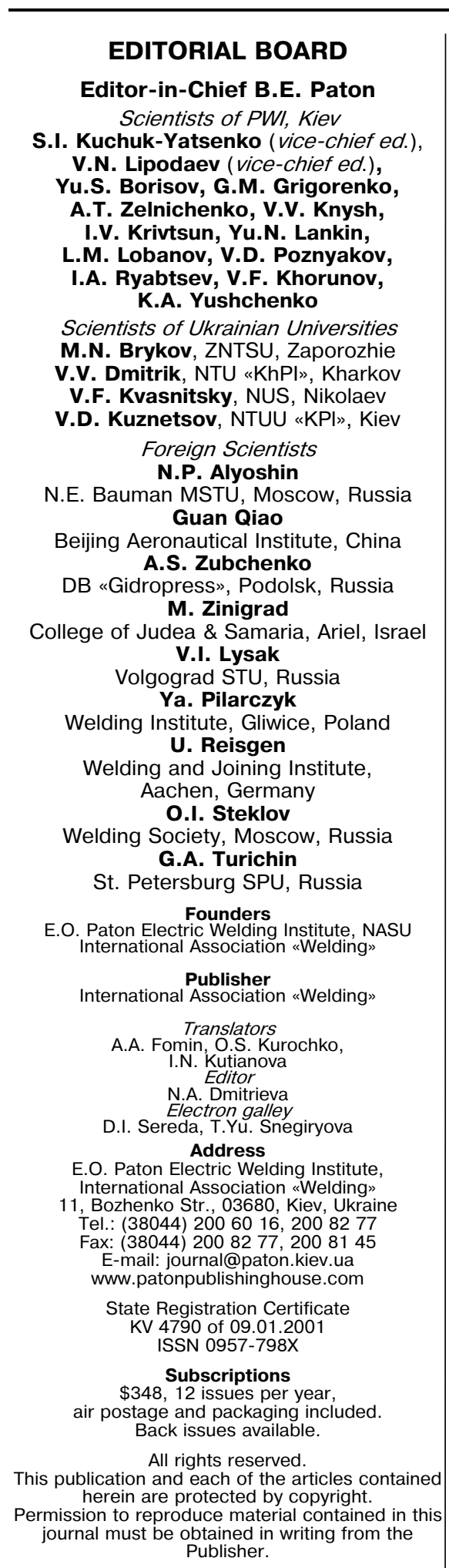

\title{
CONTENTS
}

\section{SCIENTIFIC AND TECHNICAL}

Paton B.E., Kaleko D.M., Kedrovsky S.N., Koval Yu.N., Krivtsun I.V. and Slepchenko V.N. Resistance welding of shape-memory copper-aluminium alloy

Maksymova S.V., Khorunov V.F. and Myasoedov V.V.

Effect of depressants and base metal on microstructure of brazed seams in joints of $\mathrm{Ni}_{3} \mathrm{Al}$-based alloys with

Inconel 718 alloy

Khaskin V.Yu., Korzik V.N., Sydorets V.N., Bushma A.I.,

Wu Boyi and Luo Ziyi. Improving the efficiency of hybrid welding of aluminum alloys

Tsybulkin G.A. On the influence of capacitance in the

welding circuit on stability of arc welding mode

Dmitrik V.V., Sobol O.V., Pogrebnoj M.A., Glushko A.V. and Ishchenko G.I. Structural changes in metal of welded joints of steam pipelines in operation

\section{INDUSTRIAL}

Nesterenkov V.M., Kravchuk L.A., Arkhangelsky Yu.A., Petrik I.A. and Marchenko Yu.A. Electron beam welding of medium-pressure chamber of gas turbine engine

Zubchenko Yu.V. and Ternovoj E.G. Development of new emission systems of electron beam guns for process operations under space conditions

Levchenko O.G., Maksimov S.Yu., Lukianenko A.O. and Lendel I.V. Comparative hygienic evaluation of arc welding process at constant and pulsed electrode wire feed

Pentegov I.V. and Sydorets V.N. Comparative analysis of models of dynamic welding arc

\section{INFORMATION}

Machines for flash-butt welding of band saws, rods, wires and bars

Index of articles for TPWJ'2015, Nos. 1-12 ........................... 53

List of authors for TPWJ'2015, Nos. 1-12 ........................ 57 


\title{
RESISTANCE WELDING OF SHAPE-MEMORY COPPER-ALUMINIUM ALLOY
}

\author{
B.E. PATON ${ }^{1}$, D.M. KALEKO ${ }^{1}$, S.N. KEDROVSKY ${ }^{2}$, Yu.N. KOVAL ${ }^{2}$, \\ I.V. KRIVTSUN ${ }^{1}$ and V.N. SLEPCHENKO ${ }^{2}$ \\ ${ }^{1}$ E.O. Paton Electric Welding Institute, NASU \\ 11 Bozhenko Str., 03680, Kiev, Ukraine. E-mail: office@paton.kiev.ua \\ ${ }^{2}$ G.V. Kurdyumov Institute for Metal Physics, NASU \\ 36 Acad. Vernadsky Blvd., 03680, Kiev, Ukraine. E-mail: metall@imp.kiev.ua
}

\begin{abstract}
$\mathrm{Cu}-\mathrm{Al}$ based shape-memory alloys (SMA) are an attractive replacement for expensive SMA of $\mathrm{Ti}-\mathrm{Ni}$ system in fasteners, thermal automatic device activators, and superelastic elements of instrumentation. Therefore, the problem of joining the latter in different combinations with similar material and other structural metals has become urgent. The main requirement to such joints, in addition to strength, is preservation of functional characteristics, namely temperature range of shape restoration at thermoelastic martensite transformation. Weldability of $\mathrm{Cu}-\mathrm{Al}$ alloys in the form of $0.05 \mathrm{~mm}$ thick foil, $0.3 \mathrm{~mm}$ thick strip and $1 \mathrm{~mm}$ diameter wire by spot and butt capacitor-type welding was studied, and it was shown that at pulsed welding heating the functional characteristics in the welding area are preserved in joints with rupture strength, corresponding to the respective base metal strength. Metallographic examination showed recrystallization of the initial coarse-crystalline metal in welding heating zone with formation of fine-crystalline structure, both in the solid-state joints and around the cast nugget in spot welding of $0.3 \mathrm{~mm}$ strip. Sound butt joints of SMA and copper wire were produced. 5 Ref., 1 Table, 10 Figures.
\end{abstract}

$\boldsymbol{K} \boldsymbol{e} \boldsymbol{y} \boldsymbol{w} \boldsymbol{O} \boldsymbol{d} \boldsymbol{s}: \quad$ shape-memory alloys, copper-aluminium alloys, resistance spot welding, resistance butt welding, thermoelastic martensite transformation

Alloys characterized by thermoelasticity effect, so-called shape-memory alloys (SMA), are ever wider applied in medical engineering products (implants, prostheses, instruments), as part of thermal instrument activators and in mounting devices for tight mechanical joints, for instance, of pipelines.

The most widely accepted today are alloys based on NiTi intermetallic of almost equiatomic composition (nitinol) with alloying additives, enhancing their functional capabilities. The main advantage of nitinol is its bioinertness and atoxicity, that is critical in manufacture of medical engineering products. In other applications superplasticity inherent to nitinol is used, which is manifested at temperatures above the end of austenite transformation [1-3].

Nitinol is not the only known SMA. Thermoelasticity phenomenon is observed in a number of other alloys, of which $\mathrm{Cu}-\mathrm{Al}$ alloys are the best adaptable to manufacture. Compared to nitinol, these alloys have such advantages as lowering of initial material cost and simplicity of their melting technology that is important in connection with expansion of SMA application in engineering, as well as temperature range of martensite transformations higher than that of nitinol [3].

Nitinol weldability, both in the solid, and in the molten state, was studied by a number of researchers. Analysis of these works [4] showed that the most efficient are joining processes with pulsed heating, when reactions of the change of NiTi stoichiometric state do not have enough time to run in the welding zone, with precipitation of phases with another chemical formula $\left(\mathrm{Ti}_{2} \mathrm{Ni}\right.$ and $\mathrm{TiNi}_{3}$ ). Such processes include spot and percussion capacitor-type welding of flat and roundshaped parts with the characteristic size of up to $1 \mathrm{~mm}$.

Considering the good prospects for $\mathrm{Cu}-\mathrm{Al}$ alloy application in engineering, searching for respective welding processes for small cross-section parts from these alloys remains urgent.

Investigations were conducted with $\mathrm{Cu}-\mathrm{Al}$ alloy samples, having mechanical characteristics and temperature of plasticity loss higher than those of binary alloy [3].

Chemical composition of the studied alloy in the initial condition was as follows, wt.\%: $0.162 \mathrm{Ni} ; 0.85 \mathrm{Co} ; 0.22 \mathrm{Fe} ; 3.79 \mathrm{Mn} ; 11.1 \mathrm{Al}$; $83.9 \mathrm{Cu}$.

Resistance welding of $\mathrm{Cu}-\mathrm{Al}$ system alloy was studied on samples from $50 \mu \mathrm{m}$ thick foil, $300 \mu \mathrm{m}$ thick strip and $1 \mathrm{~mm}$ diameter wire. Joint quality 
Optimum modes of spot capacitor-type welding of foil and strip from $\mathrm{Cu}-\mathrm{Al}$ SMA (capacitor capacitance of $200 \mu \mathrm{F}$, number of choke turns of 140)

\begin{tabular}{||c|c|c|c|}
\hline $\begin{array}{c}\text { Sample } \\
\text { (thickness, mm) }\end{array}$ & $\begin{array}{c}\text { Capacitor } \\
\text { charging } \\
\text { voltage, V }\end{array}$ & $\begin{array}{c}\text { Transformation } \\
\text { ratio }\end{array}$ & $\begin{array}{c}\text { Compression } \\
\text { force, daN }\end{array}$ \\
\hline Foil (0.05) & 600 & 200 & 15 \\
\hline Strip (0.30) & 750 & 150 & 30 \\
\hline
\end{tabular}

was assessed by mechanical strength, as well as by comparison of phase transition temperatures of the initial metal and the welded joint.

Overlap joints of flat samples were welded in capacitor-type TKM-17 machine [5]. Considering the high heat and electric conductivity of the tested material, special attention was given to electrode material selection. Experiments showed that in spot welding of foil, the best result is obtained with electrodes with a molybdenum insert, limiting heat removal from the welded joint, whereas in strip welding standard [5] electrodes from known M3Ts alloy can be used.

Parts surface did not require any special preparation, if it did not have scale after rolling.

Optimum welding mode (the Table) was determined by the results of mechanical tensile testing of samples, made from foil, in tensile testing machine RMU-005-01, and testing strip samples in R-05 machine.

Samples of resistance butt welding of wire were produced in a laboratory machine, using discharge current of supercapacitors, ensuring constant electric characteristics during welding. As shown by oscillogram (Figure 1), welding current value practically does not change at discharge of supercapacitors of $50 \mathrm{~F}$ capacitance for $40 \mathrm{~ms}$. This makes the process of welding by supercapacitor discharge similar to direct current welding. Here there is no need to trace distortions of current associated with its rectification.

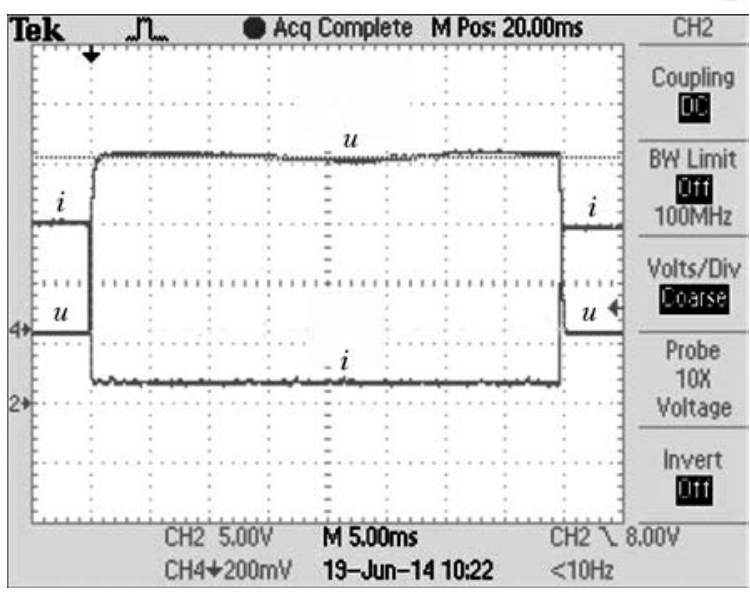

Figure 1. Oscillogram of supercapacitor discharge current and electric voltage on samples, joined in butt welding of $0.8 \mathrm{~mm}$ diameter copper and $1.0 \mathrm{~mm}$ diameter $\mathrm{Cu}-\mathrm{Al}$ based SMA

Capacitor charging voltage $(7-30 \mathrm{~V})$, discharge duration $(2-10 \mathrm{~ms})$, and compression forces $(30-50 \mathrm{~N})$ were the mode variables. Current and heating time values were monitored with TDS 2004 oscillograph. Joint quality was determined by welded sample bending (similar joints) and tension (including copper wire joints) in RMU-0.05-01 machine. Samples failing at not less that $2-3 \mathrm{~mm}$ from butt plane in bending were considered sound.

Welded joint microstructure was studied in AXIOVERT 40 MAT microscope.

Characteristic temperatures of martensite transformation of samples of $\mathrm{Cu}-\mathrm{Al}$ complex alloy were monitored by measurement of temperature dependence of electric resistance.

At tensile testing of samples from both foil and strip, joined by spot welding, the joint fails with material tearing out (Figure 2). Torn-out strip portion (Figure 3 ) has the shape of a regular circle, that would correspond to electrode contact surface, but it is elongated in the direction of load application, and the torn-put part of the joint is conical.
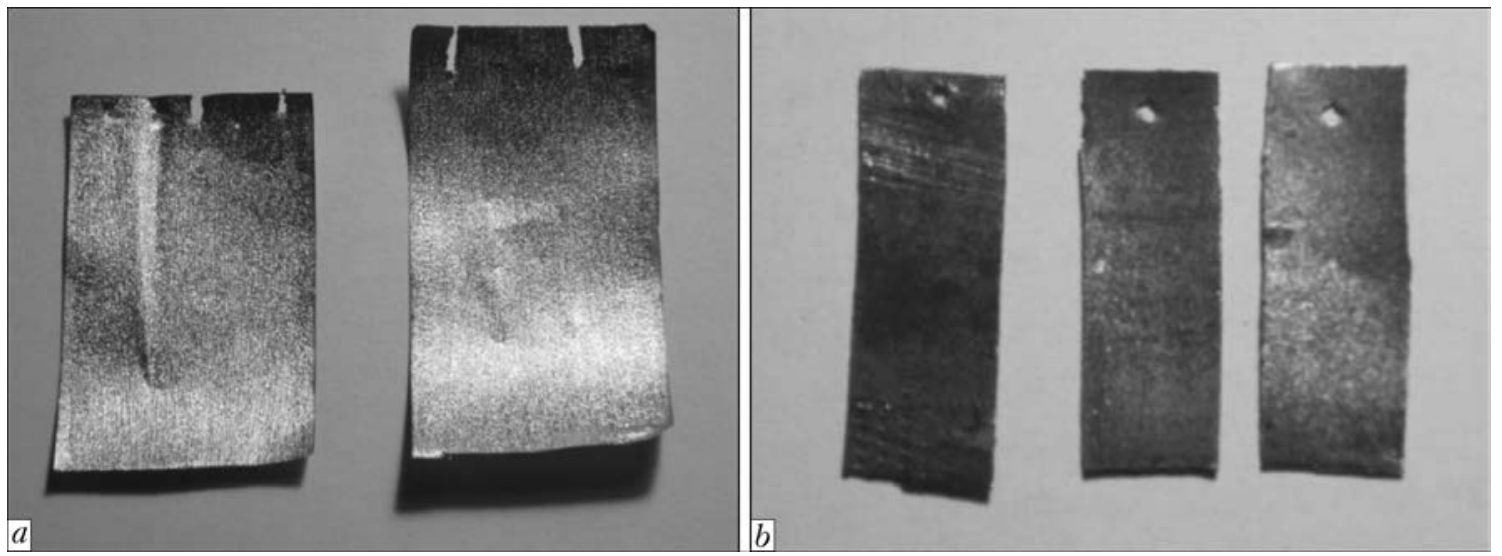

Figure 2. Samples made by spot capacitor-type welding after rupture testing: $a-$ foil $0.05 \mathrm{~mm}$ thick; $b-0.3 \mathrm{~mm}$ thick strip 
SCIENTIFIC AND TECHNICAL
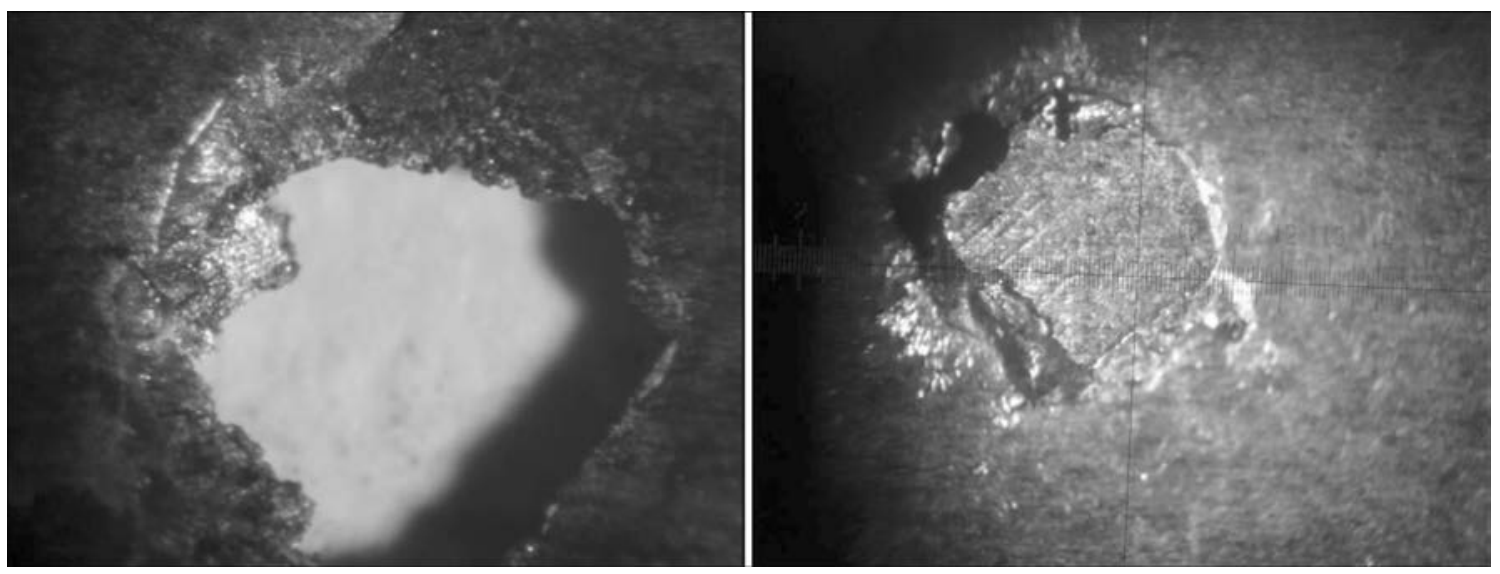

Figure 3. Shape of fracture of spot joint of $0.3 \mathrm{~mm}$ thick strip after tensile loading
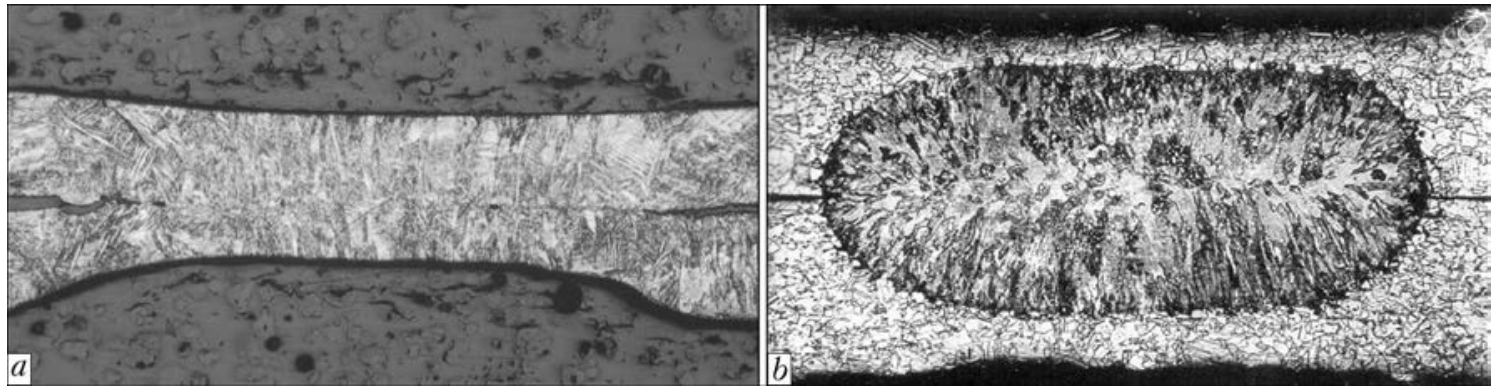

Figure 4. Microstructure of spot joint of $0.05 \mathrm{~mm}$ thick foil $(a-\times 300)$ and $0.3 \mathrm{~mm}$ thick strip $(b-\times 100)$

To improve measurement accuracy, experiments on foil $25 \mathrm{~mm}$ wide were conducted with different number of spots in the joint (from 2 up to 5 spots in a row). Average strength of one spot in such joints was equal to 0.46 daN. Breaking force of strip spot joint was equal to $80( \pm 5)$ daN.

Metallographic analysis of the structure of spot welded samples of material of different thickness $(50$ and $300 \mu \mathrm{m})$ showed a significant difference in the type of joint formation. While at foil spot welding, considering the high specific load in welding, the joint was produced in the solid state (Figure 4, $a$ ), a cast nugget formed in the strip joint (Figure 4, $b$ ).

Comparison of the structure of the joint central zone and its periphery showed (Figure 5) that the metal of foil, used in this study, has initial coarse-grained structure, which was formed as a result of annealing during drawing in fabrication. In solid-state spot welding, however, metal recrystallization in the heating zone and formation of columnar crystallites in the heat removal direction took place.

Owing to a pulsed heating mode in welding by a capacitor discharge, the joint zone is short, and structural changes, found during investigation, do not affect the functional properties of SMA.

In $0.05 \mathrm{~mm}$ samples, the most sensitive to heating, temperature dependence of electrical resistance in the state before and after welding was studied. It is found that no change of martensite transformation parameters is observed in the met-
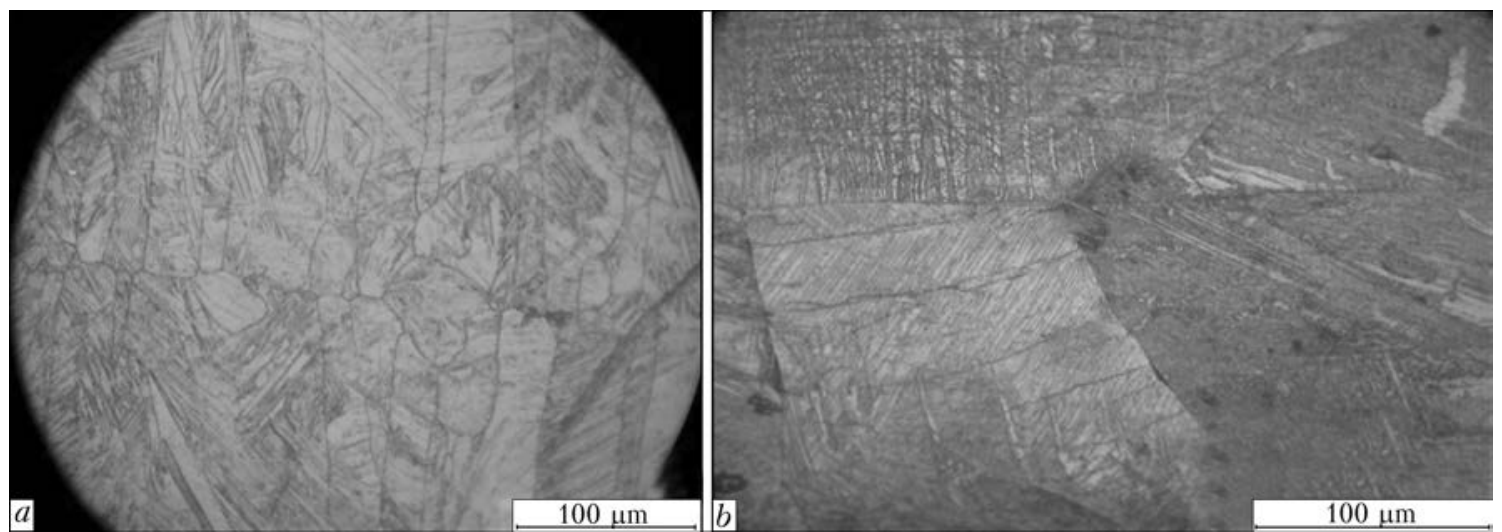

Figure 5. Microstructure of zone of foil spot welding: $a-$ central part; $b$ - base metal 

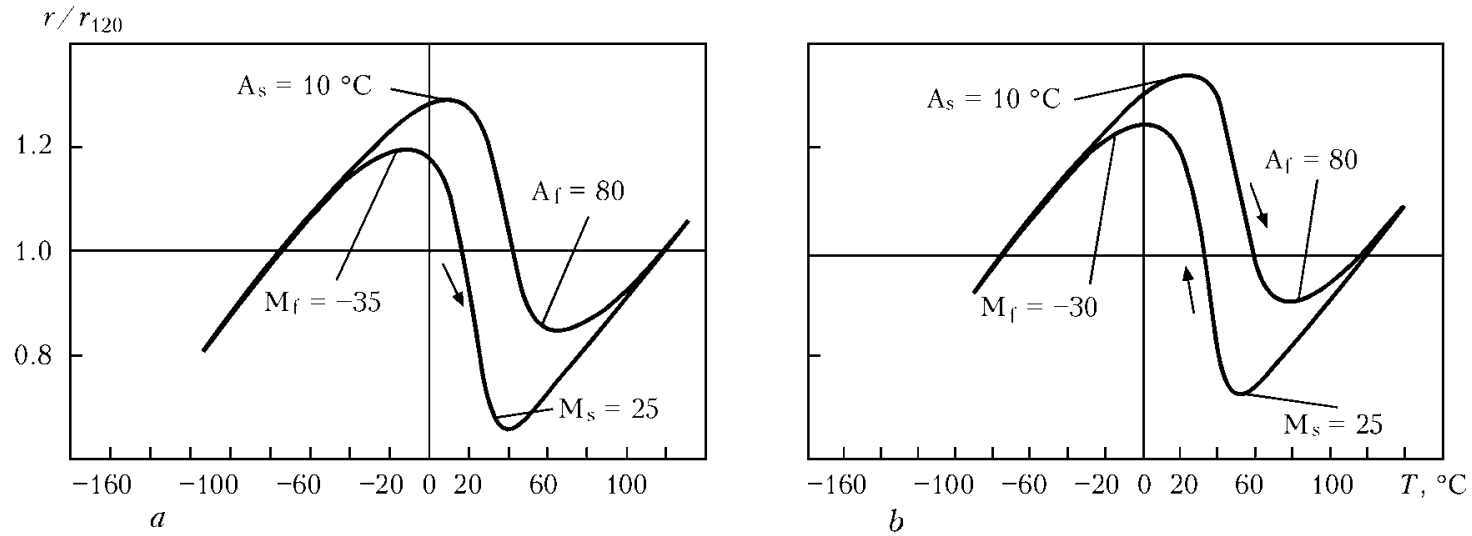

Figure 6. Temperature dependence of electrical resistance of samples outside $(a)$ and near $(b)$ the HAZ: $r_{120}-$ resistance at $120{ }^{\circ} \mathrm{C}$
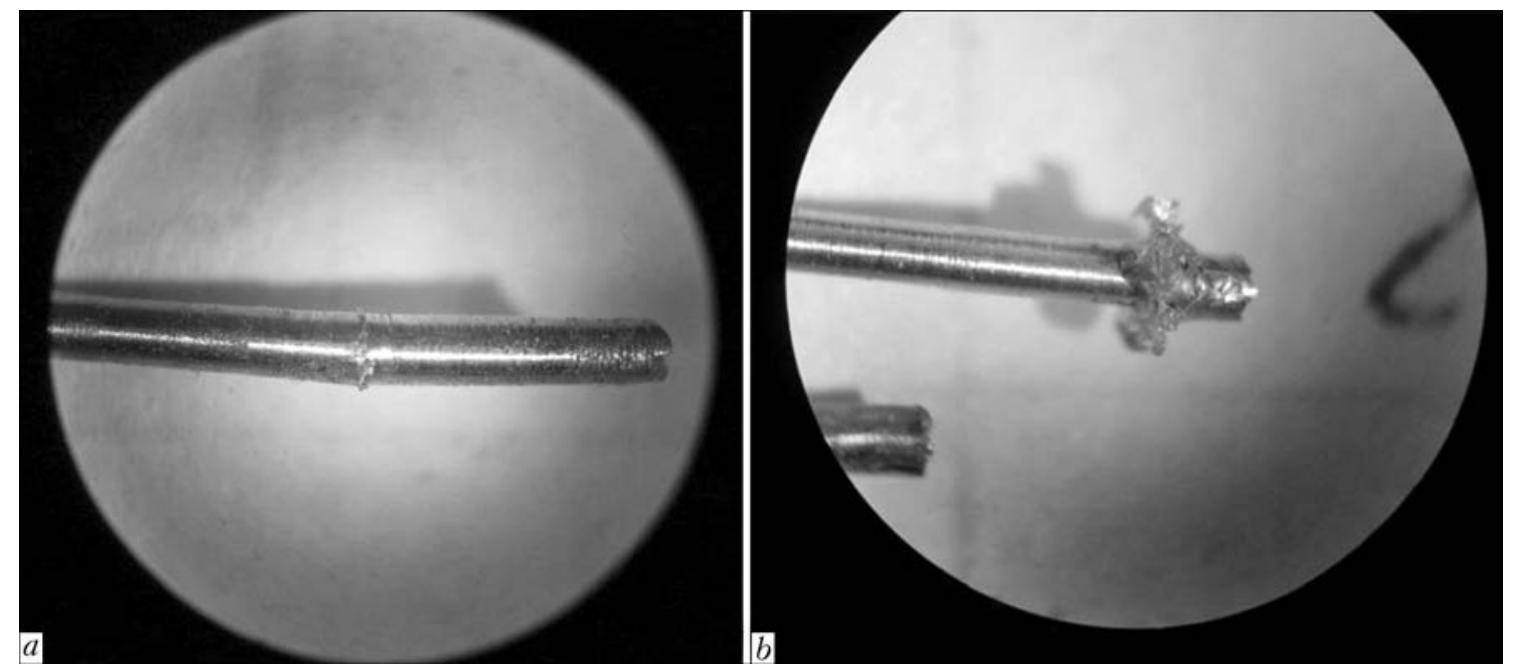

Figure 7. Appearance of butt joints of $1 \mathrm{~mm}$ diameter wire: $a$ - after welding (1250 A, $4.7 \mathrm{~ms}) ; b$ - after bend testing (610 A, $100 \mathrm{~ms})$

al not subjected to thermal impact (Figure 6, $a$ ). A certain increase of the temperature of the end of martensite transformation is observed near the HAZ (Figure $6, b$ ). It does not seem possible to study the weld zone for presence and parameters of martensite transformation, in view of its small dimensions.

Appearance of butt joints of $1 \mathrm{~mm}$ wire from $\mathrm{Cu}-\mathrm{Al}$ alloy, welded in different modes, is shown in Figure 7.

Metallographic examination showed (Figure 8) that in butt welding of the studied alloy, joining occurs in the solid state, with random formation of common grains. A characteristic feature of the microstructure near the interface is presence of scratches, which cannot be removed by polishing. Unlike spot welding (see Figure 5) in solid-state welding the metal initial structure does not change. Heat removal into the collet steel terminals in butt welding is much smaller than that into spot machine copper electrodes.

Note that metallographic investigations of butt joints were conducted on samples, which had withstood bending with fracture running beyond the butt joint.

Resistometry showed that, similar to investigation of samples of strip and foil spot joints, no change of martensite transformation temperature

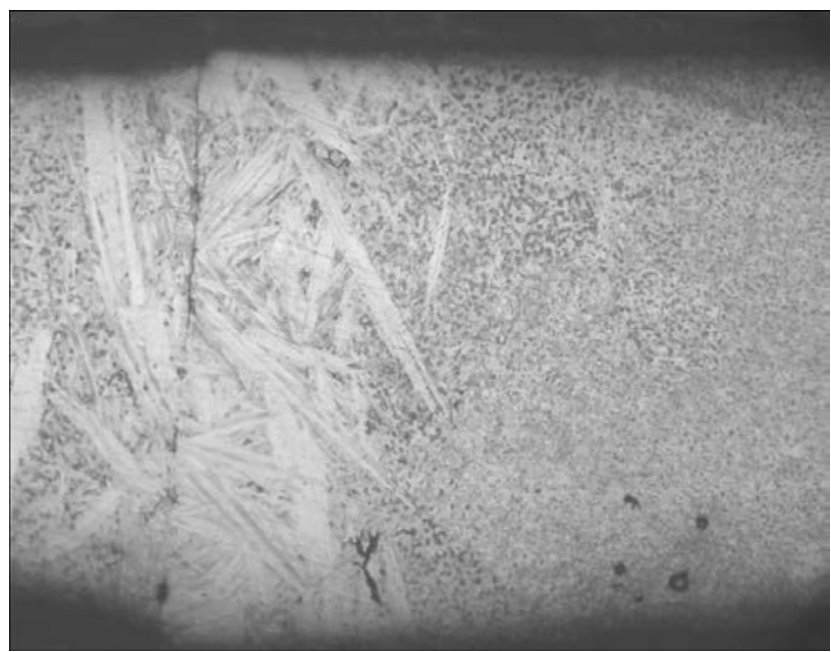

Figure 8. Microstructure $(\times 100)$ of joint of two $1 \mathrm{~mm}$ diameter wires from $\mathrm{Cu}-\mathrm{Al}$ alloy produced by butt capacitortype welding 

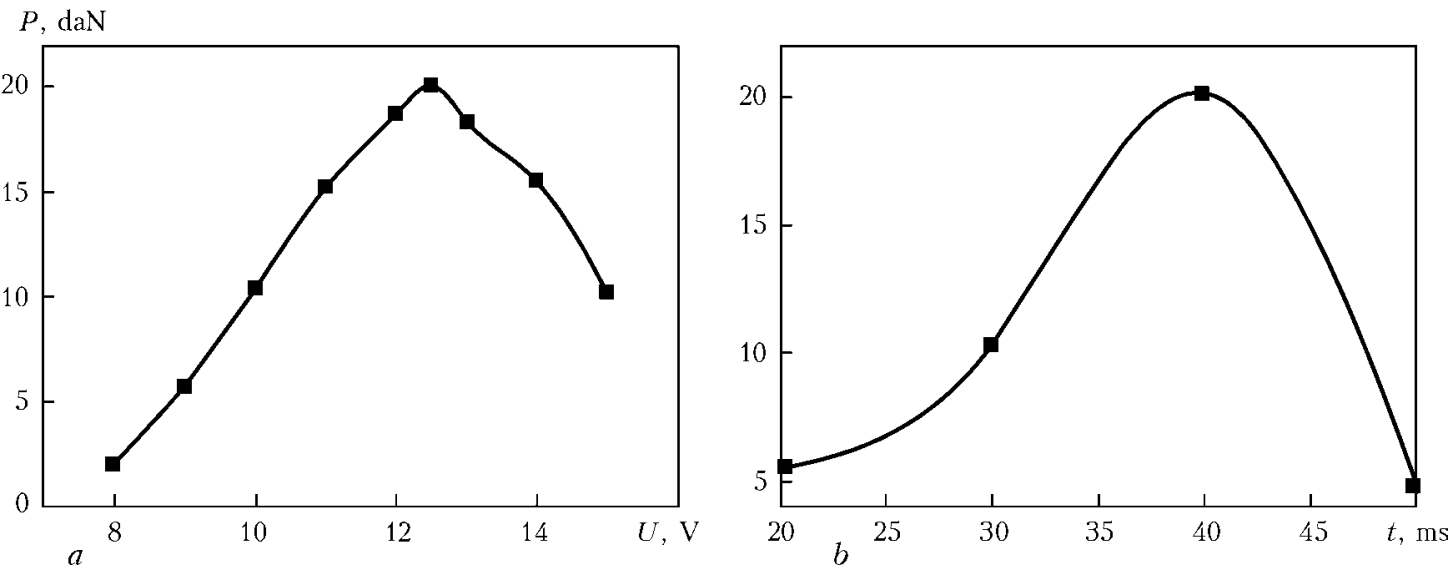

Figure 9. Dependence of strength of butt joints of copper wire with wire of $\mathrm{Cu}-\mathrm{Al}$ based complex alloy on supercapacitor charging voltage at $t=40 \mathrm{~ms}(a)$ and time of welding current running at $U=12.5 \mathrm{~V}(b)$

is observed in the peripheral zone of butt-welded joint.

Joints of functional material with structural metal, particularly with highly conductive copper and aluminium, are of practical importance.

Butt joints of $\mathrm{Cu}-\mathrm{Al}$ based complex alloy $(1.0 \mathrm{~mm}$ diameter wire) with copper wire $(0.8 \mathrm{~mm}$ diameter $)$ were studied. Maximum strength of the joint, determined by tensile testing, was obtained at supercapacitor charging voltage of $12.5 \mathrm{~V}$, welding current of $1152 \mathrm{~A}$ (see Figure 1), discharge duration of $40 \mathrm{~ms}$, length of copper wire free end of $2 \mathrm{~mm}$ and that of $\mathrm{Cu}-\mathrm{Al}$ SMA wire of $3 \mathrm{~mm}$, and upset force of $30 \mathrm{~N}$. Low longitudinal stability of copper was taken into account at selection of the sample free end length. It is also interesting to note lowering of voltage in the parts being welded in the oscillogram, associated, in our opinion, with increase of contact area. This proceeds for up to $25 \mathrm{~ms}$, which is followed by voltage increase, in keeping with increase of resistance of the parts being welded at heating.

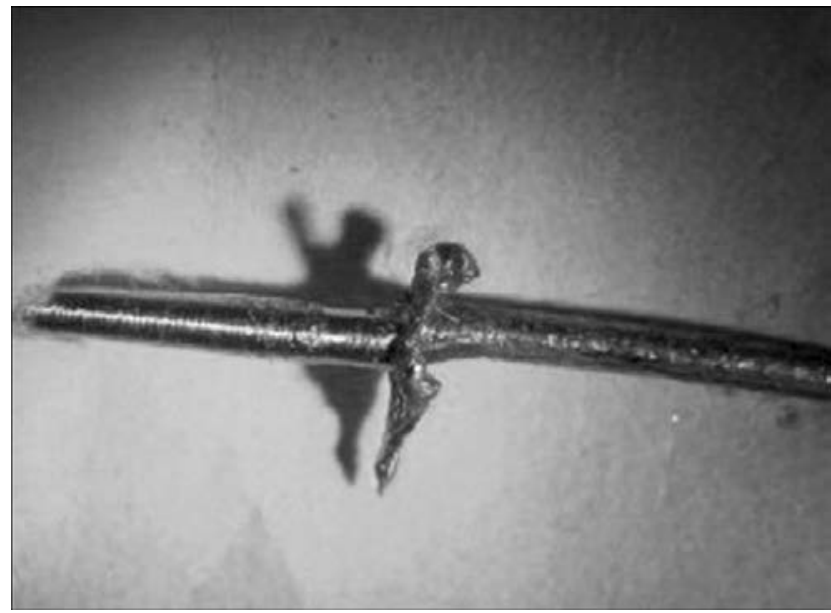

Figure 10. Sample of joint of $0.8 \mathrm{~mm}$ diameter copper wire (right) with $1.0 \mathrm{~mm}$ diameter $\mathrm{Cu}-\mathrm{Al}$ based alloy wire (left) produced by butt capacitor-type welding at $I=1152 \mathrm{~A}$ and $t=40 \mathrm{~ms}$
During investigations, welding time and capacitor charging voltage, which determines welding current value, were varied. Results of the dependence of joint strength on the mode variable parameters are given in Figure 9. As capacitor discharge voltage is measured much more accurately than the pulsed discharge current, the first was selected as the argument.

Dependencies of welded joint strength on charging voltage and welding current flowing time show the presence of mode parameter minimum. While strength improvement at increase of capacitor charging voltage (welding current value) and discharge time is readily explained by increase of joint area at increase of energy consumed in welding, strength lowering after passing the extremum point, as shown by studying the welded samples, is associated with melting out of a considerable amount of material ( $\mathrm{Fi}$ gure 10). As a result, at optimum value of the second parameter, the remaining solid metal in welding head clamps was insufficient for its reliable deformation at upsetting. Now, increase of wire extension from the collet clamp led to loss of longitudinal stability. At increase of mode parameters above those given in Figure 9, strength dropped to zero, as the wire was completely melted out right up to collet clamp contact.

A feature of dissimilar metal butt joints is more intensive heating of wire from $\mathrm{Cu}-\mathrm{Al}$ based complex alloy, compared to copper wire, having high electrical conductivity, despite its smaller diameter.

Thinning of wire from $\mathrm{Cu}-\mathrm{Al}$ based alloy, as a result of ductility increase at heating and ductile metal compression by the collet, is observed in welded samples (Figure 10), as well as noticeable upsetting of the copper wire. Owing to upsetting, as shown by metallographic examinations, the joint formed in the solid phase with a continuous boundary. This ensured equivalent 
strength of the joint on the level of that of the copper wire, i.e. at tensile testing the breaking force reached $200 \mathrm{~N}$, or about $400 \mathrm{MPa}$.

Attempts at butt welding of aluminium wire and wire from $\mathrm{Cu}-\mathrm{Al}$ based alloy failed. This is accounted for by a large difference in thermomechanical properties of the material, namely preservation of elasticity of $\mathrm{Cu}-\mathrm{Al}$ alloy at the temperature of the loss of elasticity by aluminium and the associated loss of the wire shape before sufficient heating of the functional alloy.

\section{Conclusions}

1. Owing to their low cost, shape-memory alloys of $\mathrm{Cu}-\mathrm{Al}$ system have good prospects for engineering application in automatics systems of thermal devices, structural element fasteners, undergoing considerable deformation without mechanical fracture. This accounts for the urgency of development of the technology of their joining in similar combination and in combinations with other structural metals.

2. Overlap and butt joints of complex SMA on $\mathrm{Cu}-\mathrm{Al}$ base, produced by the methods of pulsed capacitor-discharge resistance welding, are not only equivalent to base metal, but also demonstrate practically constant functional characteristics.

3. Depending on deformational characteristics of the part, spot-welded joints of the studied alloy can be produced both with a cast nugget, as by solid-state adhesion. Here the surface films (except for scale) have no adverse impact on welded joints.

4. Butt joints of wire from $\mathrm{Cu}-\mathrm{Al}$ SMA with copper wire can be produced, that allows designing items with shape restoration at heating by passing electric current.

5. Application of new type of welding system with transformerless discharge of supercapacitors for butt welding of wires showed the possibility of accurate control of heat input by variation of the time of discharge current switching on at its practically constant value, assigned by capacitor discharge voltage. Oscillographing the successive discharges at constant setting of mode parameters allows assessment of deviation from the nominal energy value of not more than $0.5 \mathrm{~J}$.

1. Koval, Yu.N., Lobodyuk, V.A. (2010) Deformation and relaxation phenomena at transformation of martensite type. Kiev: Naukova Dumka.

2. Gunter, V.E., Khodorenko, V.N., Yasenchuk, Yu.F. et al. (2006) Titanium nickelide. Medical material of new generation. Tomsk: MITs.

3. Otsuka, K., Shimizu, K. (1979) Shape memory effects in alloys. Moscow: Nauka.

4. Paton, B.E., Kaleko, D.M., Shevchenko, V.P. et al. (2006) Weldability of shape-memory alloys of $\mathrm{Ni}-\mathrm{Ti}$ system. The Paton Welding J., 5, 2-7.

5. Moravsky, V.E., Vorona, D.S. (1985) Technology and equipment for spot and capacitor-discharge projection welding. Kiev: Naukova Dumka.

Received 01.09.2015 


\title{
EFFECT OF DEPRESSANTS AND BASE METAL ON MICROSTRUCTURE OF BRAZED SEAMS IN JOINTS OF Ni3Al-BASED ALLOYS WITH Inconel 718 ALLOY
}

\author{
S.V. MAKSYMOVA, V.F. KHORUNOV and V.V. MYASOEDOV \\ E.O. Paton Electric Welding Institute, NASU \\ 11 Bozhenko Str., 03680, Kiev, Ukraine. E-mail: office@paton.kiev.ua
}

\begin{abstract}
Properties of brazed joints are caused by their microstructure. Therefore, metallographic and X-ray microspectral analysis of brazed joints have large importance in selection of composition of brazing filler metal and parameters of technological mode of brazing. Relevance of such investigations rises in development of technological processes for brazing of the joints from materials of new generation, to which nickel alloys based on $\gamma^{\prime}$-Ni3Al intermetallic can be referred. This paper represents the results of metallographic and $\mathrm{X}$-ray microspectral analysis of the brazed joints from heat-resistant nickel alloy based on $\mathrm{Ni} 3 \mathrm{Al}$ intermetallic with Inconel 718 grade wrought alloy produced with the $\mathrm{Ni}-\mathrm{Cr}-\mathrm{Fe}-\mathrm{B}-\mathrm{Si}$ and $\mathrm{Ni}-\mathrm{Pd}-\mathrm{Cr}-\mathrm{X}(\mathrm{Ge}, \mathrm{Co})$ system brazing filler metals. Effect of depressants, i.e. boron and silicon, on formation of structure in seams is shown. Influence of constituents of material being brazed on composition and morphology of seam is determined. It is found that brazing of $\mathrm{Ni} 3 \mathrm{Al}$-based alloy using $\mathrm{Ni}-\mathrm{Pd}-\mathrm{Cr}-\mathrm{X}(\mathrm{Ge}, \mathrm{Co})$ brazing filler metal provides for seam structure consisting of solid solution based on nickel and single dispersed phases. The latter are enriched with $(\mathrm{Pd}, \mathrm{X}) \mathrm{Al}$ type aluminum, a concentration of which corresponds to aluminum concentration in the base metal. Their formation takes place due to diffusion processes at interface. Single-phase areas consisting of nickel-based solid solution are observed in the brazed seam. 12 Ref., 6 Tables, 7 Figures.
\end{abstract}

Key words: vacuum brazing, heat-resistant $\mathrm{Ni} 3 \mathrm{Al}$ based alloy, microstructure, seam, X-ray microspectral analysis, solid solution, brazing filler metal

Brazing finds wide application in number of branches of industry due to possibility to preserve base metal structure (since only brazing filler metal (BFM), which has lower melting temperature, is melted) and join materials in difficultto-reach places [1-3]. Number of BFMs exist at present time. However, each material being brazed requires individual approach in selection of composition of BFM. It is caused by its structural peculiarities, specific operation conditions and required mechanical properties of the brazed joints. Brazed joint structure is determined by seam structure. Therefore, large attention is paid to metallographic and X-ray microspectral analysis of the brazed joints, which stipulate choice of BFM composition and parameters of technological mode of brazing [4]

Relevance of such investigations increases in development of technological processes for production of the brazed joints from new generation materials, to which alloys based on $\gamma^{\prime}-\mathrm{Ni}_{3} \mathrm{Al}$ intermetallic are referred. $\mathrm{Ni}_{3} \mathrm{Al}$ intermetallic bond has high melting temperature $\left(1385^{\circ} \mathrm{C}\right)$, reduced density $\left(7.5 \mathrm{~kg} / \mathrm{m}^{3}\right)$ and thermal stability of structure up to melting temperature $[5,6]$.

This work represents the results of metallographic and X-ray microspectral analysis on study the effect of base metal composition $\left(\mathrm{Ni}_{3} \mathrm{Al}-\right.$ based alloy) and depressants (boron) on structure and morphological structure of the brazed joints produced using $\mathrm{Ni}-\mathrm{Cr}-\mathrm{Fe}-\mathrm{B}-\mathrm{Si}$ and $\mathrm{Ni}-$ $\mathrm{Pd}-\mathrm{Cr}-\mathrm{X}(\mathrm{Ge}, \mathrm{Co})$ system BFMs. Nickel heatresistant alloys based on $\mathrm{Ni}_{3} \mathrm{Al}$ intermetallic in

Table 1. Base metal composition investigated

\begin{tabular}{||c|c|c|c|c|c|c|c|c|c|c||}
\hline \hline \multirow{2}{*}{ Alloy grade } & \multicolumn{10}{|c|}{ Weight fraction of chemical elements, \% } \\
\cline { 2 - 20 } & $\mathrm{Ni}$ & $\mathrm{Al}$ & $\mathrm{Cr}$ & $\mathrm{Nb}$ & $\mathrm{Mo}$ & $\mathrm{Si}$ & $\mathrm{Ti}$ & $\mathrm{W}$ & $\mathrm{Fe}$ & $\mathrm{C}$ \\
\hline $\mathrm{Ni}_{3} \mathrm{Al}(1)$ & Base & 10 & 4 & - & - & 1.5 & 1 & 3 & - \\
\hline $\mathrm{Ni}_{3} \mathrm{Al}(2)$ & Base & 9 & - & - & 18 & - & - & - & - & - \\
\hline Inconel 718 & 53 & 0.8 & 19 & 5.5 & 3.3 & - & 0.95 & - & 18 & 0.08 \\
\hline
\end{tabular}




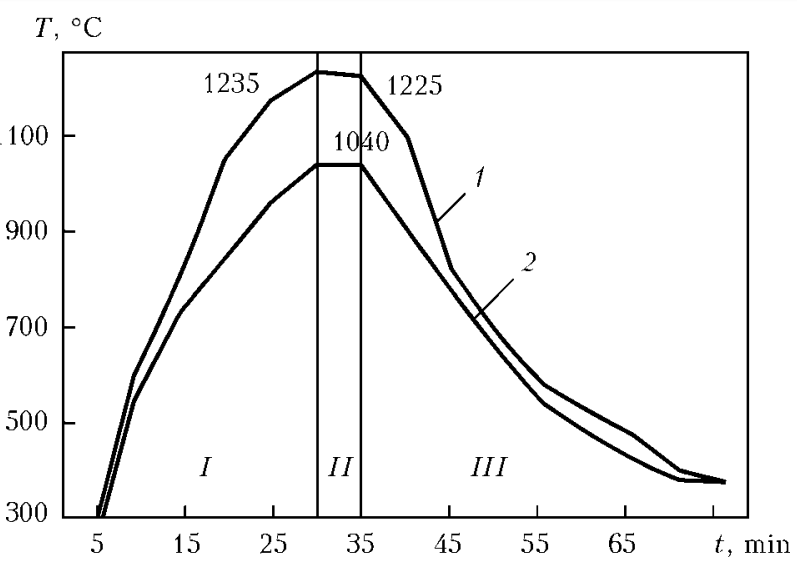

Figure 1. Curves of thermal cycle of specimen brazing: 1 palladium BFM; 2 - B-containing BFM; $I$ - heating; $I I$ - holding, $I I I$ - cooling

similar and dissimilar combinations with wrought nickel alloy Inconel 718 (Table 1) were used as base metal for experiments.

Vacuum brazing of specimen lap joints was carried out in vacuum furnace $\left(1.33 \cdot 10^{-4} \mathrm{~Pa}\right)$ with radiation heating. $\mathrm{Ni}_{3} \mathrm{Al}$-based nickel alloy and wrought alloy Inconel 718 was brazed by palladium $\mathrm{Ni}-\mathrm{Pd}-\mathrm{Cr}-\mathrm{X} \mathrm{BFM}$ using mode 1 and B-containing BFM BMF-20 ( $\mathrm{Ni}-\mathrm{Cr}-\mathrm{Fe}-\mathrm{B}-\mathrm{Si})$ using mode 2 (Figure 1).

Microsections of the brazed joints were manufactured by standard procedure for performance of metallographic and X-ray microspectral analysis using electron scanning microscope TescanMira 3 LMU equipped with Oxford Instruments energy-dispersive spectrometer $\mathrm{X}$-max $80 \mathrm{~mm}^{2}$ (with INCA software). Locality of X-ray microspectral analysis did not exceed $1 \mu \mathrm{m}$. Distribution of chemical elements and exposure of microstructures were carried out using back-side illumination mode (BSI) allowing differentiating structural constituents by atomic mass (without chemical etching).

Visual examination of received specimens in both cases showed good wetting of the materials
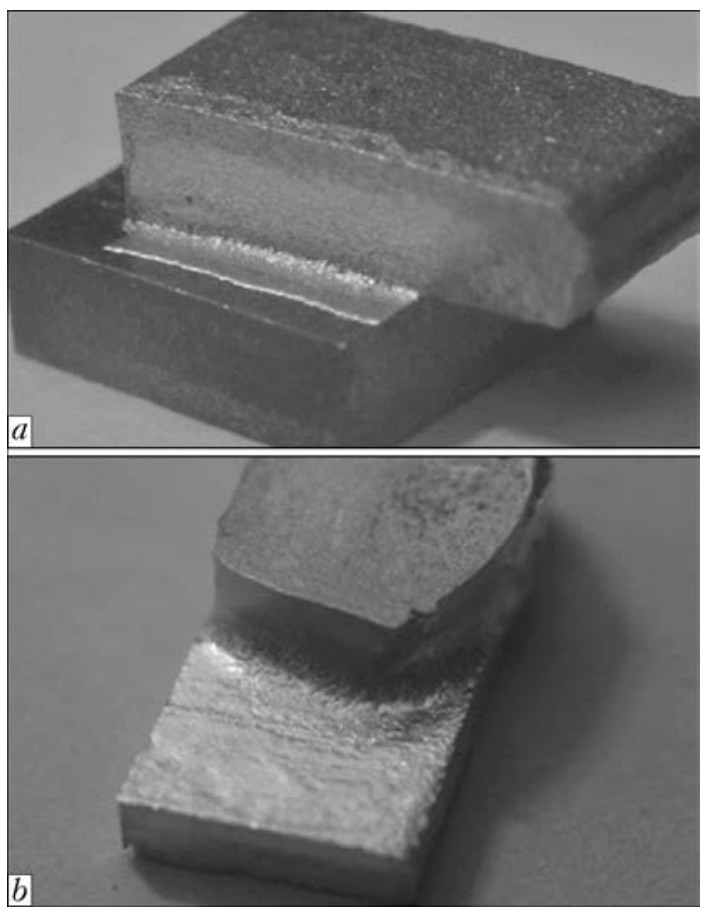

Figure 2. View of $\mathrm{Ni}_{3} \mathrm{Al}+$ Inconel 718 brazed specimens produced using BFMs of $\mathrm{Ni}-\mathrm{Cr}-\mathrm{Fe}-\mathrm{B}-\mathrm{Si}(a)$ and $\mathrm{Ni}-\mathrm{Pd}-$ $\mathrm{Cr}-\mathrm{X}(b)$ system

being brazed by BFM, filling of the clearances and formation of full fillets (Figure 2).

Metallographic examinations showed that the dark phase acicular particles (Figure $3, a-c$ ) can be observed in the seam and base Inconel 718 metal against light matrix background when using $\mathrm{Ni}-\mathrm{Cr}-\mathrm{Fe}-\mathrm{B}-\mathrm{Si}$ system $\mathrm{BFM}$. Examination of element composition distribution in local areas of the brazed joint was carried out with the help of X-ray microspectral analysis. It revealed increased concentration of chromium in these particles (Figure 3, $d$; Table 2, spectrum 1 and 2). Their precipitation is mainly observed in a zone of Inconel 718 alloy (lower specimen) adjacent to the seam and at interface in the seam zone.

Examination of change of element concentration along the scanning line, passing through this

Table 2. Distribution of elements in brazed seam of $\mathrm{Ni}_{3} \mathrm{Al}+$ Inconel 718 joint (acc. to Figure 3 )

\begin{tabular}{|c|c|c|c|c|c|c|c|c|c|}
\hline \multirow{2}{*}{$\begin{array}{l}\text { Spectrum } \\
\text { number }\end{array}$} & \multicolumn{9}{|c|}{ Chemical elements, wt.\% } \\
\hline & $\mathrm{Al}$ & $\mathrm{Si}$ & $\mathrm{Ti}$ & $\mathrm{Cr}$ & $\mathrm{Fe}$ & $\mathrm{Ni}$ & $\mathrm{Nb}$ & Mo & $\mathrm{W}$ \\
\hline 1 & 1.14 & 2.47 & 0.32 & 24.78 & 6.45 & 60.30 & 1.09 & 3.46 & - \\
\hline 2 & 0.61 & 1.50 & 0.25 & 37.93 & 5.81 & 47.45 & 0.76 & 4.68 & 1.01 \\
\hline 3 & 0.91 & 1.34 & 0.18 & 53.37 & 3.33 & 38.67 & 0.50 & 0.92 & 0.78 \\
\hline 4 & 16.13 & 1.71 & 0.09 & 4.99 & - & 76.62 & 0 & 0 & 0.46 \\
\hline 5 & 2.32 & 2.30 & 0.36 & 7.25 & 5.07 & 79.97 & 1.42 & 0.57 & 0.73 \\
\hline 6 & 9.59 & 0.62 & 1.12 & 3.76 & - & 82.65 & - & - & 2.27 \\
\hline 7 & 0.51 & 0.89 & 0.67 & 18.77 & 13.70 & 57.48 & 4.69 & 3.29 & - \\
\hline 8 & 1.93 & 2.39 & 0.40 & 13.16 & 5.49 & 74.88 & 1 & 0.29 & 0.45 \\
\hline 9 & 10.16 & 1.02 & 1.44 & 4.76 & 0.17 & 79.53 & - & - & 2.92 \\
\hline 10 & 0.45 & 0.14 & 0.90 & 19.69 & 17.16 & 51.88 & 5.91 & 3.87 & - \\
\hline
\end{tabular}




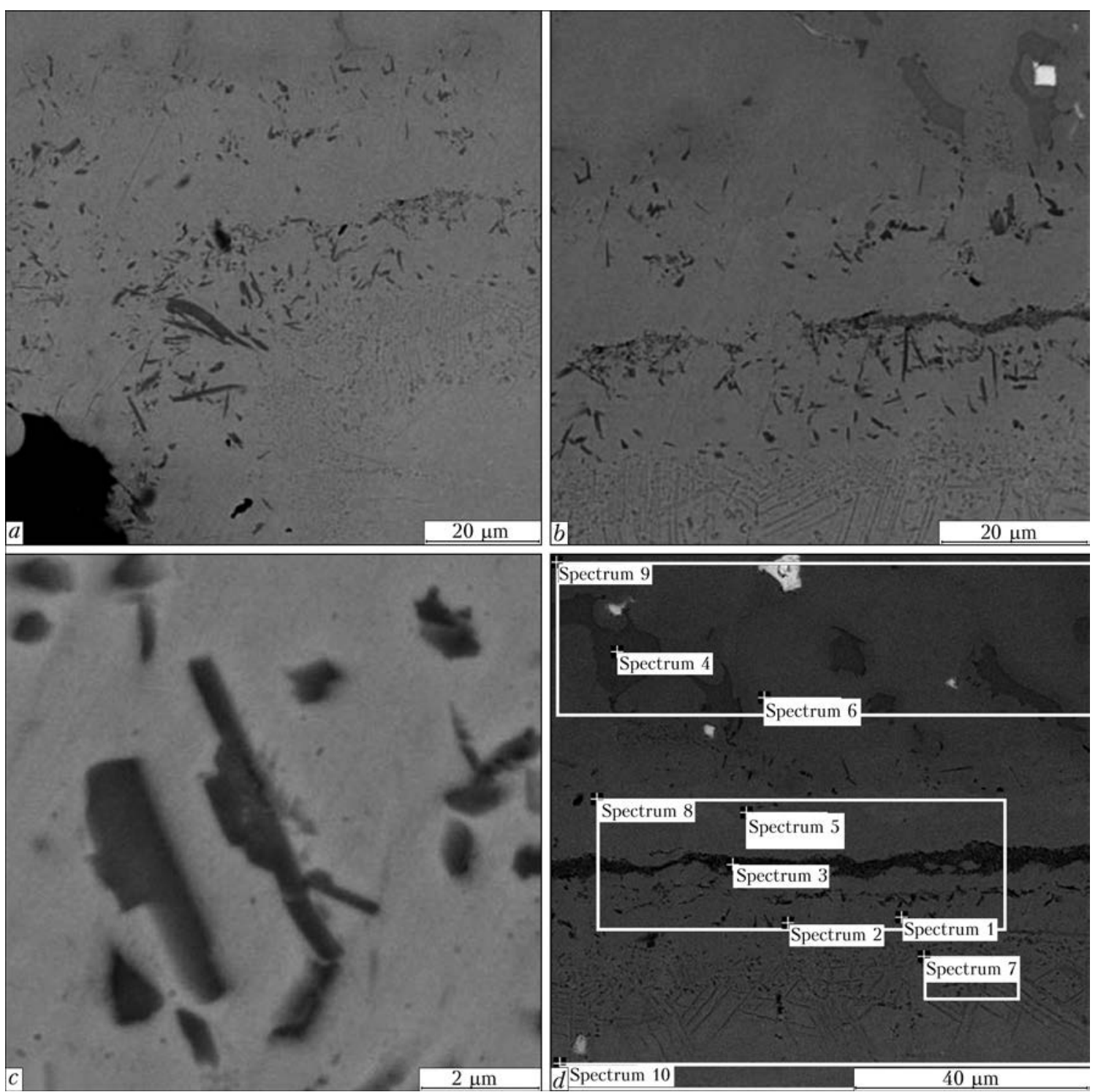

Figure 3. Microstructure of $\mathrm{Ni}_{3} \mathrm{Al}+$ Inconel 718 dissimilar brazed joint produced using $\mathrm{B}$-containing $\mathrm{BFM}$ of $\mathrm{Ni}-\mathrm{Cr}-$ Fe-B-Si system: $a-$ fillet area; $b-$ seam; $c$ - chromium borides; $d-$ examined areas

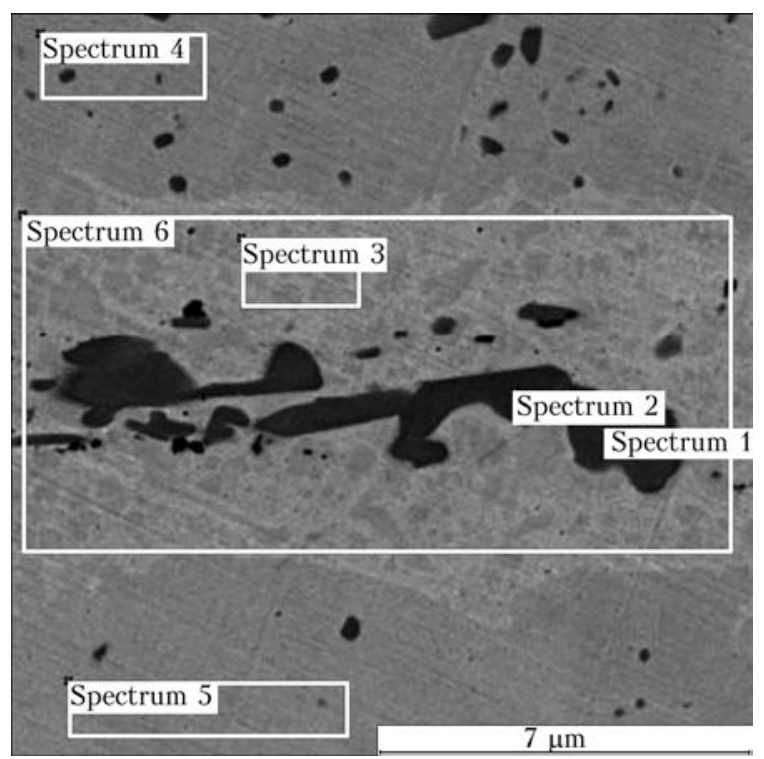

Figure 4. Microstructure of $\mathrm{Ni}_{3} \mathrm{Al}$ similar joint produced using B-containing BFM particle, showed increased content of boron and simultaneous reduction of nickel content. It indicates formation of B-containing phase. This can be explained by high chromium concentration (19\%) in brazed Inconel 718 in comparison with $\mathrm{Ni}_{3} \mathrm{Al}-$ based alloy ( $4 \%)$, that allows additional input of chromium in liquid BFM (during brazing) and assists active formation and precipitation of chromium borides. Amount of such precipitates is insignificant (Figure 3, $a, b$ ) at the interface with $\mathrm{Ni}_{3} \mathrm{Al}$-based nickel alloy (upper specimen).

Examination of chemical inhomogeneity of the brazed joints showed that increased concentration of chromium $(24.78-37.93 \%)$ is observed in acicular-like particles in the seam zone from Inconel 718 side and in the seam central zone (Figure 3, $d$; Table 2). In the latter case the Cr-based phase precipitates in a continuous band form. Such structural peculiarities have negative effect on properties of the brazed joints. 
Table 3. Distribution of elements in $\mathrm{Ni}_{3} \mathrm{Al}+\mathrm{Ni}_{3} \mathrm{Al}$ brazed joint (acc. to Figure 4)

\begin{tabular}{|c|c|c|c|c|c|c|c|c|}
\hline \multirow{2}{*}{$\begin{array}{l}\text { Spect- } \\
\text { rum } \\
\text { number }\end{array}$} & \multicolumn{8}{|c|}{ Chemical elements, wt.\% } \\
\hline & $\mathrm{B}^{*}$ & $\mathrm{Al}$ & $\mathrm{Si}$ & $\mathrm{Ti}$ & $\mathrm{Cr}$ & $\mathrm{Fe}$ & $\mathrm{Ni}$ & $\mathrm{W}$ \\
\hline 1 & 11.62 & - & - & - & 81.97 & - & 3.27 & 3.14 \\
\hline 2 & 6.58 & 2.37 & 1.16 & - & 37.70 & 1.66 & 48.72 & 1.81 \\
\hline 3 & - & 3.04 & 1.73 & 0.42 & 6.01 & 2.53 & 86.27 & - \\
\hline 4 & - & 5.83 & 1.69 & 0.31 & 3.54 & 1.06 & 86.95 & 0.62 \\
\hline 5 & - & 6.41 & 1.61 & 0.85 & 2.72 & 1.25 & 85.01 & 2.15 \\
\hline 6 & - & 2.86 & 1.55 & - & 15.91 & 2.41 & 76.57 & 0.70 \\
\hline
\end{tabular}

Brazing of nickel aluminides in similar combination (at the same mode) provokes precipitation of coarse dark particles based on nickel and chromium, enriched with boron (Figure 4; Table 3$)$, in the seam central zone.

Received examination results show that two types of borides, i.e. Ni- and Cr-based ones, are formed in brazing. Scanning along the line normal to the seam reveals increase of concentration of boron and chromium in the central zone ( $\mathrm{Fi}$ gure 5) and, respectively, decrease of nickel concentration. It is in good agreement with previous results and being an evidence of presence of boride phases in the seam center.

Similar formation of the brazed seams and element distribution is observed in brazing of stainless steel by B-containing BFMs [7, 8]. In brazing, boron actively diffuses from the seam in stainless steel, and B-containing phases precipitate at the interface of base metal grains. Presence of such a phase has negative effect on mechanical properties and corrosion resistance of the brazed joints. Formation of fusible boride eutectics and silicides in the seams and material being brazed have negative effect on long-term strength at elevated temperature [9].

In this connection further investigations are directed on elimination of formation of brittle phases in the brazed joint. For this, pilot palladium BFM based on solid solution without boron and silicon was used. Germanium, having large solubility range in nickel in comparison to silicon [10], was used as a depressant. In the initial cast state, the microstructure of given BFM consists of matrix, i.e. Ni-based solid solution, and phase dispersed Pd-based particles enriched with germanium.

Microstructure of the seams in joints from $\mathrm{Ni}_{3} \mathrm{Al}$ + Inconel 718, produced with palladium BFM on mode 1 (see Figure 1), consists of the Ni-based solid solution and Pd-based dispersed phase, enriched by aluminum up to $9.71 \%$ (Figure $6, a$; Table 4). Amount of this phase at the background of the brazed seam is insignificant, it precipitates in form of single dispersed particles (areas of up to
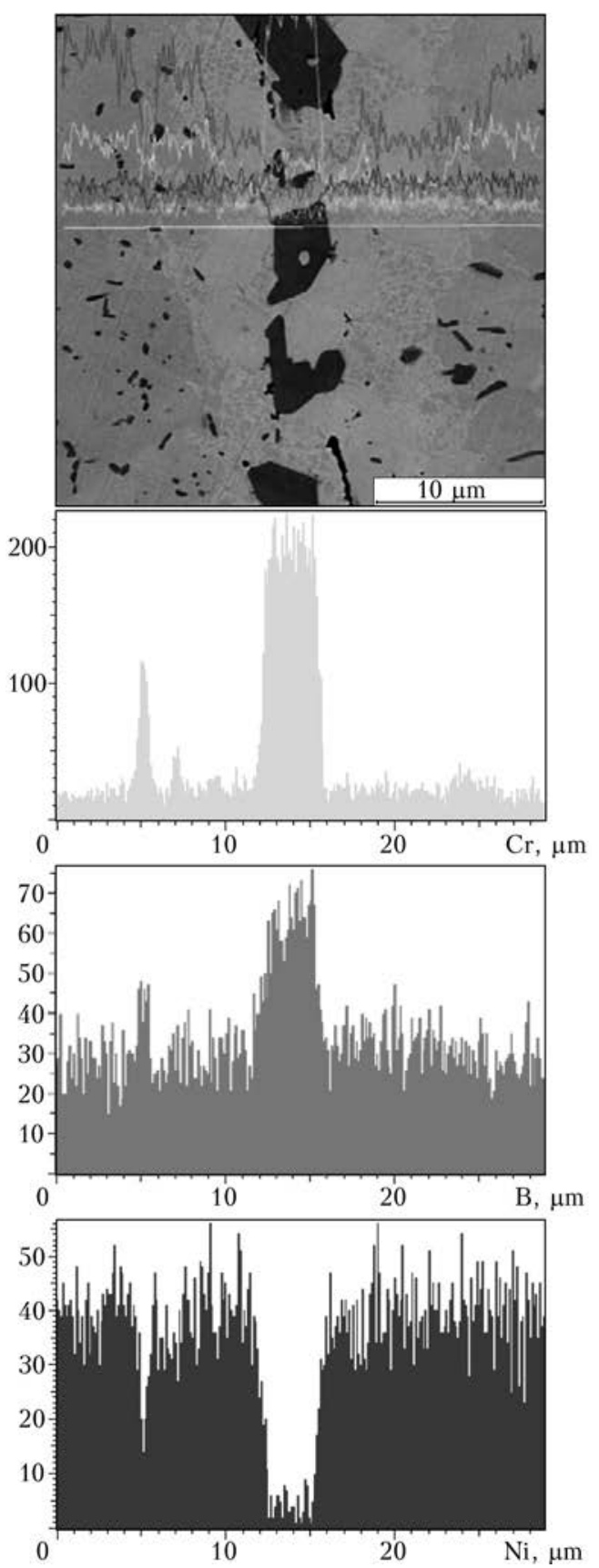

Figure 5. Distribution of BFM constituents along the scanning line of $\mathrm{Ni}_{3} \mathrm{Al}+\mathrm{Ni}_{3} \mathrm{Al}$ joint produced using B-containing BFM

$20 \mu \mathrm{m}$ size) in the solid solution matrix and can play a role of secondary strengthening phase.

Insignificant amount of constituents from materials being brazed are found in the Ni-based solid solution. Thus, concentration of iron makes $6.99 \%$ and aluminum does not exceed $1.78 \%$. It is explained by presence of concentration gradients at the interface, resulting in seam metal saturation with constituents of the base metal $[11,12]$. It should be noted that germanium is found only in the solid solution, and its concentration does not exceed $0.54 \%$.

In some sections the seam is difficult for visualization and clarified band serves as a Ni-based solid solution containing constituents of the 


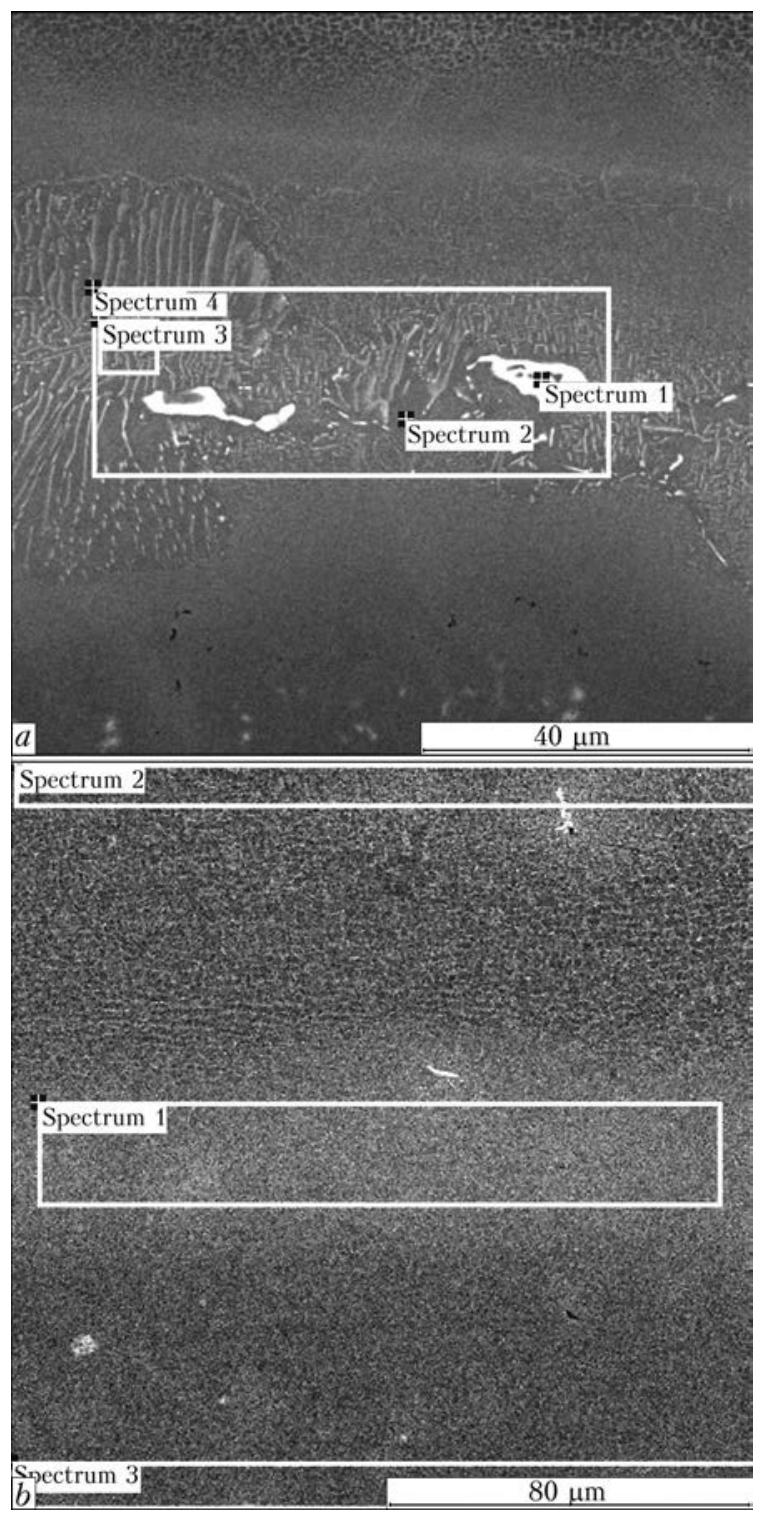

Figure 6. Examined sections of $\mathrm{Ni}_{3} \mathrm{Al}+$ Inconel 718 brazed joint produced using palladium BFM: $a-$ double-phase brazed seam with Pd-based phase; $b$ - single-phase seam with solid solution structure

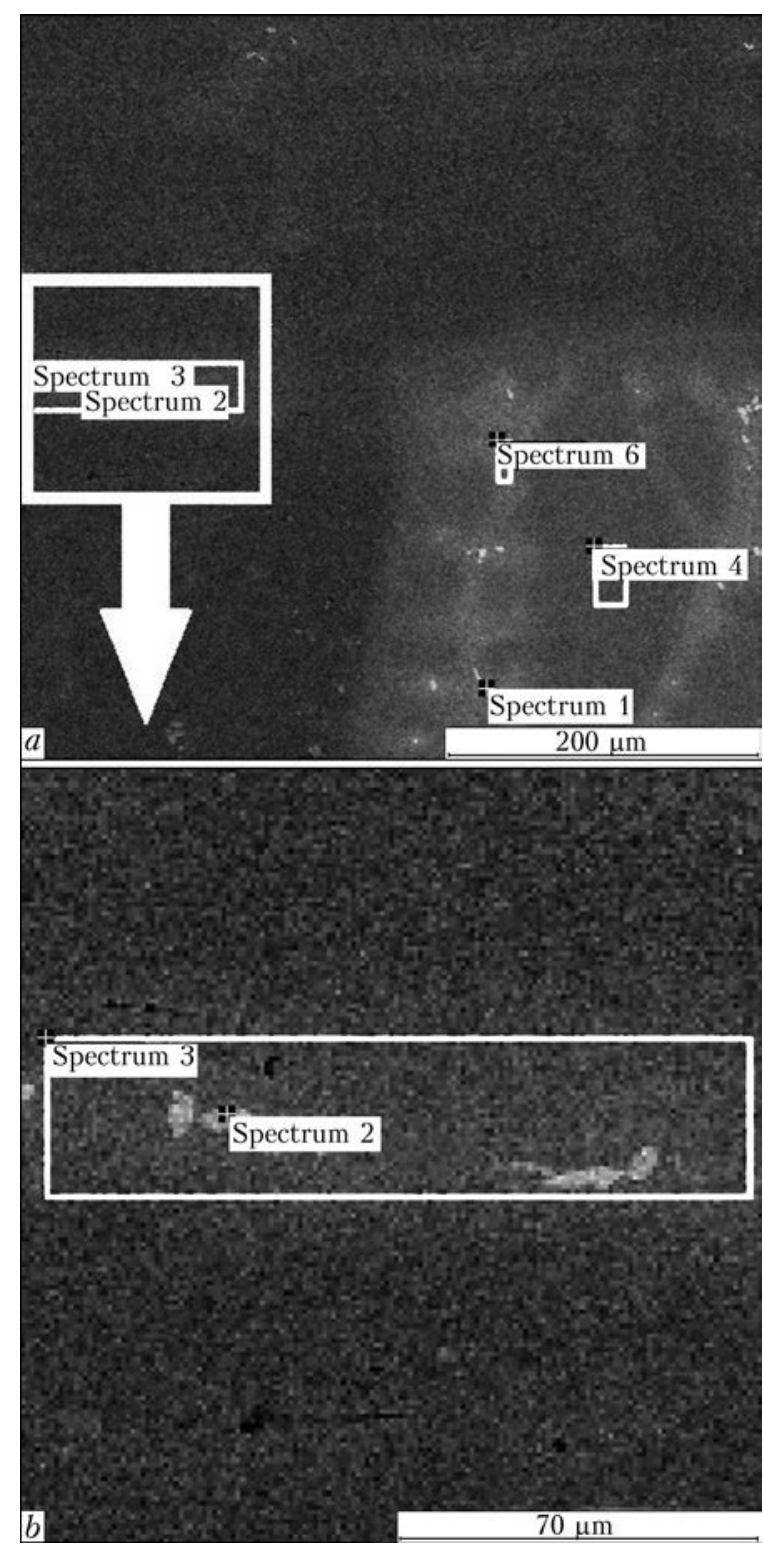

Figure 7. Microstructure of fillet section of $\mathrm{Ni}_{3} \mathrm{Al}+$ Inconel 718 brazed joint produced using palladium BFM $(a)$, and part of seam at larger magnification $(b)$

Table 4. Results of X-ray microspectral analysis of seam metal in $\mathrm{Ni}_{3} \mathrm{Al}+$ Inconel 718 brazed joint produced using palladium $\mathrm{BFM}$ (acc. to Figure 6, $a$ )

\begin{tabular}{|c|c|c|c|c|c|c|c|c|c|c|c|}
\hline \multirow{2}{*}{$\begin{array}{l}\text { Spectrum } \\
\text { number }\end{array}$} & \multicolumn{11}{|c|}{ Chemical elements, wt.\% } \\
\hline & $\mathrm{Al}$ & $\mathrm{Si}$ & $\mathrm{Ti}$ & $\mathrm{Cr}$ & $\mathrm{Fe}$ & Co & $\mathrm{Ni}$ & Ge & $\mathrm{Nb}$ & Mo & $\mathrm{Pd}$ \\
\hline 1 & 9.71 & - & 0.29 & 0.62 & 0.38 & - & 6.57 & - & - & - & 82.43 \\
\hline 2 & 0.99 & 0.13 & 0.71 & 13.64 & 6.99 & 1.08 & 53.53 & 0.54 & 4.89 & 4.79 & 12.70 \\
\hline 3 & 1.78 & 0.14 & 0.60 & 12.57 & 6.42 & 1.11 & 49.19 & 0.39 & 4.63 & 4.41 & 18.76 \\
\hline 4 & 2.23 & 0.12 & 0.50 & 12.06 & 6.08 & 1.13 & 48.23 & 0.26 & 4.06 & 4.63 & 20.69 \\
\hline
\end{tabular}

Table 5. Distribution of elements in section of seam with solid solution structure in $\mathrm{Ni}_{3} \mathrm{Al}+$ Inconel 718 brazed joint (acc. to Figure $6, b$ )

\begin{tabular}{||c|c|c|c|c|c|c|c|c|c|c||}
\hline \hline \multirow{2}{*}{$\begin{array}{c}\text { Spectrum } \\
\text { number }\end{array}$} & \multicolumn{10}{|c|}{ Chemical elements, wt.\% } \\
\cline { 2 - 23 } & $\mathrm{Al}$ & $\mathrm{Si}$ & $\mathrm{Ti}$ & $\mathrm{Cr}$ & $\mathrm{Fe}$ & $\mathrm{Co}$ & $\mathrm{Ni}$ & $\mathrm{Nb}$ & $\mathrm{Mo}$ & $\mathrm{Pd}$ \\
\hline 1 & 3.34 & 0.08 & 0.45 & 10.24 & 5.82 & 0.80 & 59.24 & 2.63 & 9.76 & 7.64 \\
\hline 2 & 7.16 & - & - & - & - & - & 75.65 & - & 17.01 & 0.18 \\
\hline 3 & 0.59 & 0.12 & 0.92 & 19.16 & 16.53 & - & 52.15 & 6.43 & 3.76 \\
\hline
\end{tabular}


Table 6. Results of X-ray microspectral analysis of seam fillet section in $\mathrm{Ni}_{3} \mathrm{Al}+$ Inconel 718 brazed joint (acc. to Figure 7 )

\begin{tabular}{|c|c|c|c|c|c|c|c|c|c|c|c|}
\hline \multirow{2}{*}{$\begin{array}{l}\text { Spectrum } \\
\text { number }\end{array}$} & \multicolumn{11}{|c|}{ Chemical elements, wt.\% } \\
\hline & $\mathrm{Al}$ & $\mathrm{Si}$ & $\mathrm{Ti}$ & $\mathrm{Cr}$ & $\mathrm{Fe}$ & $\mathrm{Co}$ & $\mathrm{Ni}$ & Ge & $\mathrm{Nb}$ & Mo & $\mathrm{Pd}$ \\
\hline 1 & 9.23 & 0.14 & 0.37 & 0.54 & 0.38 & - & 4.27 & - & - & - & 85.06 \\
\hline 2 & 13.10 & 0.08 & 0.26 & 1.97 & 1.57 & 0.15 & 14.44 & - & - & - & 68.44 \\
\hline 3 & 3.46 & 0.10 & 0.50 & 10.51 & 6.36 & 0.64 & 54.37 & 0.21 & 3.22 & 7.42 & 13.20 \\
\hline 4 & 0.65 & - & 0.25 & 16.45 & 7.60 & 1.66 & 52.18 & - & 2.10 & 3.78 & 15.32 \\
\hline 5 & 1.31 & 0.20 & 0.94 & 12.39 & 6.18 & 0.91 & 41.78 & 0.67 & 6.47 & 2.18 & 26.97 \\
\hline
\end{tabular}

BFM and material being brazed. Aluminum concentration rises from zero to $3.34 \%$ in the solid solution, while it amount makes $7.16 \%$ in the material being brazed (Figure $6, b$; Table 5).

Formation of similar structure (as in the seam), i.e. Ni-based solid solution and dispersed precipitates of Pd-based phase (Figure 6, $a, b$ ), are observed in the fillet sections. Difference is found in aluminum concentration, namely it is large in palladium phase of the seam and makes $13.10 \%$ in comparison with $9.23 \%$ of aluminum concentration in the similar phase in the fillet section (Figure 7, Table 6). Intensity and rate of growth of this phase are determined by diffusion coefficients for each element [11, 12]. Large extension of interface in the seam and narrow gap between metals being brazed provide for more favorable conditions for diffusion processes, that promotes active saturation of the seam metal by aluminum.

It is known that strength of the brazed joints and their service characteristics are determined by strength of interface bonds of the BFM elements with base metal elements. In other words, if strong bonds, mainly solid solutions, are formed in the seam, then they provide for larger strength than coarse boride phases. It should be underlined that diffusion layers and intermetallic phases in form of continuous bands along the seam, which can reduce properties of the brazed joints, are not formed in brazing by palladium BFM.

It is determined that chromium borides are formed in the seam and diffusion areas in brazing of heat-resistant nickel alloys based on $\mathrm{Ni}_{3} \mathrm{Al}$ intermetallic between themselves and their brazing to wrought nickel alloy of Inconel 718 grade with B-containing BFM.

Dense defect-free seams were produced using BFM based on $\mathrm{Ni}-\mathrm{Pd}-\mathrm{Cr}-\mathrm{X}(\mathrm{Ge}, \mathrm{Co})$ system. Interesting fact was found during composition examination that microstructure of the seam and initial BFM differ not only by chemical composition, but morphological structure as well. It is caused by presence of concentration gradient at the interface of material being brazed and liquid BFM, different value of diffusion coefficients of separate elements and non-equilibrium condi- tions of seam metal solidification resulting in active diffusion processes during brazing. The seam consists of Ni-based solid solution and single precipitates of dispersed $\mathrm{Pd}(\mathrm{X}) \mathrm{Al}$ phase, enriched with aluminum (9.71-13.10\%), in use of palladium BFM without aluminum for brazing of nickel aluminide. Morphological peculiarities of this phase can have positive effect on mechanical properties of the brazed joints. Study of mechanism of this process requires of additional detailed researches.

1. Khorunov, V.F. (2008) Principles of brazing of thinwall structures from high-alloy steels. Kiev: Naukova Dumka.

2. Radzievsky, V.N., Tkachenko, G.G. (2009) Vacuum brazing in compressor engineering. Kiev: Ekotekhnologiya.

3. Khorunov, V.F., Maksymova, S.V. (2013) Brazing of superalloys and the intermetallic alloy $(\gamma-T i A l)$. Advanced in brazing. Science, technology and applications, 85-120. Cambridge: Woodhead Publ.

4. Riggs, B., Alexandrov, B., Benatar, A. et al. (2015) Microstructural characterization of single crystal superalloy CMSX-4 brazed joints with BNi-2 and BNi-9 filler metals. IBSC-2015.

5. Grinberg, B.A., Ivanov, M.A. (2002) Intermetallics $\mathrm{Ni}$ Al: Microstructure, deformation behavior. Ekaterinburg: UrO RAN.

6. Kolobov, Yu.R., Kablov, E.N., Kozlov, E.V. et al. (2008) Structure and properties of intermetallic materials with nanophase strengthening. Moscow: MISiS.

7. Rabinkin, A. (2013) Brazing of superalloys and the intermetallic alloy $(\gamma-T i A l)$. Advanced in brazing. Science, technology and applications, 121. Cambridge: Woodhead Publ.

8. Maksymova, S.V. (2007) Amorphous braze filler metals for brazing of stainless steel with titanium and structure of brazed joints. Adgeziya Rasplavov $i$ Pajka Materialov, 40, 70-81.

9. Malashenko, I.S., Kurenkova, V.V., Belyavin, A.F. et al. (2006) Short-time strength and microstructure of brazed joints of alloy VJL12U produced using boron-containing brazing filler metal with addition of silicon. Advances in Electrometallurgy, 4, 23-38.

10. Massalski, T.V. (1990) ASM binary alloy phase diagrams. Metals Park: ASM Int.

11. Maksymova, S.V., Khorunov, V.F. (2015) Diffusion processes and formation of structure of brazed joints on titanium aluminides. J. Appl. Phys. Sci. Int., 2(1), 24-29.

12. Larikov, L.N., Isajchev, V.I. (1987) Structure and properties of metals and alloys: Refer. Book on diffusion in metals and alloys. Ed. by A.I. Rajchenko. Kiev: Naukova Dumka. 


\title{
IMPROVING THE EFFICIENCY OF HYBRID WELDING OF ALUMINUM ALLOYS*
}

\author{
V.Yu. KHASKIN ${ }^{2}$, V.N. KORZIK ${ }^{1,2}$, V.N. SYDORETS ${ }^{2}$, \\ A.I. BUSHMA ${ }^{2}$, WU BOYI ${ }^{1}$ and LUO ZIYI ${ }^{1}$ \\ ${ }^{1}$ Chinese-Ukrainian E.O. Paton Welding Institute (Guangdong General Research Institute of Industrial Technology) \\ (Guangzhou Research Institute of Non-Ferrous Metals) \\ 363 Changxing Road, Tianhe, 510650, Guangzhou, China. E-mail: vnkorzhyk@gmail.com \\ ${ }^{2}$ E.O. Paton Electric Welding Institute, NASU \\ 11 Bozhenko Str., 03680, Kiev, Ukraine. E-mail: office@paton.kiev.ua
}

\begin{abstract}
Development of new laser-arc heat sources is one of the urgent directions of modern science and engineering in the field of fusion welding of metals. Allowing for their physical features can promote increase of laser-arc welding productivity due to improvement of effective efficiency, i.e. increase of the ratio of power of the heat source applied to the metal in welding to the total power of the electric arc and laser radiation. One of the ways to improve the effective efficiency of welding is reduction of laser energy losses associated with radiation reflection from the surface being welded. The work is a study of the influence of concurrent heating, provided by the electric arc, on the change of the conditions of laser radiation absorption by aluminum alloys in their laser-arc welding. The problem of determination of temperature dependence of the coefficient of laser radiation absorption by aluminum was defined and solved within the model of almost free electrons on the base of studying vapour-gas channel behavior in hybrid welding. Comparison of obtained calculation dependencies of absorption capacity with the available experimental data showed satisfactory agreement. The respective heat conductivity equation was solved, in order to determine such parameters of laser-arc welding mode as arc component power and distance between the arc impact zone and laser beam axis. Experimental verification of the proposed approach to increase of effective efficiency of laser welding, performed on samples of aluminum alloy AMg6, confirmed the validity of the predicted results. 12 Ref., 7 Figures.
\end{abstract}

Keywords: laser-arc welding, aluminum alloys, $\mathrm{CO}_{2}$-laser radiation, absorption coefficient, welding current, welding speed

One of the urgent problems of modern science and technology in the field of fusion welding of metals is to create new heat sources, which allow control the concentration of heat energy inputted into the metal during welding. This finally makes it possible to ensure the required welding performance, quality of the welded joint, process stability and reproducibility of its results. The hybrid laser-arc source is increasingly used in recent years as such controlled heat source for welding of metal materials, which is implemented by jointly thermal effects on the metal being welded (within the total heating zone) by focused laser beam and electric arc [1].

In addition, the patterns of mutual effects of the components of laser-arc heat source and their joint effect on various metal materials are not studied enough.
The study of physics of the processes of interaction of components of the laser-arc heat energy source between themselves and their combined effect on the welded metal, the development of appropriate mathematical models and computer simulations of these processes are highly relevant scientific and technical problems. These tasks include consideration of physical characteristics of the hybrid laser-arc welding of aluminum alloys, which allows increasing its performance by increasing the effective efficiency, i.e. increasing the ratio of power of the heat source, acting in the metal during welding, to the total power of the electric arc and laser radiation. One of the ways to improve the efficiency of welding is reduction of laser energy losses associated with the reflection of radiation from the surface being welded.

Therefore, the objective of this work is to study the influence of concurrent heating, ensured by electric arc, on changing the conditions of absorption of laser radiation by aluminum alloys in their laser-arc welding, as well as the

\footnotetext{
* This work was support by the Financial Funding by Foreign Experts Program of China (No. WQ20124400119) by Innovative R\&D Team of Guangdong Province (No. 201101C0104901263) and by China International science and technology cooperation special items «Research on High Efficient Welding Equipment and Key Technology for Special Ships of Aluminum Alloy» (No. 2013DFR70160).
} 
definition of welding parameters, ensuring increasing the effective efficiency by reducing losses of laser energy.

Laser-arc welding, as well as laser welding, is characterized by the formation of vapor-gas channel of penetration in the welded metal. Paper [2] describes in detail the behavior of this channel during welding. In particular, it was noted that in its front wall there is a layer of molten metal, which is under constant «indignation» as the formation of step-like curvature, which periodically moves along the height of the channel. At this, the removal of material from the front wall is carried out layer by layer while moving downward step. This can be explained by increasing of the molten metal layer at the front wall, occurring due to transfer of radiation energy into the heat energy emitted at this wall, in combination with the hydrodynamic processes in the weld pool.

It is known that the part of radiation energy is absorbed by the welded metal, and another part is reflected from it. The proportion of the absorbed radiation greater, the higher is the temperature of the metal. Melt formed on the front wall absorbs radiation, but at the account of moving along the direction of welding the front part of the laser beam always contact the slightly heated metal, that leads to lowering of absorption coefficient.

It is logical to assume that the local heating up to certain temperatures of a small site of the welded metal, located directly in front of vapor-gas channel along the direction of welding, can significantly increase the rate of absorption of laser radiation. In the case of laser-arc welding, performed under the scheme provided in Figure 1, such local heating is carried out by electric arc. There is a task of achieving minimum temperatures sufficient for maximum possible increasing the radiation absorption coefficient, depending on welding speed and welded item geometry.

To determine the temperature dependence of the coefficient of absorption of laser radiation by metal materials $A\left(T_{s}\right)$ we will consider the studied metal (aluminum) in framework of model of almost free electrons. In this case, according to the formulas of Drude-Zener [3], for the actual $\varepsilon_{1}$ and imaginary $\varepsilon_{2}$ parts of the complex dielectric permeability of the metal on the frequency of laser radiation $\omega=2 \pi c / \lambda$ (where $c-$ light velocity, and $\lambda-$ wavelength of radiation), we get:

$$
\begin{gathered}
\varepsilon_{1}=1-\frac{\omega_{\mathrm{p}}^{2}}{\omega^{2}+\omega_{\mathrm{c}}^{2}}, \\
\varepsilon_{2} \omega=4 \pi \sigma=\frac{\omega_{\mathrm{c}} \omega_{\mathrm{p}}^{2}}{\omega^{2}+\omega_{\mathrm{c}}^{2}} .
\end{gathered}
$$

Here $\omega_{\mathrm{p}}$ is the frequency of the plasma oscillations of metal free electrons; $\omega_{c}$ is the frequency

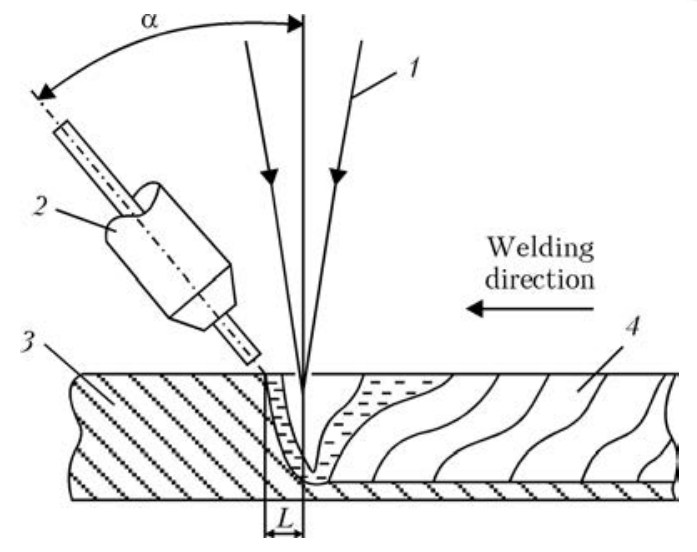

Figure 1. Scheme of hybrid laser-arc welding: 1 - focused laser radiation; 2 - consumable-electrode arc; 3 - specimen; 4 - welded joint; $L$ - distance between electrode wire and laser axis

numerically equal to the reverse time of relaxation time of the conduction electrons.

The value of the plasma frequency is determined by formula

$$
\omega_{\mathrm{p}}^{2}=\frac{4 \pi n e N_{\mathrm{e}}}{m_{\mathrm{e}}^{*}},
$$

where $e$ and $m_{\mathrm{e}}^{*}$ is the charge and effective mass of electron in the metal [4]. Concentration of the conduction electrons $N_{\mathrm{e}}=V / \Omega$ is determined by valence $V$ and atom volume $\Omega$. Valence for aluminum was assumed to be 3 . Atom volume was obtained on the basis of experimental data on density of aluminum provided in [5].

In the limiting case of constant field when $\omega$ $=0$, the high optical conductivity $\sigma$ turns into static conductivity of the metal:

$$
\sigma(0)=\frac{N_{\mathrm{e}} e}{m_{\mathrm{e}} \omega_{\mathrm{c}}} .
$$

The temperature dependence of the relaxation frequency $\omega_{\mathrm{c}}$ for the considered metals in solid state was taken into account using the following formula [6]:

$$
\omega_{\mathrm{c}}=K^{\prime} T^{5} \int_{0}^{\theta / I} \frac{z^{4} d z}{e^{z}-1},
$$

where $\theta$ is the Debye temperature; $K^{\prime}$ is the constant. Values $\omega_{c}$ and, consequently, $K^{\prime}$ at room temperature for aluminum were chosen in accordance with data of [7]. For aluminum in liquid state the experimental values from [8,9] were used. The design data obtained using this way are shown in Figure 2.

The temperature dependence presented has distinctive gap at melting point of the metal $T_{\mathrm{m}}$. According formulas (1) and (2) with use of (3)-(5) the temperature dependences of actual and imaginary parts of the complex dielectric permeability for aluminum at radiation frequency of $\mathrm{CO}_{2}$-laser $(\lambda=1.06 \mu \mathrm{m})$ were developed (Figure 3$)$.

For further calculations, it is convenient to introduce the actual $n$ and imaginary $k$ parts of 


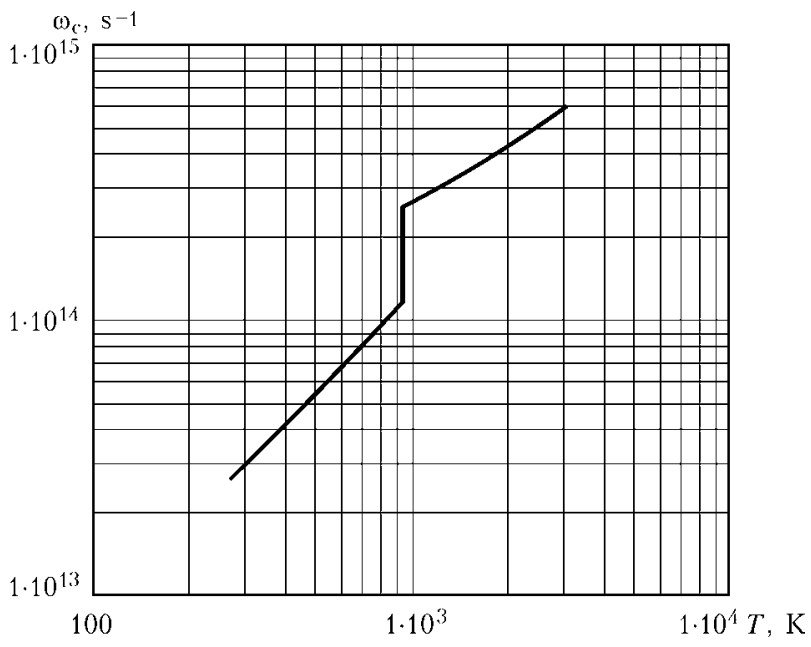

Figure 2. Relaxation frequency $\omega_{\mathrm{c}}$ versus temperature $T$ for aluminum at influence of $\mathrm{CO}_{2}$-laser radiation on it $(\lambda=$ $=10.6 \mu \mathrm{m}$ )

complex refraction index of the metal at frequency of the laser radiation:

$$
\sqrt{\varepsilon}=\sqrt{\varepsilon_{1} i \varepsilon_{2}}=n+i k
$$

using the following formulas:

$$
\begin{aligned}
& n=\frac{\sqrt{\sqrt{\varepsilon_{1}^{2}+\varepsilon_{2}^{2}+\varepsilon_{1}}}}{2}, \\
& k=\frac{\sqrt{\sqrt{\varepsilon_{1}^{2}+\varepsilon_{2}^{2}-\varepsilon_{1}}}}{2} .
\end{aligned}
$$

The temperature dependence of actual and imaginary parts of the complex refraction index for aluminum are shown in Figure 4.

Using obtained $n$ and $k$ values, we determine the absorption coefficient of laser radiation normally incident on a flat surface of metal (absorbability), using the well-known formula

$$
A=\frac{4 n}{(1+n)^{2}+k^{2}} \text {. }
$$

In some cases, a more important parameter is coefficient of reflection (reflectivity), which can be defined by formula

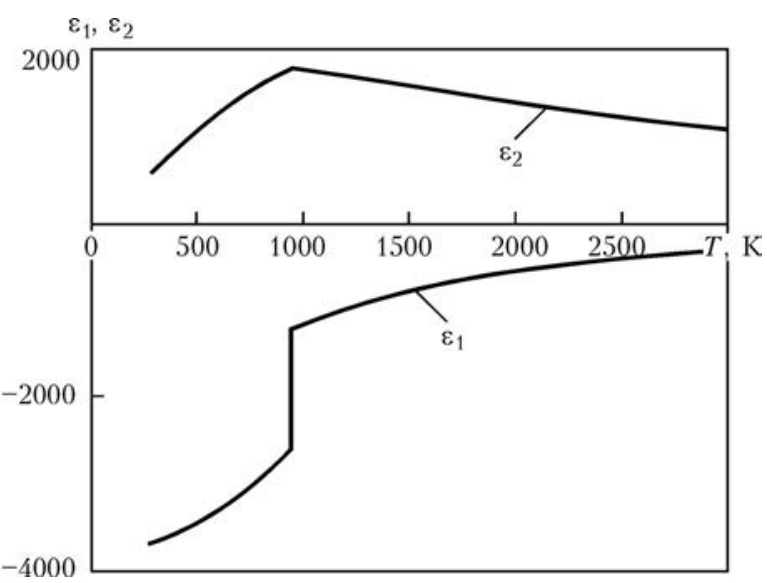

Figure 3. Temperature dependence of actual $\varepsilon_{1}$ and imaginary $\varepsilon_{2}$ parts of complex dielectric permeability of aluminum

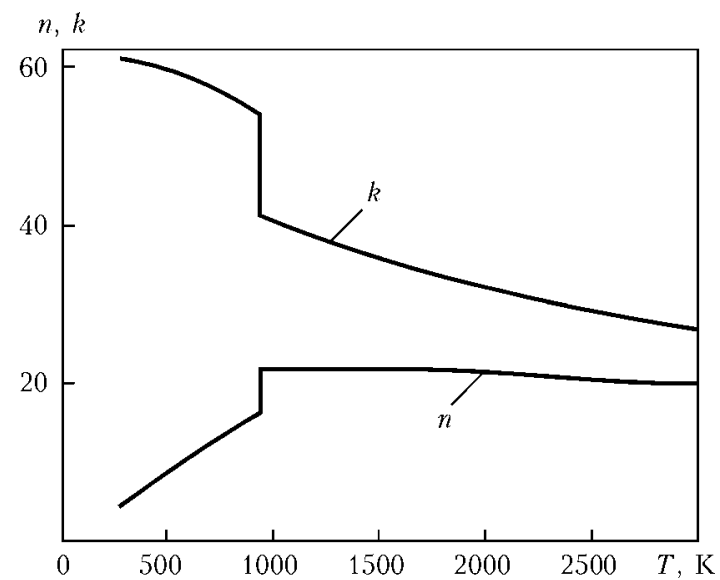

Figure 4. Dependence of actual $n$ and imaginary $k$ parts of complex refraction index of aluminum on temperature

$$
R=1-A=\frac{(1-n)^{2}+k^{2}}{(1+n)^{2}+k^{2}} .
$$

Figure $5, a$ shows the results of calculations of the temperature dependences of coefficient of $\mathrm{CO}_{2}$-laser radiation absorption for aluminum in the temperatures range from room to boiling ones and above. Similar calculations were conducted for determining the absorbability of aluminum surface in the case of falling of radiation of Nd:YAG-laser $(\lambda=1.06 \mu \mathrm{m})$ on it. They showed identical behavior of both dependences with the difference that the absolute values of the radiation absorption coefficient of Nd:YAG-laser is higher than that of $\mathrm{CO}_{2}$-laser (Figure $5, b$ ).

Estimated dependences of absorbability obtained for both types of radiation was compared with the available experimental data [6-9], and the match was quite satisfactory. According to the dependences, shown in Figure 5, to achieve the maximum values of absorption coefficient the surface of aluminum alloy being welded in the zone of action of laser radiation of both wavelengths should be heated up to melting temperature $T_{\mathrm{m}}$. However, even heating up to $T_{\mathrm{m}}$ is sufficient to dramatically abrupt increase the absorbability.

To determine such parameters of laser-arc welding mode as power $Q_{\mathrm{a}}$ of arc component and distance $L$ between the point of feeding the electrode wire and the axis of laser radiation (see Figure 1), it is necessary to solve the corresponding equation of heat conductivity. To simplify the task, we will consider the stationary case of heating of aluminum plate of thickness $\delta$ by arc source, the heat flow of which is determined by dependence

$$
Q_{\mathrm{a}}=\eta I U,
$$

where $\eta$ is the efficiency of consumable-electrode arc usually taken as $0.8 ; I$ is the welding current, A; $U$ is the arc voltage, $\mathrm{V}$.

Let us assume that the spatial distribution of heat flow inputted into the sample symmetrically 
with axis, perpendicular to its surface (i.e. symmetrically with laser beam axis).

In this regard, we formulate a mathematical model of heating of considered sample in axially symmetric statement. Equation of heat conductivity in a metal can be written in the cylindrical coordinate system taking into account the axial symmetry of the temperature field:

$$
\begin{gathered}
C_{\mathrm{m}}(T) \rho_{\mathrm{m}}(T) \frac{\partial T}{\partial t}=\frac{1}{r} \frac{\partial}{\partial r}\left(r \lambda_{\mathrm{m}}(T) \frac{\partial T}{\partial r}\right)+ \\
+\frac{\partial}{\partial z}\left(\lambda_{\mathrm{m}}(T) \frac{\partial T}{\partial z}\right),
\end{gathered}
$$

where $C_{\mathrm{m}}(T), \rho_{\mathrm{m}}(T), \lambda_{\mathrm{m}}(T)$ is the effective heat capacity of metal (taking into account the melting latent heat), the density and thermal conductivity coefficient, respectively, wherein the $r$-axis is directed along the sample surface, and the $z$-axis is directed into the sample, perpendicular to its surface.

Boundary equation (12) we put in the range $0 \leq r \leq R, 0 \leq z \leq \delta, t \geq 0$ (where $R$ - radius of the computational region, and $\delta$ - sample thickness). As the initial conditions in the entire region the temperature $T_{0}$ is given, which is equal to the ambient temperature. At $r=0$ we put the condition of temperature field symmetry

$$
\frac{\partial T}{\partial r_{r=0}}=0 .
$$

It is expected that at characteristic time, during which it is necessary to find a solution of the problem, the thermal perturbation does not reach the outer limits of the computational region, i.e. at these limits the initial temperature is

$$
T(r, \delta, t)=T(R, z, t)=T_{0} .
$$

On the sample surface affected by the pulsed heat source we put the following boundary condition:

$$
-\lambda_{\mathrm{m}}(T) \frac{\partial T}{\partial z_{z=0}}=Q_{\mathrm{a}} .
$$

Here $Q_{\mathrm{a}}(r, t)$ is the space-time distribution of the heat flow introduced into the metal by pulsed arc discharge, determined according to dependences (11) on the average value of welding current.

Maximum temperature $T_{\mathrm{c}}$ in the arc center of supply power $Q_{\mathrm{a}}$ was determined by the Newton-Richmann law (where $Q_{\mathrm{a}}=\alpha\left(T_{\mathrm{c}}-T_{0}\right)-$ heat transfer coefficient $\left[\mathrm{W} /\left(\mathrm{m}^{2} \cdot \mathrm{K}\right)\right]$ found experimentally for aluminum alloy $\operatorname{AMg} 6(1 / \alpha=$ $=0.55-0.60)$ ).

The solution of problem (12)-(15) was found numerically by the Peasmen-Rachford method [10] for aluminum plate $2 \mathrm{~mm}$ thick. In carrying out of all calculations thermal characteristics of aluminum alloy $\mathrm{AMg} 6$ given in [11] have been used.
A, \%
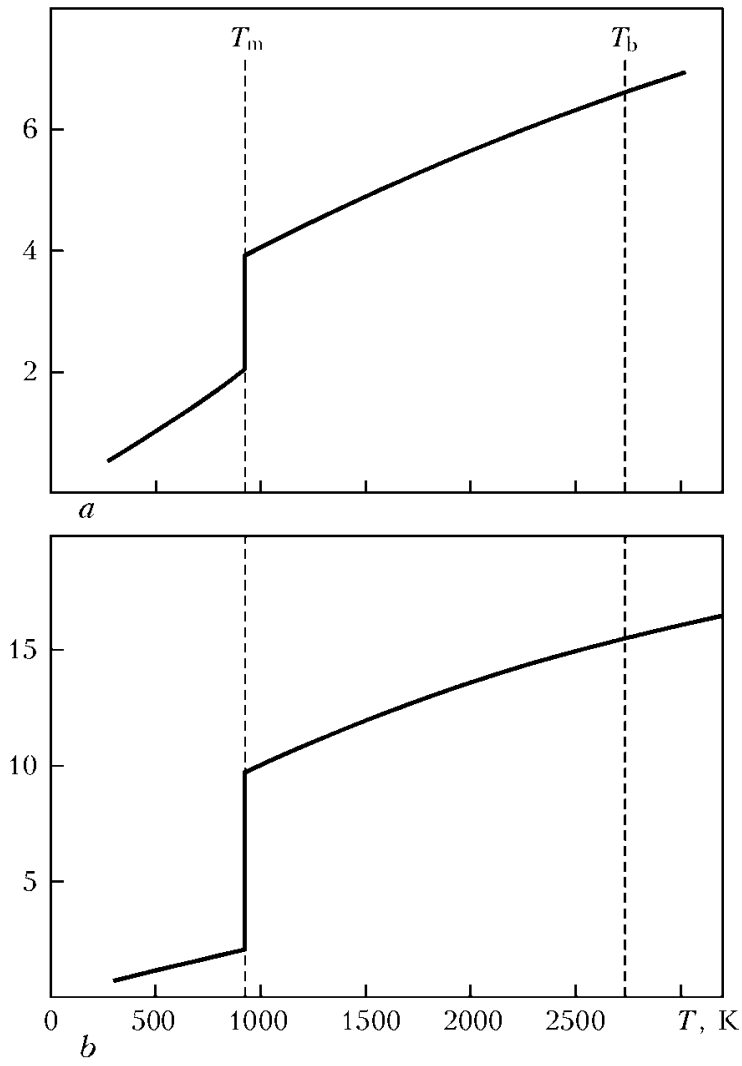

Figure 5. Absorption capacity $A$ versus temperature $T$ for aluminum at wavelength of $10.6(a)$ and $1.06(b) \mu \mathrm{m}$

We calculated the temperature distribution created by arc source power $Q_{\mathrm{a}}$ on the surface of aluminum plate along the $x$-axis in direction opposite the direction of welding. Welding speed $v_{\mathrm{w}}$ we considered in determining the exposure time of arc source, calculated by dependence $\tau=d / v_{\mathrm{w}}$ (where $d-$ size of heat source on the surface of plate being welded (we took $d=2 \mathrm{~mm}$ )).

Calculations for three cases of welding were carried out: with average technological parameters $Q_{\mathrm{a}} \approx 3.1 \mathrm{~kW}, I \approx 150 \mathrm{~A}, v_{\mathrm{w}}=130 \mathrm{~m} / \mathrm{h}$; at economy mode with relatively low speed and power $\left(Q_{\mathrm{a}} \approx 2.1 \mathrm{~kW}, I \approx 100 \mathrm{~A}, v_{\mathrm{w}}=120 \mathrm{~m} / \mathrm{h}\right)$; and with high performance $\left(Q_{\mathrm{a}} \approx 4.1 \mathrm{~kW}, I \approx\right.$ $\left.\approx 200 \mathrm{~A}, v_{\mathrm{w}}=300 \mathrm{~m} / \mathrm{h}\right)$. For these cases we determined the distribution of temperatures along the $x$-axis from the center of action of the arc power source (Figure 6).

Results of calculations have showed that in case of welding with average process parameters, distance $L$ (see Figure 1) should not exceed $2 \mathrm{~mm}$. During welding at economy mode, $L$ should be in the range up to $0.8 \mathrm{~mm}$, and during high-performance welding - up to $1.5 \mathrm{~mm}$. The excess of calculated distance will reduce the absorption capacity $A(T)$, increase the proportion of losses of laser radiation due to its reflection from the surface of aluminum alloy and, consequently, reduce the productivity. It should be noted that further increase of hybrid welding 


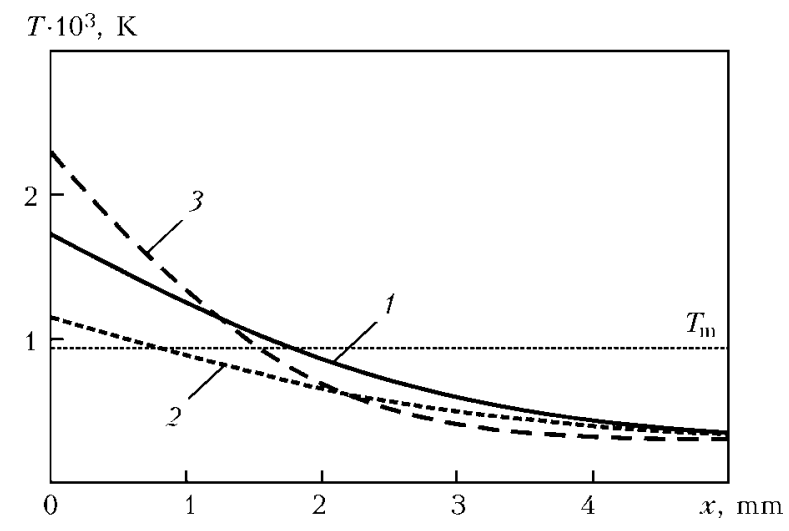

Figure 6. Temperature distribution on the surface of aluminum plate $2 \mathrm{~mm}$ thick from the arc source in welding direction $x: 1-I=150 \mathrm{~A}, v_{\mathrm{w}}=130 \mathrm{~m} / \mathrm{h} ; 2-I=100 \mathrm{~A}$, $v_{\mathrm{w}}=120 \mathrm{~m} / \mathrm{h} ; 3-I=200 \mathrm{~A}, v_{\mathrm{w}}=300 \mathrm{~m} / \mathrm{h}$

performance leads to the need in distance $L$ reduce. This, on reaching certain mode parameters, may lead to deterioration of absorption capacity and getting the lacks-of-fusion because of problematic of ensuring condition $L<1 \mathrm{~mm}$.

Experimental verification of the predicted approach to improve the effective efficiency of hybrid welding due to selection of distance $L$ between the point of wire supply and the laser axis was conducted on samples of aluminum alloy AMg6 with $\delta=2 \mathrm{~mm}$ using welding wire SvAMg6 of $1.2 \mathrm{~mm}$ diameter. At this, we used up to $10 \mathrm{~kW} \mathrm{CO}$-laser LT-104 [12] and standard equipment Fronius TPS-2700 for GMAW. Hybrid welding was performed in argon with $8^{-}$ $101 / \mathrm{min}$ consumption for root weld, and 12$14 \mathrm{l} / \mathrm{min}$ for weld pool shielding. At this, power of radiation incident on the sample was $2.5 \mathrm{~kW}$, welding current was varied in the range 60$300 \mathrm{~A}$, and distance $L$ was $1-2 \mathrm{~mm}$ (in average $1.5 \mathrm{~mm}$ ). Electric arc was placed first during the welding direction, and then focused laser beam was used. During the experiments, increasing current $I$, welding speed was determined by the criteria of formation of high-quality welded joint. In the result, the dependence, shown in Figure 7, was obtained.

The analysis of the nature of this dependence suggests the following. As long as power of the arc heat source acting on the surface of aluminum alloy being welded was not enough to create the molten pool on it, the length of which along the $x$-axis would exceed $L$ value, welding performance is almost did not increased with increasing of welding current.

At this, the substantial portion of the laser power was lost due to reflection from the alloy surface. Once the power of heat source was sufficient to create the desired length of the molten pool, there was a sharp increase in welding performance, determined by its speed. In our opinion, it is determined by an abrupt increasing of

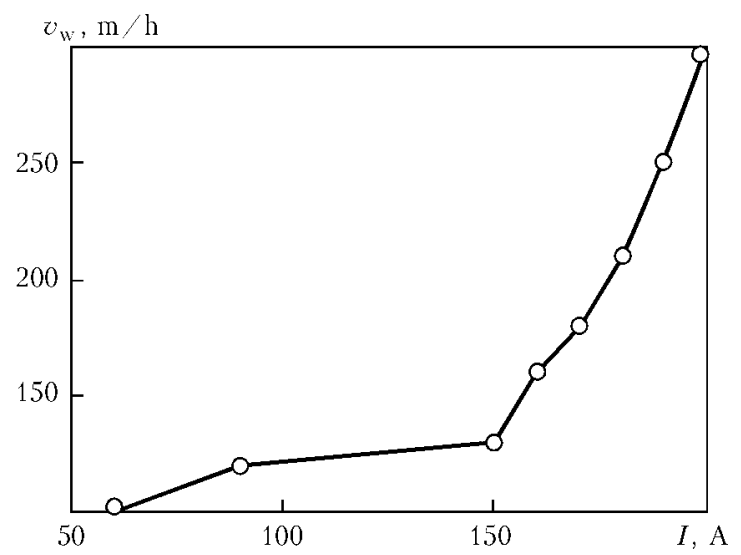

Figure 7. Welding speed versus arc current for laser-arc welding of alloy AMg6 with $\delta=2 \mathrm{~mm}$ at $2.5 \mathrm{~kW}$ power of $\mathrm{CO}_{2}$-laser radiation

absorption capacity and, consequently, improving of effective welding efficiency due to reducing the laser energy losses.

Thus, during hybrid laser-arc welding of aluminum alloys to improve the effective efficiency of the process, the electric arc should provide such concurrent heating, which will allow creating a molten pool, covering the zone of action of focused laser radiation. At this, the share of absorbed laser radiation abruptly increases at least twice for $\mathrm{CO}_{2}-$ laser wavelength, and about 3 times for Nd:YAGlaser wavelength, that has a positive effect not only for total energy contribution, but also for stabilization of the electric arc.

1. Shelyagin, V.D., Khaskin, V.Yu. (2002) Tendencies in development of laser-arc welding (Review). The Paton Welding J., 6, 25-28.

2. Grigoriants, A.G. (1988) Laser equipment and technology: Refer Book. Vol. 5: Laser welding of metals. Moscow: Vysshaya Shkola.

3. Noskov, M.M. (1983) Optical and magneto-optical properties of metals. Sverdlovsk: UNTs AN SSSR.

4. Kiselev, A.I., Akashev, L.A., Kononenko, V.I. (2004) Effective mass of electrons in the alloys of aluminum, cesium and binary system $\mathrm{Al}-3$ at.\% Ce. Zhurnal Tekhnich. Fiziki, 74(3), 20-23.

5. Zinoviev, V.E. (1989) Thermal properties of metals at high temperatures: Refer. Book. Moscow: Metallurgiya.

6. Ujihara, K. (1972) Reflectivity of metals at high temperatures. J. Appl. Physics, 43(5), 2376-2383.

7. Ordal, M.A., Long, L.L., Bell, R.J. et al. (1983) Optical properties of the metals $\mathrm{Al}, \mathrm{Co}, \mathrm{Cu}, \mathrm{Au}, \mathrm{Fe}$, $\mathrm{Pb}, \mathrm{Ni}, \mathrm{Pd}, \mathrm{Pt}, \mathrm{Ag}, \mathrm{Ti}$, and $\mathrm{W}$ in the infrared and far infrared. Appl. Optics, 22(7), 1099-1119.

8. Miller, J.C. (1969) Optical properties of liquid metals at high temperatures. Phil. Magazine, Issue 168, 20(12), 1115-1132

9. Comins, N.R. (1972) The optical properties of liquid metals. Ibid., Issue 4, 25, 817-831.

10. Peacemen, D.W., Rachford, H.H. (1955) The numerical solution of parabolic and elliptic differential equations. J. Soc. Ind. Appl. Math., 3, 28-41.

11. Beletsky, V.M., Krivov, G.A. (2005) Aluminum alloys (composition, properties, technology, application): Refer. Book. Kiev: Komintekh.

12. Garashchuk, V.P., Shelyagin, V.D., Nazarenko, O.K. et al. (1997) Technological CO2-laser LT104 of $10 \mathrm{~kW}$ power. Avtomatich. Svarka, 1, 36-39.

Received 30.09.2015 


\title{
ON THE INFLUENCE OF CAPACITANCE IN THE WELDING CIRCUIT ON STABILITY OF ARC WELDING MODE
}

\author{
G.A. TSYBULKIN \\ E.O. Paton Electric Welding Institute, NASU \\ 11 Bozhenko Str., 03680, Kiev, Ukraine. E-mail: office@paton.kiev.ua
}

\begin{abstract}
Profound study of the influence of various kinds of destabilizing factors on welding process stability is one of the main tasks in its robotization. The influence of capacitance («parasitic» or purposefully included into the welding circuit) on stability of the mode of consumable-electrode gas-shielded arc welding was studied in this work. It is shown that at high and medium welding currents, i.e. when the working point is located in the rising or flat section of the arc volt-ampere characteristic, presence of a capacitance in the welding circuit does not affect the stability of steady-state arc welding mode. Now, in the case of small currents, when the working point is located in the falling section of this characteristic, ensuring the arc welding mode stability is possible only at limited values of the above capacitance. Established criteria in the form of algebraic inequalities allow comparatively simple evaluation of the region of this capacitance values, within which stable modes are guaranteed. Results presented in this paper will be useful in development of robotic welding technologies and respective process equipment. 17 Ref., 5 Figures.
\end{abstract}

Keywords: robotic arc welding, consumable electrode, capacitance, steady-state modes, stability, transient processes

The recently published paper [1] deals with the influence of capacitance on processes running in the electric arc powered from a direct current source. To study these processes, the authors used a circuit of a two-pole element substitution for an electric arc, including the arc differential resistance and small stray inductance connected in parallel with it, which is shunted by ohmic resistance, and a capacitance is connected in parallel to a two-pole element.

A similar problem was considered in a somewhat different aspect in the fundamental work «Theory of vibrations» [2]. Stability of steadystate modes in an electric circuit with an arc, connected in series with an inductance and shunted by a capacitance, was studied in it as an example (Figure 1). Now, the arc proper was regarded as a certain electric circuit element, static volt-ampere characteristic (VAC) of which reflects the main properties of the arc, and is known [3-10] to be essential for selection of the method of its powering and stabilizing.

In [2] conditions of asymptotic stability of steady-state modes were obtained in the form of the following inequalities:

$$
R+S_{\mathrm{a}}>0, \quad L+S_{\mathrm{a}} R C>0,
$$

where $S_{\mathrm{a}}=d u_{\mathrm{a}} / d i$ is the tangent of the angle of inclination of arc VAC (arc differential resis- tance) in the vicinity of a point, corresponding to steady-state mode, and the meaning of other designations is clear from Figure 1. It is seen directly from expressions (1) that if $S_{\mathrm{a}} \geq 0$, then both the inequalities will be fulfilled and, therefore, the steady-state mode will be asymptotically stable at any values of capacitance $C$. Now, if $S_{\mathrm{a}}<0$ (falling section of arc VAC), the steadystate mode will be asymptotically stable only up to those circuit parameter values, which satisfy the following conditions:

$$
R>\left|S_{\mathrm{a}}\right|, \quad C<\frac{L}{R\left|S_{\mathrm{a}}\right|} .
$$

The first inequality in (2) is called Kauffman criterion $[3,8]$; it is more often expressed as $\left|\partial u_{R} / \partial i\right|>\left|\partial u_{\mathrm{a}} / \partial i\right|$, where $u_{R}$ is the potential drop across resistance $R$.

Results obtained in [2] pertain to the case, when electric arc length during its arcing remains unchanged (voltaic arc). The question naturally arises: what is the influence of capacitance $C$ on stability of the processes running in the real weld-

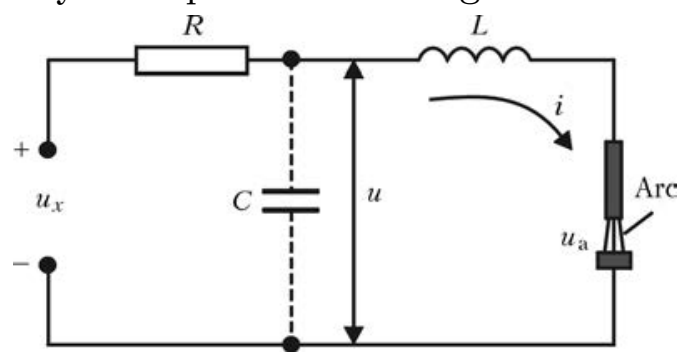

Figure 1. Schematic of circuit with electric arc, resistance $R$, inductance $L$ and capacitance $C$ 


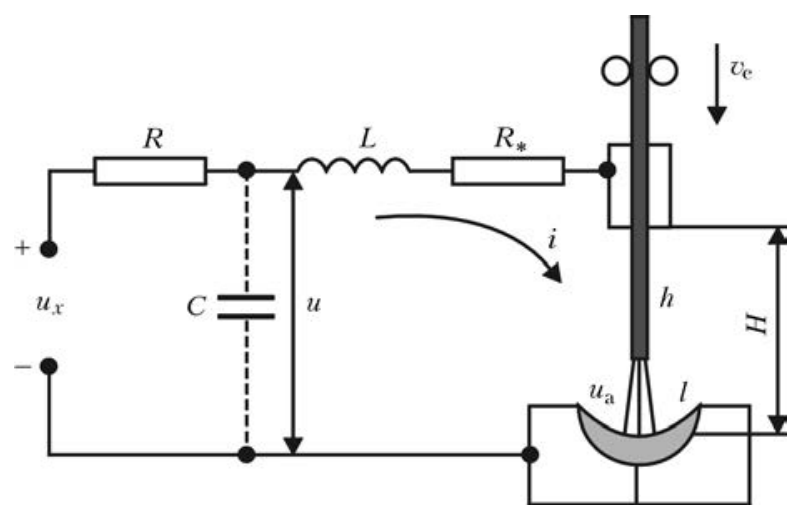

Figure 2. Schematic of welding circuit with consumable electrode and capacitance

ing circuit in consumable-electrode gas-shielded arc welding, when the arc length is a variable value in principle? Judging by the known publications (see, for instance [3-12] and references given there), this still remained insufficiently studied. Considering that consumable-electrode gas-shielded arc welding is one of the predominant welding technologies, the posed question is of practical interest and in our opinion it deserves a more detailed study.

Let us consider the schematic of the welding circuit, shown in Figure 2. It differs from the circuit in Figure 1 by that it uses a consumable electrode, which is fed into the welding zone at certain rate $v_{\mathrm{e}}$. Electrode feed rate $v_{\mathrm{e}}=$ const and its melting rate $v_{\mathrm{m}}=v_{\mathrm{m}}(t)$ at an arbitrary moment of time $t$ are connected to current value of electrode extension $h=h(t)$ by the following relationship:

$$
h=h_{0}+v_{\mathrm{e}} t-\int_{0}^{t} v_{\mathrm{m}}(t) d t,
$$

where $h_{0}$ is the initial value of electrode extension. Electrode melting rate, in its turn, depends on welding current $i=i(t)$ and on thermophysical and geometrical properties of the electrode. This dependence is often approximated by linear function $[5,6,13]$

$$
v_{\mathrm{m}}=M i,
$$

where $M$ is the parameter, characterizing the above properties.

Distance $H$ between the edge of current-conducting nozzle and weld pool free surface in robotic arc welding is maintained constant. This distance, as is seen from the circuit, is equal to a sum of current values of arc length $l=l(t)$ and electrode extension $h=h(t)$, i.e.

$$
H=l+h=\text { const. }
$$

We will complement relationships (3) $-(5)$ by the following dependence $[12,13]$ :

$$
u_{\mathrm{a}}=u_{0}+E l+S_{\mathrm{a}} i
$$

and differential equations

$$
L \frac{d i}{d t}+R_{*} i=u-u_{\mathrm{a}}, \quad C \frac{d u}{d t}=\frac{u_{x}-u}{R}-i,
$$

composed on the basis of the considered circuit and Kirchhoff's laws.

In equations (6) and (7) $u_{\mathrm{a}}$ is the arc voltage; $u_{0}$ is the sum of near-electrode voltage drops; $E=$ $=d u_{\mathrm{a}} / d l$ is the electric field intensity in the arc column; $R_{*}$ is the total resistance of current-conducting wires, electrode extension and sliding contact in welding torch nozzle.

Excluding $i, h, v_{\mathrm{m}}, u, u_{\mathrm{a}}$ variables from the system of equations (3)-(7), we will obtain one differential equation for variable $l$ :

$$
\begin{gathered}
C L \frac{d^{3} l}{d t^{3}}+\left(\mu C R+\frac{L}{R}\right) \frac{d^{2} l}{d t^{2}}+(1+\mu+C E M) \frac{d l}{d t}+ \\
+\frac{E M}{R} l=\frac{M}{R}\left(u_{x}-u_{0}\right)-(1+\mu) v_{\mathrm{e}} .
\end{gathered}
$$

All the dimensional parameters, appearing in this equation, are positive. Dimensionless parameter $\mu$, equal to

$$
\mu=\frac{R_{*}+S_{\mathrm{a}}}{R},
$$

can take both a positive, and a negative value, depending on $S_{\mathrm{a}}$ sign and the relationship between $\left|S_{\mathrm{a}}\right|$ and $R_{*}$ in the vicinity of working point. Furtheron we will assume that $|\mu|<1$. Steady-state value of arc length $l_{\infty}=\lim _{l \rightarrow \infty} l(t)$, i.e. its value at

$$
\frac{d^{3} l}{d t^{3}}=0, \quad \frac{d^{2} l}{d t^{2}}=0, \quad \frac{d l}{d t}=0
$$

is determined according to (8) by the following expression:

$$
l_{\infty}=\frac{u_{x}-u_{0}}{E}-\frac{R(1+\mu)}{E M} v_{\mathrm{e}},
$$

which, as we can see, does not include capacitance $C$.

Now, let us consider the influence of this capacitance on arc welding mode stability. We will introduce variable $\lambda=l-l_{\infty}$. Allowing for this variable and expressions (8) and (10), we obtain the following equation:

$$
\begin{gathered}
C L \frac{d^{3} \lambda}{d t^{3}}+\left(\mu C R+\frac{L}{R}\right) \frac{d^{2} \lambda}{d t^{2}}+ \\
+(1+\mu+C E M) \frac{d \lambda}{d t}+\frac{E M}{R} \lambda=0,
\end{gathered}
$$


describing the transient process in the welding circuit.

From this equation it is immediately evident that if the following conditions are fulfilled:

$$
\begin{gathered}
\mu C R^{2}+L>0, \quad 1+\mu+C E M>0, \\
\mu R^{2} E M C^{2}+\mu R^{2}(1+\mu) C+L(1+\mu)>0,
\end{gathered}
$$

then according to Hurwitz criterion [14] the steady-state mode will be asymptotically stable in the considered circuit.

Let us separately consider three special cases.

1st: $S_{\mathrm{a}} \leq 0$. i.e. the arc VAC rises or remains unchanged in working point vicinity (arc welding at large and medium currents). In this case, $\mu>0$ according to (9). It is easy to see that here all the three conditions of stability (12) are satisfied at any values of capacitance $C$;

2nd: $S_{\mathrm{a}}<0$ and, in addition, $\left|S_{\mathrm{a}}\right| \leq R_{*}$. This corresponds to falling section of arc VAC (small current welding) and the case, when arc differential resistance $S_{\mathrm{a}}$ by its absolute value is smaller or equal to total resistance of current-conducting wires, electrode extension and sliding contact in welding torch nozzle. In this case, $\mu \geq 0$. Therefore, now also all the three conditions of stability are fulfilled at any values of capacitance $C$ (12);

3rd: $S_{\mathrm{a}}<0$, but at the same time $\left|S_{\mathrm{a}}\right|>R_{*}$. In this case, according to $(9) \mu<0$, and it means that the steady-state mode (10) will be stable, only when the following conditions are fulfilled according to (12):

$$
\begin{gathered}
C<\frac{L}{|\mu| R^{2}}, \quad 1+C E M>|\mu|, \\
\frac{E M}{(1-|\mu|)} C^{2}+C<\frac{L}{|\mu| R^{2}} .
\end{gathered}
$$

Considering these conditions, it is easy to see that at $|\mu|<1$ the second condition is always fulfilled. If the third condition is fulfilled here, the first condition is sure to be fulfilled, too. Now, the third condition proper is an algebraic inequality of the second kind for $C$. Its solution has the following form:

$$
C<-a+\sqrt{a^{2}+2 a b},
$$

where

$$
a=\frac{1-|\mu|}{2 E M}, \quad b=\frac{L}{|\mu| R^{2}} .
$$

Inequality (14) yields the region of possible values of capacitance $C$, which guarantee the stability of arc welding mode, described by equation (8) at $\mu<0$. In some cases, for instance at express-analysis of stability, it is more convenient to use a simpler relationship, instead of (14):

$$
C<\sqrt{a b},
$$

which at $b>4 a$ also satisfies the third inequality from (13), but limits a somewhat smaller region of values of capacitance $C$, compared to «precise» region determined by relationship (14). Note that condition $b>4 a$ can be ensured by selection of the required $R$ value in formulas (15), which actually determines the steepness of VAC of welding arc power source in the considered working point $R=|d u / d i|$.

So, in welding at small currents, when arc VAC has a falling section, and here $\left|S_{\mathrm{a}}\right|>R_{*}$, condition (14) and two simpler $C<\sqrt{a b}$ and $b>$ $>4 a$ conditions should be fulfilled in addition to condition $|\mu|<1$, to ensure the stability of arc welding mode. In the latter case, conditions of stability, allowing for (15) and (16), can be written in the following final form:

$$
|\mu|<1, \quad \frac{L E M}{2|\mu|}, \quad C^{2}<\frac{L(1-|\mu|)}{2 R^{2}|\mu| E M} .
$$

The first condition from (17) at $R_{*}=0$ is reduced, according to (9), to Kauffman criterion $\left|S_{\mathrm{a}}\right|<R$, i.e. it is a certain refinement of this criterion. The second condition assigns the upper limit of possible angles of inclination of arc power source VAC at already selected other parameters of the welding circuit. The third condition limits the value of capacitance $C$ from the top. Conditions of stability (17), unlike conditions (2), connect not only parameters $C, L, R, S_{\text {a }}$, but also parameters $R_{*}, M$ and $E$, characterizing the electrical, thermophysical and geometrical properties of the consumable electrode and electric field intensity in the arc column.

It should be noted, however, that fulfillment of conditions (17) ensures just the fundamental possibility of the system reaching the steady state after a small external disturbance, but it does not guarantee absence of negative influence of capacitance $C$ on the nature of transient processes in the welding circuit. To obtain the most complete idea of the extent of the above influence, let us use computer simulation of arc welding process. We will focus on small welding current modes, in the region of which, as is known [3-6, 8], the arc characteristic is falling. These are exactly the modes, in which, according to (17), an essential influence of capacitance $C$ on the transient processes should be anticipated.

During simulation we will use typical values of mode parameters of robotic arc welding at small currents [15], namely $u_{x}=30 \mathrm{~V}, i=40 \mathrm{~A}, v_{\mathrm{e}}=$ $=25 \mathrm{~mm} / \mathrm{s}, H=15 \mathrm{~mm}$, and real parameters of welding circuit $R=6 \cdot 10^{-2} \mathrm{Ohm}, R_{*}=1 \cdot 10^{-2} \mathrm{Ohm}$, 


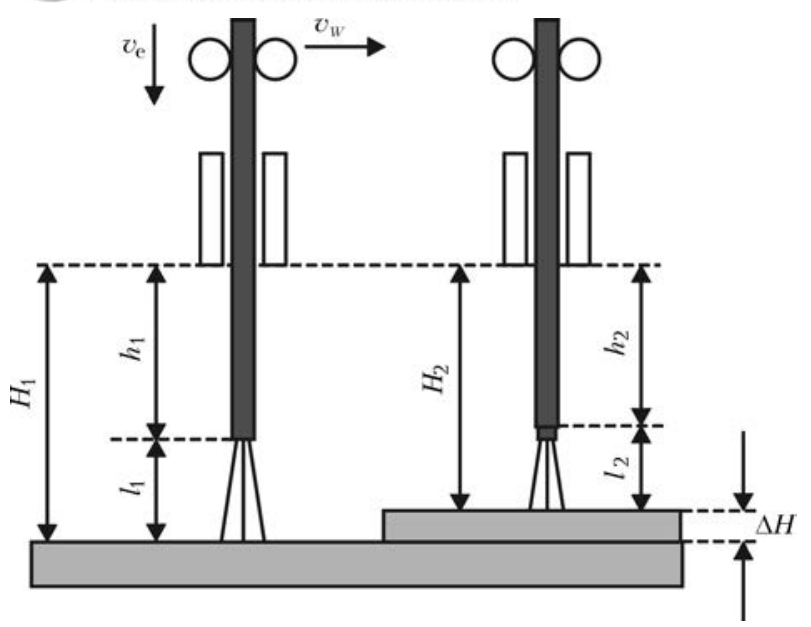

Figure 3. Schematic of realization of jump-like disturbance $\Delta H$

$L=1 \cdot 10^{-3} \mathrm{H}, E=2 \mathrm{~V} / \mathrm{mm}, u_{0}=18 \mathrm{~V}, M=$ $=0.5 \mathrm{~mm} /(\mathrm{s} \cdot \mathrm{A})$. As regards arc differential resistance $S_{\mathrm{a}}$, we will take the value from the graph of VAC given in [6], because of the known difficulties of its direct measurement: in small current region $(i=20-60 \mathrm{~A})$ it is equal to $S_{\mathrm{a}} \approx$ $\approx-1.5 \cdot 10^{-2} \mathrm{~V} / \mathrm{A}$.

Assigning the range of possible values of capacitance $C$ during modeling, we will proceed from the following considerations. Any electric

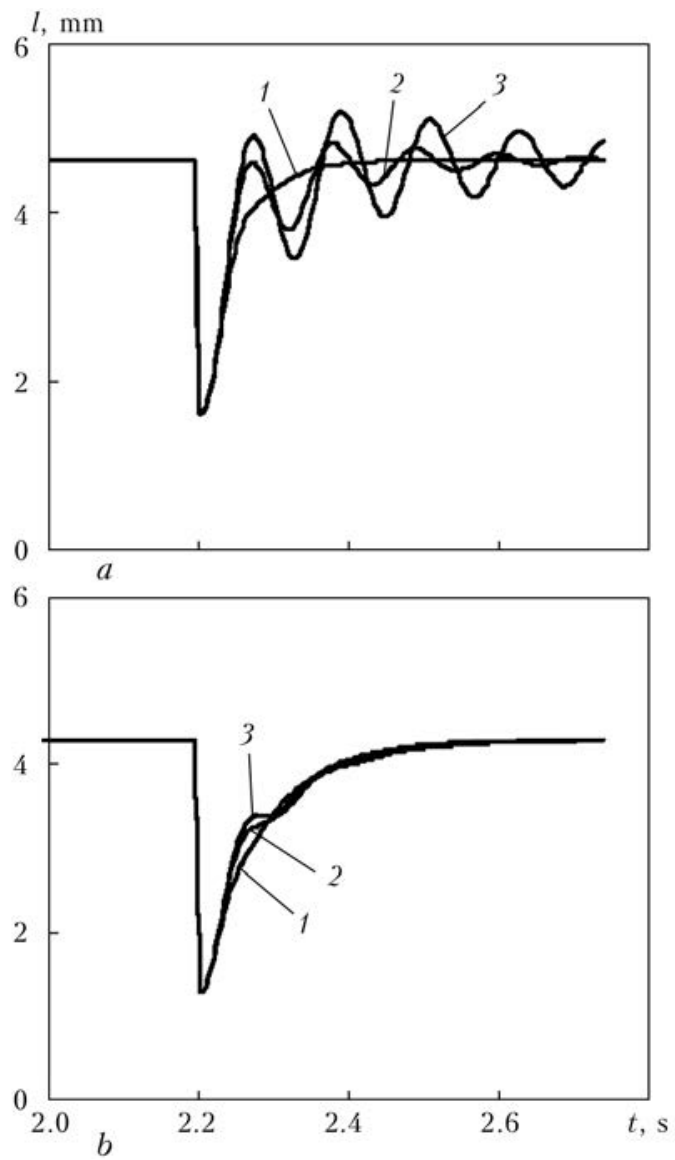

Figure 4. Transient processes $l=l(t)$ at $S_{\mathrm{a}}=-1.5 \cdot 10^{-2}$ (a) and $1.5 \cdot 10^{-2}(b) \mathrm{V} / \mathrm{A}: 1-C \leq 0.1 ; 2-C=0.3$; $3-C=0.4 \mathrm{~F}$ circuit contains the so-called «parasitic» capacitance. Its minimum value for the welding circuit, according to [6], is equal to $C_{\mathrm{m}} \approx 1 \cdot 10^{-8} \mathrm{~F}$. At the same time, it is known [1] that capacitance can be specially added to the welding circuit. In such a case, it is desirable to determine the upper limit of this capacitance values, above which the transient process becomes unsatisfactory in terms of technical requirements to consumable-electrode arc welding.

As disturbing action, giving rise to transient process (11) in the welding circuit, we will use, as shown in Figure 3, the jump-like variation of distance $\Delta H=H_{2}-H_{1}$ between the edge of current-conducting tip and weld pool free surface. Figures 4 and 5 show the results of computer simulation.

Figure 4, $a$ presents three graphs $l=l(t)$, showing the reaction of arc length $l(t)$ to disturbance $\Delta H=-3 \mathrm{~mm}$ at $S_{a}=-1.5 \cdot 10^{-2} \mathrm{~V} / \mathrm{A}$ and at different values of capacitance $C$. Curve 1 is the graph of several transient processes, which practically coincide, although the capacitance values, at which these graphs were derived, fall within a broad range $0<C \leq 0.1 \mathrm{~F}$. Hence, it follows that until capacitance $C$ does not exceed a certain value (in our case, $0.1 \mathrm{~F}$ ), its influence on the transient process is negligibly small. Only at further increase of this capacitance, the shape of transient process curves changes noticeably (curves 2 and 3), acquiring an oscillatory nature, with oscillation amplitude rising with capacitance increase.

Figure 4, $b$ shows graphs $l=l(t)$ plotted at the same values of capacitance $C$ as the graphs in Figure 4, $a$. However, unlike these, the graphs in Figure 4, $b$ were plotted at condition $S_{\mathrm{a}}>0$. Comparing these graphs, we come to the conclusion that in the case when $S_{\mathrm{a}}<0$, influence of capacitance $C$ on transient processes in the weld-

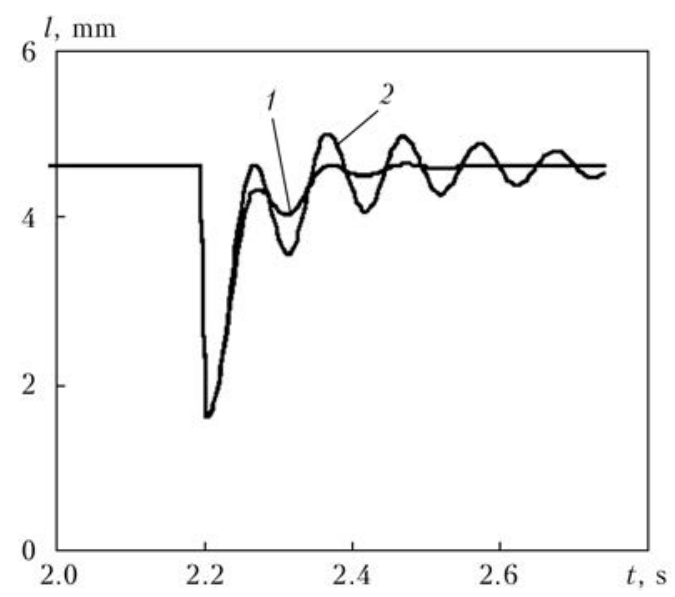

Figure 5. Transient processes $l=l(t)$ at $C=0.2 \mathrm{~F}$ and $S_{\mathrm{a}}=$ $=-1.5 \cdot 10^{-2} \mathrm{~V} / \mathrm{A}: 1-R_{*}=1 \cdot 10^{-2} \mathrm{Ohm} ; 2-R_{*}=0$ 
ing circuit is much higher than in the case when $S_{\text {a }}>0$.

Note one more important circumstance. To get an adequate insight into the transient processes running in the welding circuit at $S_{\mathrm{a}}<0$, it is necessary to take into account total resistance $R_{*}$, alongside its other parameters. This impedance is usually ignored, being considered negligibly small. In reality, as to its order of magnitude, it is commensurate with absolute value of the arc differential resistance $S_{\mathrm{a}}$. Therefore, its influence on the transient process in the welding circuit can turn out to be quite tangible.

Results, given in Figure 5, are an illustration to the above-said. It presents $l=l(t)$ graphs, plotted at two different values of resistance $R_{*}$. Curve 1 is the reaction of arc length $l(t)$ to disturbance $\Delta H=-3 \mathrm{~mm}$, when $R_{*}=1 \cdot 10^{-2} \mathrm{Ohm}$, and curve 2 is the same at $R_{*}=0$. It is readily seen from the Figure that these curves differ considerably from each other. This immediately implies that ignoring resistance $R_{*}$, we certainly obtain incorrect information about the transient processes, running in the welding circuit.

The above-said leads to the following conclusions.

1. At high and medium welding currents, when the working point is located in the rising or flat section of the arc VAC, presence of capacitance in the welding circuit does not affect the stability of arc welding mode. Capacitance $C$ does not influence the stability in the case of small currents, either, when the working point is located in the falling section of this characteristic, but only if the arc differential resistance $S_{\text {a }}$ is smaller by absolute value than the total resistance of current-conducting wires, electrode extension and sliding contact in welding torch nozzle, i.e. if $\left|S_{\mathrm{a}}\right|<R_{*}$.

2 . In the case when $\left|S_{\mathrm{a}}\right|>R^{*}$, presence of sufficiently large capacitance in the welding circuit can lead to loss of stability of arc welding mode. Established criteria in the form of algebraic inequalities (17) allow evaluation of upper limit of the region of this capacitance values, within which stable welding modes are guaranteed.

3. Results of computer modeling of processes running in the welding circuit show that small capacitance (of the order of hundredth of a farad) does not have any noticeable influence on transient processes in arc welding, either at small or at high currents. Further increase of this capacitance in welding at small currents leads to generation of noticeable oscillations of arc length, which increase as the capacitance approaches the limit of stability, determined by conditions (17).
The given modeling results confirm one more important finding that in order to obtain an adequate insight into the transient processes running in the welding circuit, it is necessary to take into account the real resistances of current-conducting wires, electrode extension and sliding contact in welding torch nozzle.

In conclusion we will note that recently specialists' attention was focused on solving one of the difficult problems, associated with robotisation of arc welding of thin-walled items and structures $[16,17]$. It is obvious that their welding should be performed at small and very small welding currents. In this connection, the results set forth in this paper, will be useful in development of robotic welding technologies and respective process equipment.

1. Vereshchago, E.N., Kostyuchenko, V.I. (2014) Mode instability in circuit with capacity and electric arc supplied by direct current source. The Paton Welding J., 8, 42-46.

2. Andronov, A.A., Vitt, A.A., Khajkin, S.E. (1959) Theory of vibrations. Moscow: Ph.-Math. Literatura.

3. Finkelnburg, W., Maecher, H. (1961) Electric arcs and thermal plasma. Moscow: IL.

4. Khrenov, K.K., Esibyan, E.M. (1962) Influence of static characteristics of arc and power source on stability of arc running and mode. Svarochn. Proizvodstvo, 5, 10-13.

5. Paton, B.E., Lebedev, V.K. (1966) Electric equipment for arc and slag welding. Moscow: Mashinostroenie.

6. Leskov, G.I. (1970) Electric welding arc. Moscow: Mashinostroenie.

7. Esibyan, E.M. (1963) Study of electric and technological properties of low-amperage welding arc. In: Coll. on Welding of special metals and alloys, 137152. Kiev: AN Ukr.SSR.

8. Sisoyan, G.A. (1974) Electric arc in electric furnace. Moscow: Metallurgiya.

9. Ionov, Yu.G. (1986) To theory of non-stationary processes of direct current electric arc. Izvestiya $S O$ AN SSSR. Series Techn. Sci., Issue 1, 4, 84-88.

10. Lenivkin, V.A., Dyurgerov, N.G., Sagirov, Kh.N. (1989) Technological properties of welding arc in shielding gases. Moscow: Mashinostroenie.

11. Pan, J. (1990) Arc welding and control theory. In: Proc. of JWS Int. Symp., 11, 1033-1035.

12. Sudnik, V.A., Erofeev, V.A., Logvinov, R.V. (1999) Study of stability of gas-shielded arc welding process, 110-120. Tula: TulGU.

13. Tsybulkin, G.A. (2008) On the influence of small parameters on $\mathrm{MIG} / \mathrm{MAG}$ welding stability. The $P a-$ ton Welding J., 8, 22-25.

14. Tsybulkin, G.A. (2014) To evaluation of stability of same class dynamic systems. Problemy Kontr. $i$ Informatiki, 3, 5-11.

15. Tsybulkin, G.A. (2014) Adaptive control in arc welding. Kiev: Stal.

16. Gritsyna, A.N. (2014) Problems of formation of sound welded joints of thin-walled structures in their welding by nonadaptive robots. In: Proc. of 6th Int. Sci.-Pract. Conf. on Innovative Technologies in Machine-Building and Metallurgy (10 Sept. 2014), 339-350. Rostov-na-Donu: DGTU.

17. Lyudmirsky, Yu.G. (2002) Robotisation in production of low rigidity welded structures. Rostov-naDonu: SKNTs. 


\title{
STRUCTURAL CHANGES IN METAL OF WELDED JOINTS OF STEAM PIPELINES IN OPERATION
}

\author{
V.V. DMITRIK ${ }^{1}$, O.V. SOBOL ${ }^{1}$, M.A. POGREBNOJ ${ }^{1}$, A.V. GLUSHKO ${ }^{1}$ and G.I. ISHCHENKO ${ }^{2}$ \\ ${ }^{1}$ NTU «Kharkov Polytechnic Institute» \\ 21 Frunze Str., 61022, Kharkov, Ukraine. E-mail: svarka126@ukr.net \\ ${ }^{2}$ OJSC «Turboatom»
}

199 Moskovsky Ave., Kharkov, Ukraine. E-mail: office@turboatom.com.ua

\begin{abstract}
Extension of service life of steam pipelines is a relevant task. Investigation of peculiarities of structural state in metal of welded joints of long-lasting operation steam pipelines allows evaluating a level of their damageability and grounding residual life. This study determined that structural changes of welded joints from $15 \mathrm{Kh} 1 \mathrm{M} 1 \mathrm{~F}$ and $12 \mathrm{Kh} 1 \mathrm{MF}$ steels are caused by diffusion processes, formation of intergranular segregations, carbide reactions, nucleation and propagation of creep pores. The ways are outlined for regulation of structural state of metal of HAZ areas, which are directed at reduction of structural inhomogeneity and extension of service life. 10 Ref., 10 Figures.
\end{abstract}

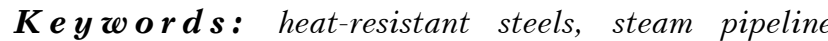
welded joints, structure, carbides, pores, damageability, diffusion, deformation, heat-affected zone

Degradation of metal of long-lasting operation steam pipelines from $15 \mathrm{Kh} 1 \mathrm{M} 1 \mathrm{~F}$ and $12 \mathrm{Kh} 1 \mathrm{MF}$ steels is provided by physical-chemical processes taking place in them. Intensity of such processes, promoting structural changes in metal of the welded joints, is higher than in the base metal. It is caused by presence of initial structural, chemical and mechanical inhomogeneity being formed under the effect of welding heat. The level of inhomogeneity in the welded joints is significantly higher than in the base metal.

Chemical, structural and mechanical inhomogeneity of metal of welded joints receive further development in processes of operation of the steam pipeline, in particular after $250,000 \mathrm{~h}$ of running. From our point of view, inhomogeneity of each type at first shall be studied separately for further investigation of their general effect on welded joint degradation.

Aim of the work lies in study of peculiarities of structural changes of metal of the long-lasting operation welded joints from $15 \mathrm{Kh} 1 \mathrm{M} 1 \mathrm{~F}$ and $12 \mathrm{Kh} 1 \mathrm{MF}$ steels, that allows evaluating the level of their damageability and specifying residual life.

Weld metal and areas of HAZ of welded joints from given heat-treatable steels can have initial (after high-tempering) sorbite, ferrite-bainite, ferrite-sorbite structures as well as other structures allowed by reference documents [1-4]. The highest level of structural and mechanical inhomogeneity has an area with incomplete re-crys- tallization of HAZ metal, where new products of austenite decay in the initial structure represent (depending on welding heat) pearlite, sorbite, troostite or even martensite. It is relevant to produce welded joints with probably smaller structural inhomogeneity by means of welding heat optimizing, for example, ferrite-bainite or bainite weld metal structure [5-7].

Structures of the welded joints in process of long-lasting operation under creep conditions (temperature of operation $T_{\mathrm{op}}=545-585{ }^{\circ} \mathrm{C}$, operating pressure $P_{\text {op }}=20-25 \mathrm{MPa}$ ) are transformed with various intensity into different on content ferrite-carbide mixtures. Intensity of structural changes, significantly depending on their initial condition, to the most extent after more than $250,000 \mathrm{~h}$ of running of welded joint, is obvious in areas of fusion, overheating and incomplete re-crystallization of HAZ metal [8, 9]. Structural changes are caused by diffusion displacement of chromium and molybdenum from central zones of $\alpha$-phase crystals in their nearboundary zones (volumetric diffusion) and diffusion displacement of given elements over the grain boundaries (grain-boundary diffusion) as well as formation of segregations in the nearboundary zones of crystallites and displacement of dislocations by means of glide and climb, that resulted in appearance of fragmentation (polygonization) of $\alpha$-phase grains; by transfer of chromium and molybdenum from $\alpha$-phase into carbides as well as formation of new carbides VC and $\mathrm{Mo}_{2} \mathrm{C}$; passing of carbide reactions $\mathrm{M}_{3} \mathrm{C} \rightarrow$ $\rightarrow \mathrm{M}_{7} \mathrm{C}_{3} \rightarrow \mathrm{M}_{23} \mathrm{C}_{6}$; coagulation of carbide phases of the 1st group; nucleation and propagation of 


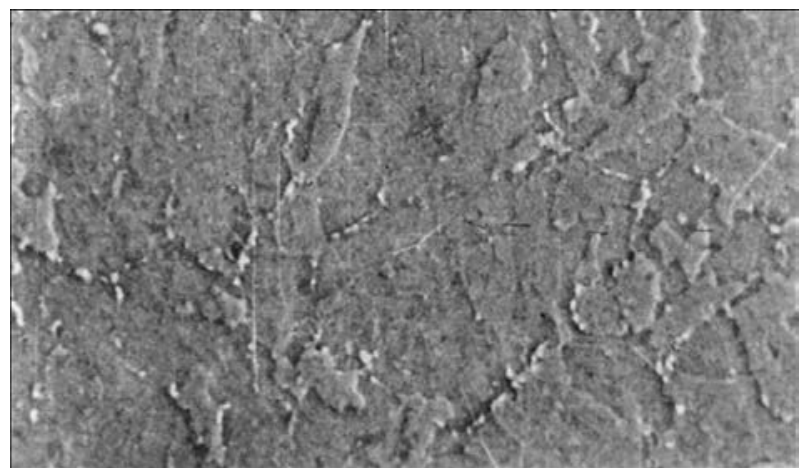

Figure 1. Carbide precipitates in initial structure of areas of HAZ metal incomplete re-crystallization of welded joint from steel $15 \mathrm{Kh} 1 \mathrm{M} 1 \mathrm{~F}(\times 2500)$

creep micropores as well as their transformation in macropores and macrocracks. Each of indicated processes, respectively, promotes for change of metal structure in the welded joints, that in total determines its degradation and reduction of heat resistance. In this connection, damageability on corrosion-fatigue mechanism requires separate consideration.

Initial structure of $15 \mathrm{Kh} 1 \mathrm{M} 1 \mathrm{~F}$ and $12 \mathrm{Kh} 1 \mathrm{MF}$ steels (Figure 1) contains carbides of the 1st group $\mathrm{M}_{3} \mathrm{C}$ (mainly), $\mathrm{M}_{7} \mathrm{C}_{3}$ and $\mathrm{M}_{23} \mathrm{C}_{6}$ (small amount) as well as $2 \mathrm{~d}$ group ones, namely fine $\mathrm{VC}$ carbides in $\alpha$-phase grain body and in their interfaces. Initially they have circular or acicular (VC) form.

In process of aging, self-diffusion of chromium and molybdenum from central zones of $\alpha$-phase grains in their near-boundary zones provokes change of bonding forces between the atoms. Diffusion displacement of atoms of chromium and molybdenum, caused by gradients of their chemical potentials, results in formation of near-boundary segregation zones in $\alpha$-phase crystals $[8,9]$. Presence of such zones develops the conditions for carbide reactions $\mathrm{M}_{3} \mathrm{C} \rightarrow \mathrm{M}_{7} \mathrm{C}_{3} \rightarrow \mathrm{M}_{23} \mathrm{C}_{6}$ as well as coagulation of $\mathrm{M}_{7} \mathrm{C}_{3}$ carbides and, mainly, $\mathrm{M}_{23} \mathrm{C}_{6}$. The coagulation of carbides along the grain interface takes place by means of coalescence, that results in formation of elongated, with possible branching, carbide forms ( $\mathrm{Fi}^{-}$ gure 2). Coagulating (with lower intensity) $\mathrm{M}_{7} \mathrm{C}_{3}$ and $\mathrm{M}_{23} \mathrm{C}_{6}$ carbides, which are located in $\alpha$-phase grain body, mainly have the form close to circular one. Vanadium carbide $\left(a_{0}=\right.$ $=0.416 \mathrm{~nm}$ ) remains stable to $290,000 \mathrm{~h}$ of running [7]. Stability of dispersed vanadium carbides is one of the factors determining life of these steels.

Irregular chains (Figure 3) are formed from elongated $\mathrm{M}_{7} \mathrm{C}_{3}$ and $\mathrm{M}_{23} \mathrm{C}_{6}$ carbides, having diameter of around $0.15-0.30 \mu \mathrm{m}$, along the $\alpha$ phase grain interface in process of aging $\left(t_{\mathrm{op}}>\right.$

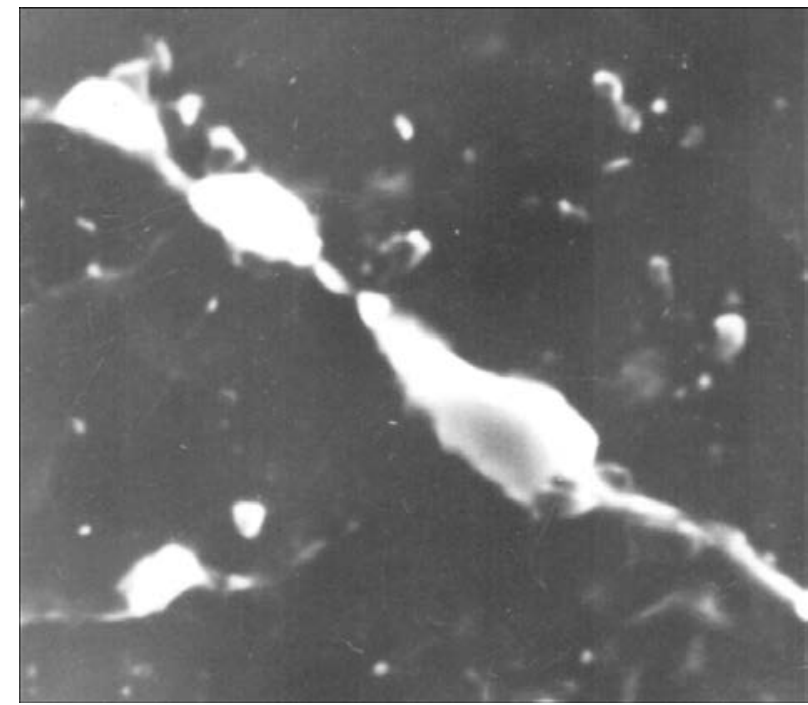

Figure 2. Coagulation by means of coalescence of $\mathrm{M}_{23} \mathrm{C}_{6}$ carbides on $\alpha$-phase grain interface $(\times 4000)$

$>270,000$ h). Given carbides have close crosssection dimensions and significantly different lengths.

It can be outlined that $\mathrm{M}_{7} \mathrm{C}_{3}$ and $\mathrm{M}_{23} \mathrm{C}_{6}$ carbides of elongated form located at grain interface have decisive effect on brittleness. For example, impact toughness of the welded joint of steam pipelines, operating under conditions of main steam and having metal structure given in $\mathrm{Fi}^{-}$ gure 3 , made $K C U=31 \mathrm{~J} / \mathrm{cm}^{2}$ and that of the base metal with uniformly distributed carbides was $K C U=74 \mathrm{~J} / \mathrm{cm}^{2}$. It is found that coagulation of carbide phases along the grain interface promotes for further reduction of impact toughness to the value below allowed one [1-4]. In course of long-lasting running ( $t_{\mathrm{op}}>>250,000 \mathrm{~h}$ ) of chromium and molybdenum diffusing from $\alpha$-phase form new carbides ( $\mathrm{VC}$ and $\mathrm{Mo}_{2} \mathrm{C}$ ) as well as transfer into the 1st group carbides, mainly in

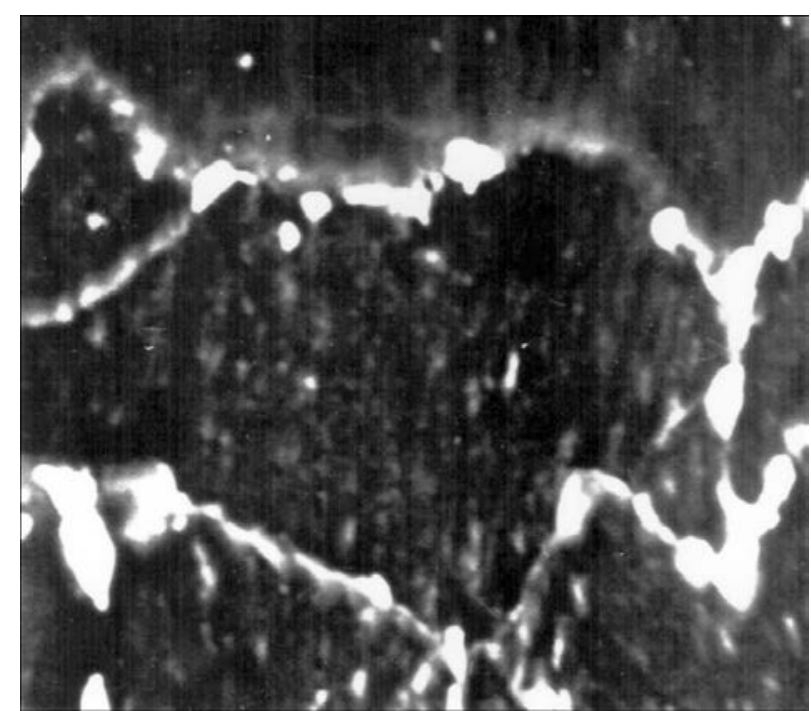

Figure 3. Distribution of $\mathrm{M}_{23} \mathrm{C}_{6}$ carbides on $\alpha$-phase grain interface $(\times 2500)$ 


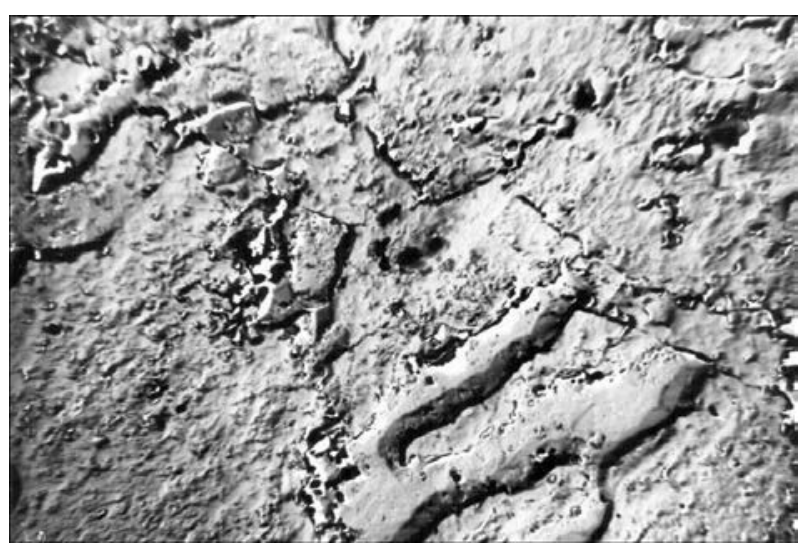

Figure 4. Microstructure $(\times 4500)$ of grain in area of HAZ metal overheating

$\mathrm{M}_{23} \mathrm{C}_{6}$. It is determined that total content of alloying elements in the carbides in metal of HAZ overheating area after $270,000 \mathrm{~h}$ running made 60-65\% Cr, 70-75\% Mo and 80-82\% V. Different length of carbides, from our point of view, is caused by varying rate of their lattice build-up that is related with the level of segregation of chromium and molybdenum in the near-boundary $\alpha$-phase zones, and their diffusion displacement. Difference in diffusion displacement intensity is typical for volumetric as well as grain-boundary diffusion. Increase of the near-boundary segregation zones on width, in our opinion, is mainly provided by means of volumetric diffusion, and their length is caused by grain-boundary diffusion. Periodic change of transfer direction of separate atoms of chromium and molybdenum at stated general direction of their diffusion displacement is noted in the processes of long-term aging. This corresponds to fillet diffusion mechanism [10] which is type of vacancy mechanism. Realization of transfers of studied mechanism seems to be possible only in presence of the fillet-like vacancies.

Process of aging increases diffusion mobility of the vacancies as well as mobility of disloca-

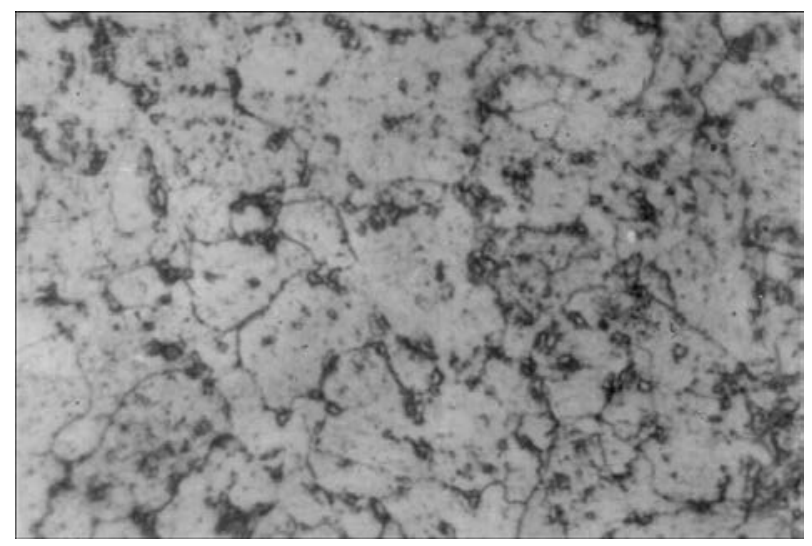

Figure 5. Microstructure $(\times 360)$ of area of HAZ metal incomplete re-crystallization with new products of austenite decay which represent themselves globular pearlite tions, which displace by means of glide and climb.

Metallographic method was used for dislocation detection. It allowed determining places of dislocation emergence on working surface of microsection. Also method of transmission microscopy was used that provided the possibility of qualitative evaluation of dislocation density.

Dislocation displacement effect on glide and climb mechanism, resulting in partial elimination of grain boundary, was noted before [6]. Diffusion of grain boundary area providing further grain coarsening can be considered as initial stage of processes of initial re-crystallization. Hindering of dislocations results in their lining up and then banding. It provides for appearance of fragmentation (polygonization) of grains (Figure 4) and stipulates increase of pore nucleation intensity. Newly formed carbide phases $\mathrm{VC}$ and $\mathrm{Mo}_{2} \mathrm{C}$ rise hindering of dislocation displacement, that also promotes formation of $\alpha$-phase grain polygonal structure. It should be noted that steam pipeline metal is subjected to simultaneous strengthening and softening [7] under typical for it aging condition with different intensity.

It is determined that the highest level of polygonization of $\alpha$-phase grains as well as effect of dislocation displacement is noted in area of incomplete recrystallization of HAZ metal. In this case the new products of austenite decay are globular pearlite located in form of fringes along the boundaries of actual austenite grains. Hindering of dislocations displacing by means of glide is mostly supported by sub-fine $\mathrm{VC}$ carbides, and $\mathrm{Mo}_{2} \mathrm{C}$ and $\mathrm{M}_{7} \mathrm{C}_{3}$ as well as $\mathrm{M}_{3} \mathrm{C}$ are somewhat less effective. It is important that carbides, particularly VC, have uniform distribution along the grain body and interfaces.

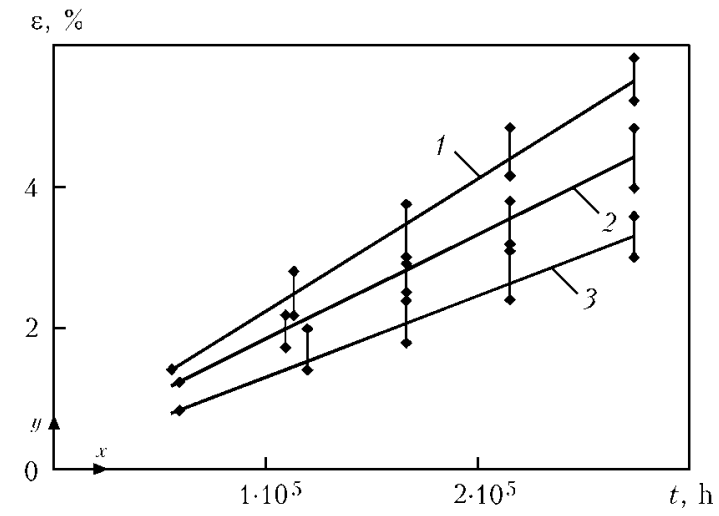

Figure 6. Dependence of residual deformation on structure of new products of austenite decay in area of HAZ metal incomplete re-crystallization: 1 - globular pearlite; $2-$ sorbite; 3 - troostite 


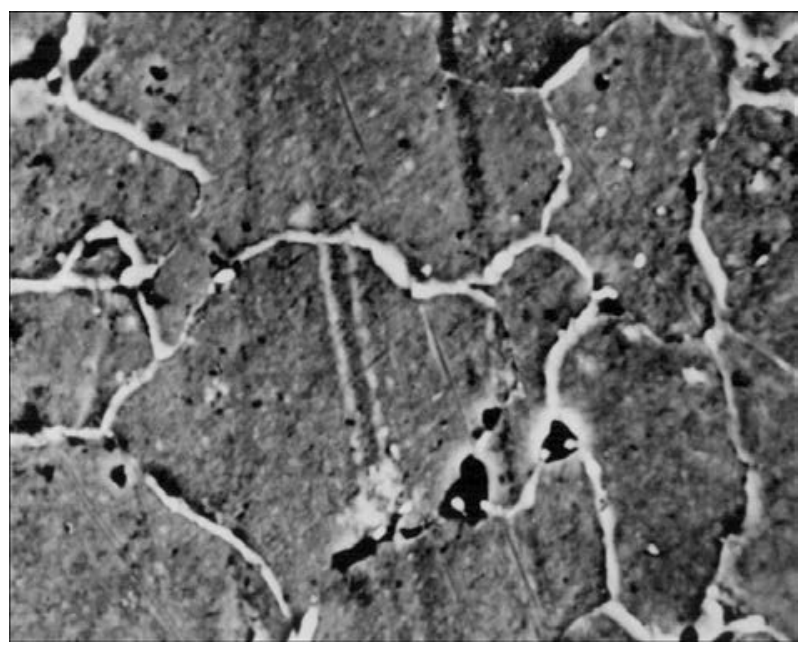

Figure 7. Creep pores on the $\alpha$-phase grain interface at $275,000 \mathrm{~h}$ running of welded joints $(\times 2500)$

At bulk deformation of welded joints of the steam pipelines less than $1 \%$ (running under creep conditions around 250,000 h), the areas of incomplete re-crystallization of HAZ metal (soft interlayer), according to data of F.A. Khromchenko [5], can be deformed by $6-8 \%$. It is determined [7] that, applicable to running of similar welded joints of around 276,000 h, its deformation makes 4-5\%. Level of deformation was determined on elements of the operating steam pipelines and in the specimens, being tested for long-term strength. Structure, fragmentation of $\alpha$-phase grains, lines and bands of glides were studied on specimens, cut out from the operating pipelines, that also proved their deformation level.

It was determined that the weld metal, having bainite structure (alloy of 09KhMFA type, base metal - $15 \mathrm{Kh} 1 \mathrm{M} 1 \mathrm{~F}$ grade steel), is characterized by the lowest creep rate in comparison with other initial structural conditions being allowed by reference documents. Value of the weld metal deformation, having a structure of upper

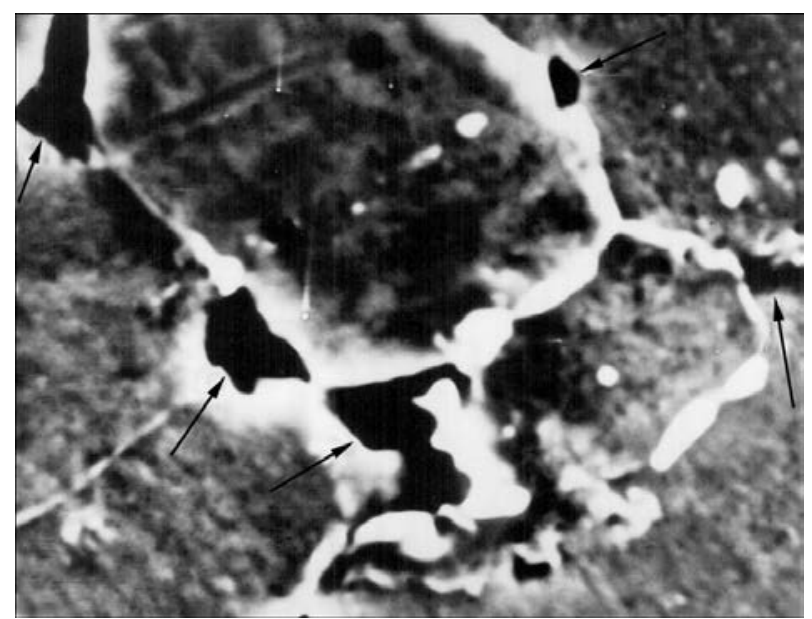

Figure 8. Form of creep pores (indicated by arrows) after welded joint running $(\times 3500) 276,000 \mathrm{~h}$

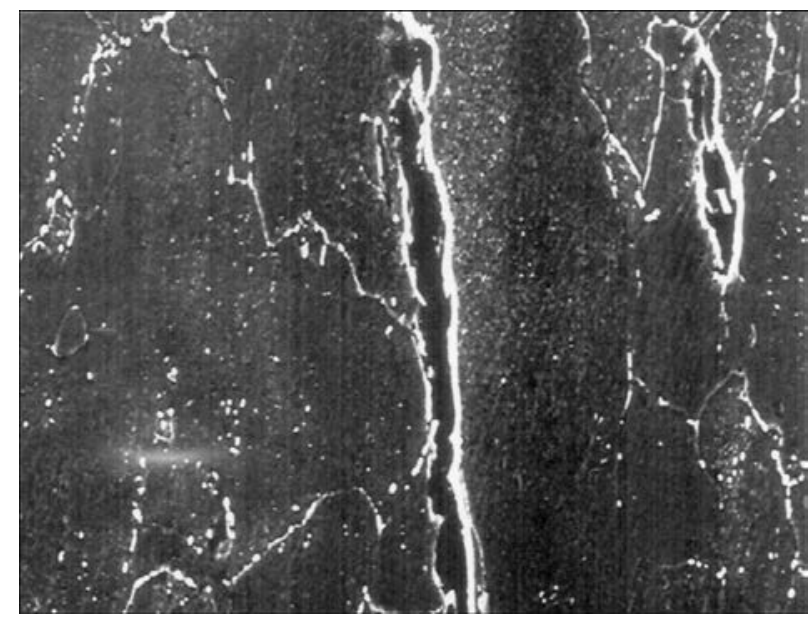

Figure 9. Creep crack in welded joint at 280,000 h running $(\times 2500)$

and lower tempered bainite, has insignificant difference (around 7-9 \%). It allows omitting its structural differences. It was found that metal of area of HAZ incomplete re-crystallization with structure, where the new austenite decay products represent globular pearlite (Figure 5), is deformed to larger extent than metal where the new products are sorbite, troostite or bainite (Figure 6). It should be noted that optimizing of welding thermal conditions allows preventing formation of the new austenite decay products in form of martensite or globular pearlite in this area [3].

Process of deformation of the welded joints provokes nucleation and propagation of creep pores in their metal. Pore detection was carried out on microsections, which were firstly subjected to mechanical polishing, and then electric polishing in strong orthophosphoric acid and further etching in $5 \% \mathrm{HNO}_{3}$. Indicated treatment was carried out 3-4 times on microsections from $12 \mathrm{Kh} 1 \mathrm{MF}$ steel, and from 5 to 7 times on mircosections from steel $15 \mathrm{Kh} 1 \mathrm{M} 1 \mathrm{~F}$ at presence of bainite constituent in their structure. The most

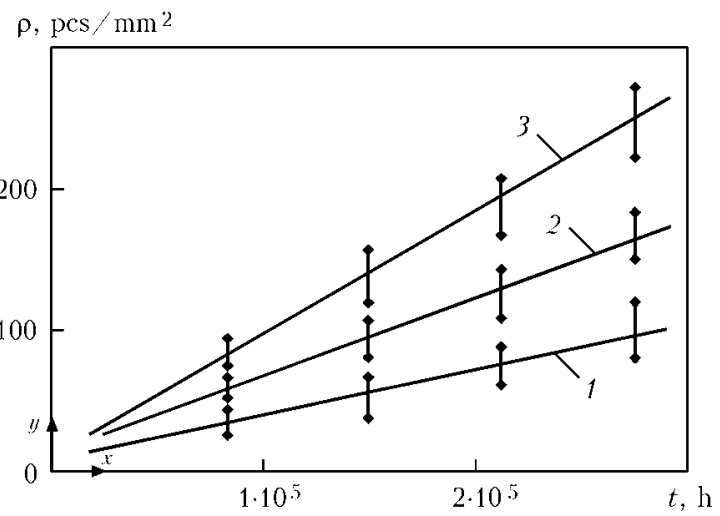

Figure 10. Dependence of density of creep pores of longitudinal $0.5-3.0 \mu \mathrm{m}$ size located on the $\alpha$-phase grain interface on numbers of austenite grains of area of HAZ metal overheating in welded joint from steel $15 \mathrm{Kh} 1 \mathrm{M} 1 \mathrm{~F}$ at 276,000 h running: $1-$ number $6 ; 2-5 ; 3-4$ 
intensive pore nucleation (Figure 7) is noted in the structure of area of HAZ metal incomplete re-crystallization, during its $4-6 \%$ deformation, at interface of two or three grains, where interfaces of austenite grains match with interface of grains of studied structure and coagulating carbides $\mathrm{M}_{23} \mathrm{C}_{6}$ are located. Amount of pores was significantly smaller at grain interface where was no coagulating carbides. From our point of view, pores of $0.03-0.07 \mu \mathrm{m}$ can be considered as nucleation ones. Formation of the nucleation pores can be considered as initial damageability stage. Creep pores in the welded joint metal are mainly formed along grain the interface and on their body (less intensively) normal to tensile stresses. Location of pores in the welded joints became chaotic in processes of their running $>250,000 \mathrm{~h}$. It should be noted that formation of pores was approximately $40-60 \%$ more than in the base metal in areas of fusion and HAZ metal incomplete re-crystallization (direct steam pipeline welded joints from steel $12 \mathrm{Kh} 1 \mathrm{MF}$, running $>270,000 \mathrm{~h}$ ). It makes $30 \%$ in overheating area. In process of development the form of pores became branched (Figure 8), and creep pores ( $\mathrm{Fi}_{-}$ gure 9), propagating on brittle mechanism, are formed in coalescence of the separate pores. Amount as well as intensity of propagation of pores and creep cracks depend on value of austenite grains (Figure 10) (GOST 5639-82), that is typical for areas of fusion and HAZ metal overheating.

Creep-rupture tests determined that critical level of residual deformation of area of HAZ metal incomplete re-crystallization in butt joints of the steam pipelines from $15 \mathrm{Kh} 1 \mathrm{M} 1 \mathrm{~F}$ steel should not exceed $1.5 \%$ and that for steel $12 \mathrm{Kh} 1 \mathrm{MF}$ makes $2 \%$ at their bulk deformation not less that $1 \%$, and its exceed promotes for rapid increase of pore formation intensity.

\section{Conclusions}

1. It is determined that structural changes of metal of long-lasting operation welded joints of the steam pipelines from steels $15 \mathrm{Kh} 1 \mathrm{M} 1 \mathrm{~F}$ and $12 \mathrm{Kh} 1 \mathrm{MF}$ are caused by diffusion processes, formation of segregations, displacement of chromium and molybdenum in the carbides and formation of new carbides, carbide reactions, nucleation and propagation of creep pores.

2. It is determined that reduction of level of structural inhomogeneity, formed under conditions of long-lasting operation of welded joints, results in decrease of intensity of creep pore formation.

1. SO 153-34.17.456-2003 (2005): Procedural recommendations on assessment of service life of heat power plants. Moscow: ORGRES.

2. OST 34-70-690-96: Metal of steam-power equipment of power plants. Methods of metallographic analysis in service conditions. Moscow: VTI.

3. SO 153-34.17.455-2003: Instruction on extension of service life of steam pipelines from centrifugal-cast pipes at heat power plants. Moscow: ORGRES

4. $R D$ 153-34.1-17.467-2001: Express method for evaluation of residual life of welded joints of boiler and steam pipeline collectors according to structural factor Moscow: ORGRES.

5. Khromchenko, F.A. (2002) Life of steam pipeline welded joints. Moscow: Mashinostroenie.

6. Elpanova, N.V., Berezina, T.G. (1989) Influence of structure on fracture kinetics of $12 \mathrm{Kh} 1 \mathrm{MF}$ steel at creep. Metallovedenie $i$ Termich. Obrab. Metallov, 7, 36-39.

7. Dmitrik, V.V. (2013) Welded joints of steam pipelines. Kharkov: Majdan.

8. Dmitrik, V.V., Bartash, S.N. (2014) Peculiarities of degradation of metal of welded joints of steam pipelines of heat power plants. The Paton Welding J., 6/7, 29-30

9. Dmitrik, V.V., Bartash, S.N. (2010) Features of damageability of steam pipeline welded joints by the creep mechanism. Ibid., 6, 19-21.

10. Butyagin, P.Yu. (2006) Chemical physics of solids. Moscow: MGU. 


\title{
ELECTRON BEAM WELDING OF MEDIUM-PRESSURE CHAMBER OF GAS TURBINE ENGINE
}

\author{
V.M. NESTERENKOV ${ }^{1}$, L.A. KRAVCHUK ${ }^{1}$, Yu.A. ARKHANGELSKY ${ }^{1}$, \\ I.A. PETRIK ${ }^{2}$ and Yu.A. MARCHENKO ${ }^{2}$ \\ ${ }^{1}$ E.O. Paton Electric Welding Institute, NASU \\ 11 Bozhenko Str., 03680, Kiev, Ukraine. E-mail: office@paton.kiev.ua \\ ${ }^{2}$ Company «Motor-Sich» \\ 15 Motorostroiteli Ave., 69068, Zaporozhie, Ukraine. E-mail: motor@motorsich.com
}

\begin{abstract}
Investigations were performed in order to develop the technology of manufacturing all-welded outer part of front case of GTE medium-pressure chamber, and schemes of welding the inner and outer butt welds of posts were selected, providing defect-free formation of face and root weld beads at through-thickness penetration of cast titanium $\alpha$-alloy VT5L of 5-26 mm thickness in one pass. System of computer control of the process of EBW in UL-209M machine allows performing in one process cycle cleaning of the butt vicinity from remains of contamination and oxides, using low-power electron beam focused on the metal surface, as well as spot, short and continuous tack welds. Rotators with vertical and horizontal axes of rotation are provided for positioning, fixing and rotation of the item relative to electron beam gun. Programs for EBW given in the form of tables, assign the values of coordinates of points of each path section, to which it is necessary to move, values of welding and focusing currents, process scan amplitudes, as well as speed of displacement in a given section. At constant welding speed $12 \mathrm{~mm} / \mathrm{s}$, values of welding current and focusing current in the transition points of the change of working distance and thickness of edges being welded were varied by a linear law, that ensured formation of the weld face and root beads without undercuts or depressions along the entire butt length. 15 Ref., 7 Figures.
\end{abstract}

$\boldsymbol{K} \boldsymbol{e} \boldsymbol{y} \boldsymbol{w} \boldsymbol{o r d} \boldsymbol{s}:$ electron beam welding, electron beam, through-thickness penetration, weld face and root beads, variable thickness, welding scheme, porosity, macrostructure, computer control, videocontrol device, welding program

Development of design solutions and technological processes in manufacture of gas turbine engines (GTE) in aircraft industry showed that improvement of adaptability to fabrication of structures, coefficient of metal utilization, lowering of labour and power consumption of the items are possible through application of welded structures.

It is known that EBW is extensively applied in local and foreign aircraft and space industry in manufacture of aircraft engine elements [1-4].

This work gives the sequence and content of process operations for manufacturing the allwelded outer part of front case of medium-pressure chamber (MPC), consisting of posts and vanes, by EBW. In keeping with technical requirements, vanes and posts from cast titanium alloy VT5L after assembly in a rigid assemblywelding fixture should be welded to each other along the inner and outer shroud platforms, ensuring the required relative position of the vanes and posts with respect to the engine axis ( $\mathrm{Fi}^{-}$ gure 1). Number of vanes and posts is $34 \mathrm{pcs}$, and total number of welds along the inner and outer diameters is 68, MPC front case outer diameter does not exceed $1390 \mathrm{~mm}$ in assemblywelding fixture. EBW process should provide complete penetration of edges of variable crosssection along the entire butt length with guaranteed formation of weld face and root beads without undercuts or depressions, as well as protection of vane airfoil and adjacent surfaces from damage by the electron beam.

Cast medium-strength titanium $\alpha$-alloy VT5L was selected as the material for the vanes and posts. Alloy composition, according to GOST 19807-74, includes (wt.\%): 4.3-6.2. Al and $\geq 0.8$ Mo. Regulated impurities content is as follows, wt.\%:

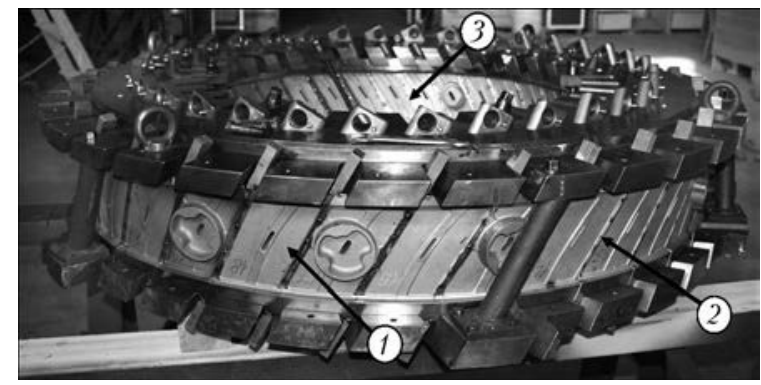

Figure 1. Appearance of outer part of MPC front case in assembly-welding fixture: 1 - posts; 2 - outer butt between posts; 3 - inner butt between posts 
$0.20\left[\mathrm{O}_{2}\right] ; 0.05\left[\mathrm{~N}_{2}\right] ; 0.015\left[\mathrm{H}_{2}\right]$. VT5L alloy is applied for parts operating at up to $350{ }^{\circ} \mathrm{C}$ temperature for a long time, and is not subjected to strengthening heat treatment.

Initial testing of the modes of VT5L alloy EBW on $100 \times 250 \mathrm{~mm}$ plates of various thickness was performed in UL-209M machine designed by PWI with computer control of all the parameters and systems. This machine is fitted with power unit based on ELA-60 / 60 and electron beam gun, moving inside the vacuum chamber along linear coordinates $X, Y, Z$, as well as rotatable around axis $Y-Y$ along $V G$ coordinate to angle of $0-90^{\circ}$. At accelerating voltage $U_{\text {acc }}=60 \mathrm{kV}$ the electron beam gun with metal tungsten cathode of $3 \mathrm{~mm}$ diameter provides electron beam current range $I_{\mathrm{b}}=0-500 \mathrm{~mA}$ and performance of beam technological scans during EBW (circle, ellipse, dash, triangle) with $0-5 \mathrm{~mm}$ amplitude. Accuracy of positioning the electron beam gun along the coordinates was not less than $0.1 \mathrm{~mm}$.

Electron beam focusing on the surface of plates being welded, alignment of electron beam with the butt, visualization of EBW process during cleaning of near-weld zone by low-power sharply focused electron beam and making short tack welds, was performed automatically by a program, using RASTR system in secondary emission image [5], which ensured alignment accuracy of not less than $0.1 \mathrm{~mm}$ and 5 times increase of the object of observation. Control of focusing by image sharpness on RASTR system monitor was checked visually by brightness of circular scan of electron beam of diameter $d_{\text {circ }} \approx 5 \mathrm{~mm}$ with $I_{\mathrm{b}} \approx 10 \mathrm{~mA}$ on copper plate. Discrepancy between the compared values of focusing current at working distance from gun edge to plate $l_{\text {work }}=$ $=250 \mathrm{~mm}$ was equal to $\pm 1 \mathrm{~mA}$ on the level of $I_{\mathrm{f}}=620 \mathrm{~mA}$, that is quite acceptable for practical application.

Developed computer control of UL-209M machine allows implementation of EBW program control by successive performance of the following processes [5]:

- plotting 3D virtual representation of the situation inside the vacuum chamber;

- selection of initial butt trajectory, using the constructed virtual representation;

- system training to perform displacement for following the butt trajectory.

EBW programs, presented in the form of tables, assign the values of point coordinates of each section of the path, where it is necessary to move, values of welding and focusing currents, process scan amplitudes, as well as displacement speed in this section.
Rotators with vertical and horizontal axes of rotation are envisaged in UL-209M machine for mounting, fixation and rotation of the outer part of MPC front case relative to electron beam gun. Faceplate diameter in both the rotators is equal to $1200 \mathrm{~mm}$.

Selection of relative position of electron beam and butt in welding VT5L alloy of thickness in the range of 5-26 $\mathrm{mm}$ with through-thickness penetration in one pass and defect-free formation of the face and root beads of the weld is the starting point of research. The principle of soundness of critical structures from titanium alloys in aircraft and space industry implies producing sound welded joints, formed at EBW, without pores or undercuts on both sides of the weld. Above-mentioned defects are inadmissible, as they lead to deterioration of welded joint performance. Elimination of undercuts in UL-209M machine can be achieved by repeated cosmetic pass, as well as selection of the scheme of EBW by horizontal electron beam with electron beam gun downward displacement along $Z-Z$ coordinate [6]. Horizontal position of the weld pool facilitates liquid metal degassing and its refining that, in its turn, lowers weld metal porosity and requirements to cleanliness of metal being welded.

Selection of optimum welding speed value is determined, on the one hand, by the condition of minimum intensity of hydrodynamic disturbances in the weld pool [7] and, on the other hand, by the condition of minimum weld width for reducing deformations, increasing crack resistance, and preservation of volatile alloying elements in weld metal. While the first condition requires lowering the welding speed, the second one requires its increase. Precising the value of welding speed for specific alloys and thicknesses to produce a sound welded joint plays a paramount role in development of welding technology. For UL-209M machine, allowing for thickness of welded edges of VT5L titanium alloy varying in the range of $5-26 \mathrm{~mm}$, as well as ensuring $I_{\mathrm{b}}=0-500 \mathrm{~mA}, 12 \mathrm{~mm} / \mathrm{s}$ welding speed was selected constant along the entire butt length.

Reproducibility of sound welds can be ensured due to a multitude of hardware developments, guaranteeing stabilization and repeatability of electron beam geometry [8-10]. Narrow and deep welds with parallel walls of the cast zone are produced due to application of electron beam with small $\left(\leq 5 \cdot 10^{-2} \mathrm{rad}\right)$ angles of convergence $[10,11]$, its scanning in a circular or elliptical pattern [8, 9, 12]. We applied a circular scan, which ensured reproducibility of weld formation 
at inclined butt of the posts relative to the direction of downward displacement of electron beam gun along coordinate $Z-Z$.

Porosity is the main defect of weld metal at EBW of titanium and its alloys. To prevent pore formation, it is necessary to ensure removal of adsorbed moisture and oil films from the surface of edges being welded, as well as create conditions for maximum degassing of the weld pool. Cleaning of the butt vicinity from remains of contaminations and oxides using electron beam focused on the metal surface can be performed in one EBW process cycle in UL-209M machine. A pass along the entire butt length is performed in the mode of $U_{\mathrm{acc}}=60 \mathrm{kV}, I_{\mathrm{b}} \approx 10 \mathrm{~mA}, v_{\mathrm{w}}=$ $=10 \mathrm{~mm} / \mathrm{s}$ and $d_{\text {circ }} \approx 10 \mathrm{~mm} \mathrm{[5]}$.

At EBW of titanium and its alloys precise fit-up of the item for welding and strict maintenance of admissible gap dimensions between the part edges being welded are required to produce sound welds. As shown in [13], at $5 \mathrm{~mm}$ thickness of butts being welded the admissible gap value should not exceed $0.07 \mathrm{~mm}$, and $0.17 \mathrm{~mm}$ at $\delta_{\mathrm{m}}=$ $=26 \mathrm{~mm}$.

Before developing programs of EBW of inner and outer butt welds on posts from alloy VT5L measurements were taken of the thickness of edges to be welded along the length of a butt with complex contour. It was established that several characteristic thicknesses of different length are in place: for geometry of outer butt weld end face $-5,14,17 \mathrm{~mm}$; for geometry of inner butt weld end face $-5,17,19$ and $26 \mathrm{~mm}$. At optimization of the modes of EBW of the post outer butt welds by horizontal electron beam by the downward scheme, through-thickness penetration was performed on flat samples at $v_{\mathrm{w}}=$ $=12 \mathrm{~mm} / \mathrm{s}, l_{\text {work }}=250 \mathrm{~mm}$ without local beam scanning $\left(d_{\text {circ }}=0\right)$ and with circular beam scan$\operatorname{ning}\left(d_{\text {circ }}=1.2 \mathrm{~mm}\right)$ with weld face and root bead formation in one pass. For defect-free formation of the weld root bead electron beam current was set in the range of $(1.75-2) I_{0}$, where $I_{0}$ is the beam current, at which the first indications of throughthickness penetration are visible [14].

Performed metallographic analysis of welded joints of VT5L alloy with through-thickness penetration of flat samples revealed certain features. As shown in Figure 2, formation of weld face and root beads at all the available thicknesses occurs regularly along the entire length without undercuts; if required, the weld face bead is smoothed by a repeated cosmetic pass. Starting from welded edge thickness $\delta_{\mathrm{m}}=14 \mathrm{~mm}$ the weld forms with practically parallel walls of the cast zone in the case of application of a circular scan

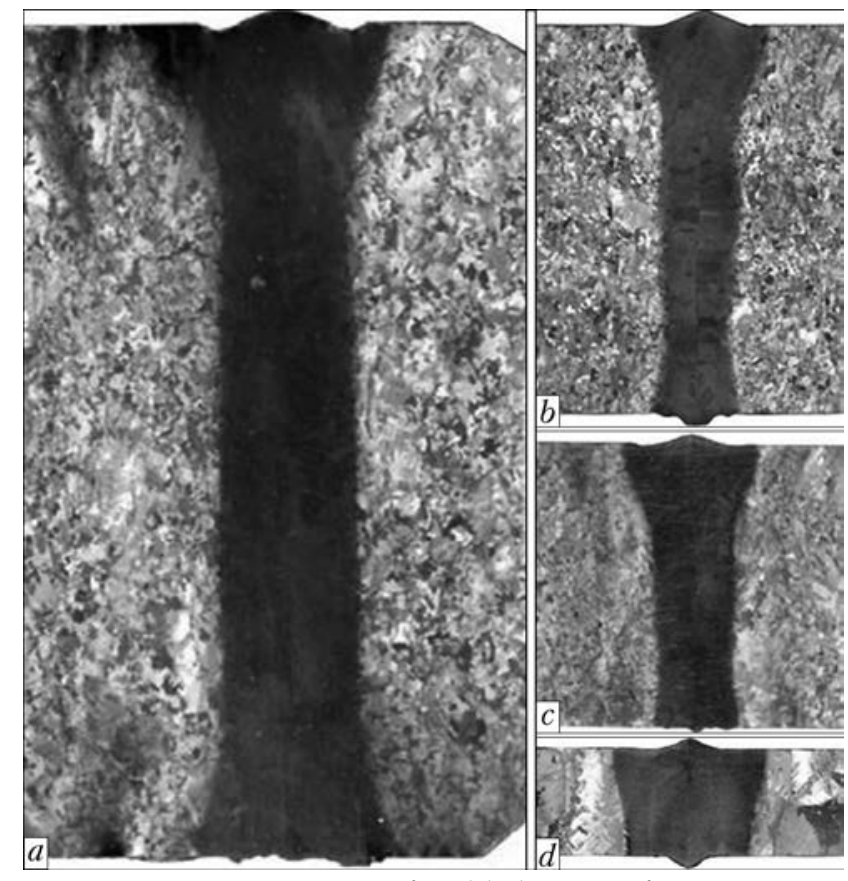

Figure 2. Macrostructure of welded joints of cast titanium alloy VT5L of different thickness, and formation of weld face and root beads in EBW with through-thickness penetration of outer butt welds of posts by horizontal electron beam: $a-\delta_{\mathrm{m}}=26 ; b-17 ; c-14 ; d-5 \mathrm{~mm}$

of the electron beam with $d_{\text {circ }}=1.2 \mathrm{~mm}$, and weld width in the root part varies in the range of 2.4-2.6 mm. Such results on penetration geometry lead to the conclusion that welding electron beam deviation from the butt to a value of $0.1 \mathrm{~mm}$ will not affect weld quality.

Derived data on welding flat samples by horizontal electron beam were applied in development of a program of welding outer butt welds on post-samples of alloy VT5L, in which the butt configuration in welding area corresponds to batch-produced parts. In the program at constant welding speed $12 \mathrm{~mm} / \mathrm{s}$, the values of welding and focusing current in the points of transition at the change of working distance and thickness of edges being welded were varied by a linear law [15].

As shown in Figure 3, the weld forms without defects along the entire butt length, and the weld root bead can be used for controlling the welding quality. The system of computer control of EBW process in UL-209M machine allows performing in one process cycle also spot, short and continuous tack welds. Spot welds on the butt of run-off tab and post are performed, in order to eliminate crater formation.

It should be noted that all the welded samples and mock-ups of items from VT5L alloy with through-thickness penetration by a horizontal electron beam have passed X-raying. No defects in the form of cavities, pores, undercuts or lacksof-fusion were found. 


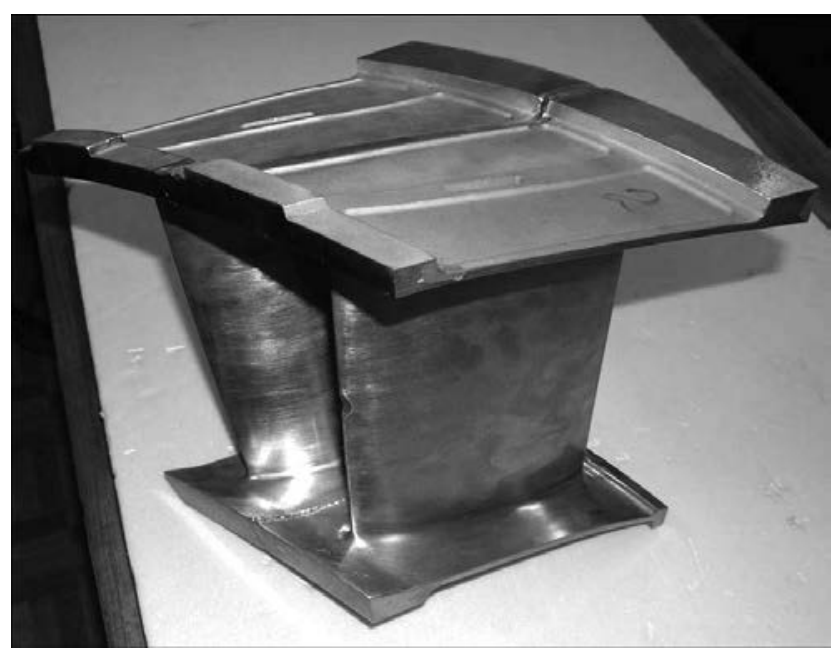

Figure 3. Appearance of weld face and root beads on postssamples in EBW of outer and inner butt welds at $U_{\text {acc }}=$ $=60 \mathrm{kV}, v_{\mathrm{w}}=12 \mathrm{~mm} / \mathrm{s}$ and $l_{\text {work }}=250 \mathrm{~mm}$

After mounting run-off tabs from titanium alloy VT5L on the inner and outer butts of the posts using argon-arc welding, the outer part of MPC front case was placed on the rotator faceplate coaxially with the vertical axis of rotation (Figure 4), electron beam gun was moved into the horizontal position $\left(V G=0^{\circ}\right)$ at distance to the item $l_{\text {work }}=250 \mathrm{~mm}$, gun axis was moved to one of the 34 butts, value of rotator coordinate $W$ was zeroed, and UL-209M machine was prepared for performance of EBW of the post outer butt welds by the program.

After achieving the working vacuum in the welding chamber and electron beam gun, RASTR video-monitoring system was used to make a new program of EBW of the first butt of the post at downward displacement of the gun along $Z-Z$ coordinate or to correct EBW program on postssamples. Trial run of the electron beam gun by the program was performed and in the case of electron beam hitting the butt along its entire length, WELDING mode was run (Figure 5).

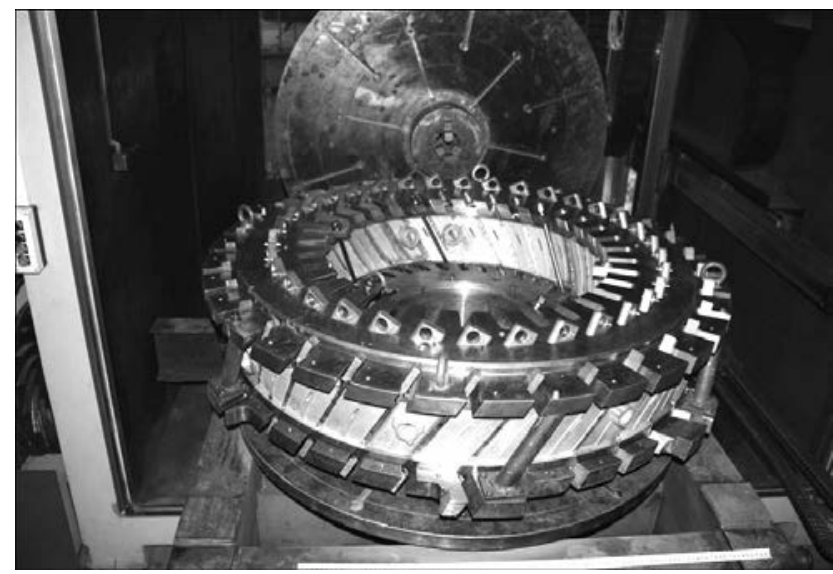

Figure 4. Appearance of outer part of MPC front case placed onto rotator with vertical axis of rotation for EBW of post outer butt welds

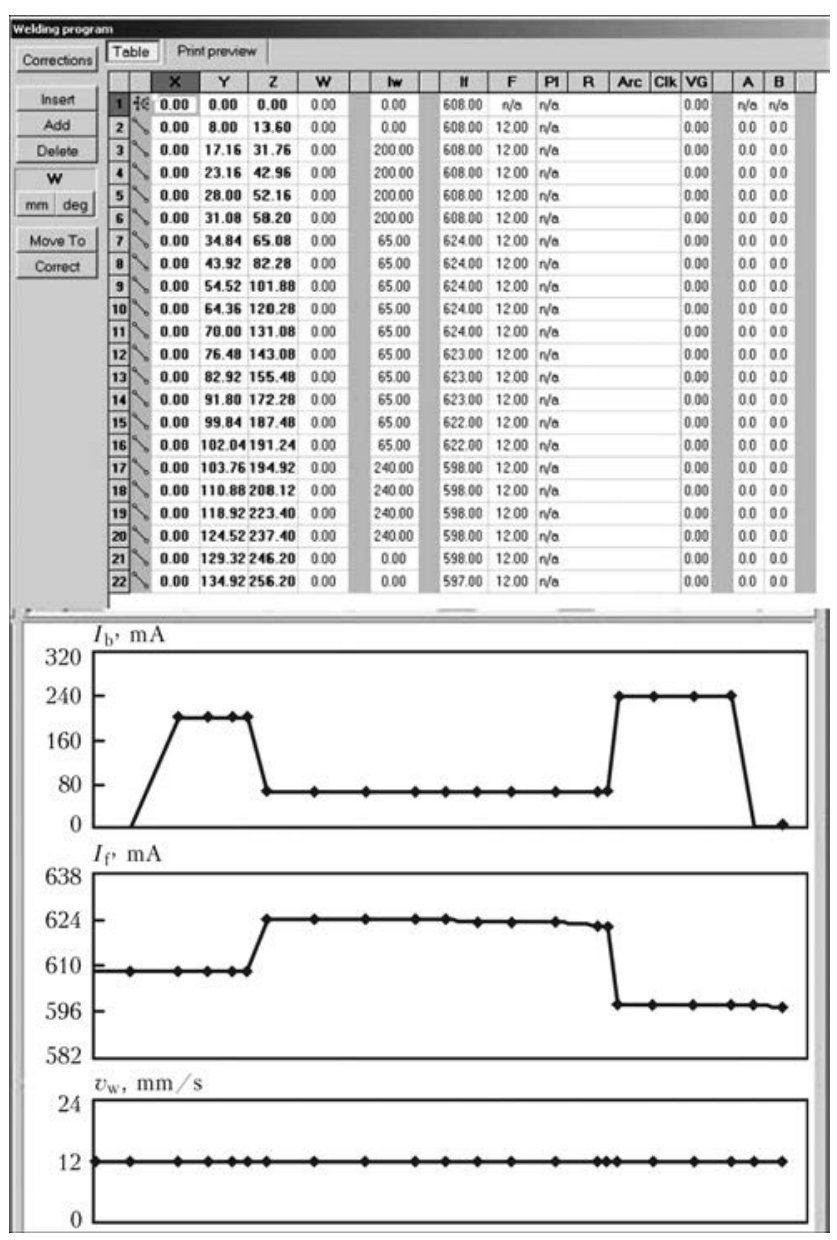

Figure 5. Program of EBW of outer butt welds of posts with computer control of displacements along coordinates $Y$ and $Z$, as well as welding $I_{\mathrm{b}}$ and focusing $I_{\mathrm{f}}$ currents and welding speed $v_{\mathrm{w}}$

Cyclogram of welding and focusing current variation with reference to specific points is given in Figure 6. After rotation of MPC front case through $180^{\circ}$ along rotator coordinate $W$, EBW of the post butt weld from the opposite side was performed. The described operational sequence is performed till the last butt weld on the posts.

Welding of outer butt welds of the posts by horizontal electron beam in a rotator with vertical axis of rotation was followed by starting the preparation for the technological process of EBW of inner butt welds. Transition to a rotator with the horizontal axis of rotation, inclination of the electron beam gun to $V G=35^{\circ}$ from the vertical and gun displacement by coordinate $X-X$ along the vacuum chamber longitudinal axis turned out to be the working variant (Figure 7). Working distance from the gun edge to the item was equal to $330 \mathrm{~mm}$. It should be noted that the sequence of operations of EBW of inner butt welds did not change, compared to welding the outer butt welds, and it was not necessary to change the value of electron beam current. 


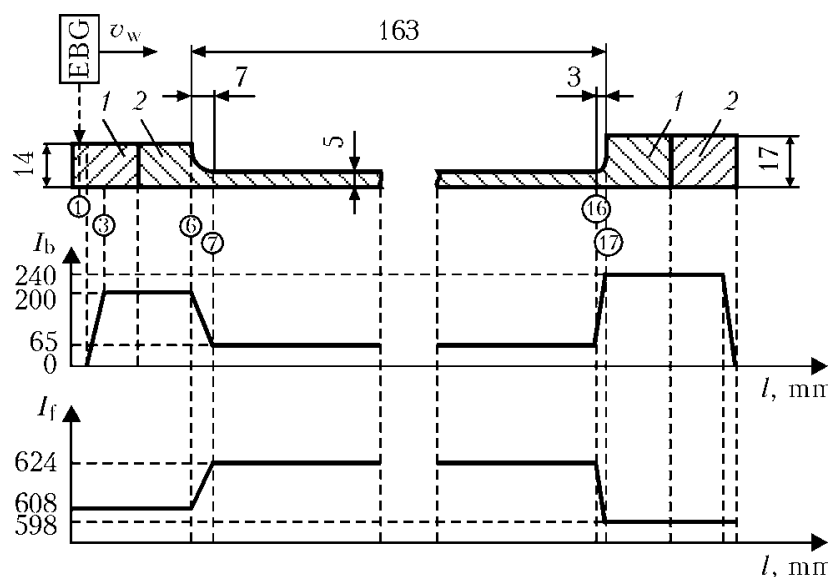

Figure 6. Cyclogram of variation of welding $I_{\mathrm{b}}$ and focusing $I_{\mathrm{f}}$ currents in EBW of outer butt welds of posts: 1 - run-off tabs; 2 - posts; (1), (3), (6), (7), (16), (17) - line numbers in EBW program table

Thus, the proposed technology of manufacturing the all-welded MPC case and the selected scheme of welding the outer and inner butt welds of the posts provide defect-free formation of the weld face and root beads at through-thickness penetration of cast titanium alloy VT5L 5$26 \mathrm{~mm}$ thick in one pass.

1. Pavlenko, V.N., Rudnev, Yu.T., Barinov, V.V. et al. (1989) Electron beam welding of GTE multisection wheel from titanium alloy. In: Abstr. of AllUnion Sci.-Techn. Conf. on Electron Beam Welding in Mechanical Engineering (Nikolaev, Ukraine, 1989), 13-14

2. Gejkin, V.A., Poklad, V.A. (2001) Welded joints in aircraft engines. Tekhnologiya Metallov, 1, 9-14.

3. Lobanov, L.M., Pivtorak, V.A., Zadery, B.A. et al (1993) Residual stresses in electron beam welded elements of gas turbine engine rotor structures. In: Proc. of Conf. on EBW, Book 2, 57-61. Moscow: TsRDZ.

4. Imamura, T. (1999) Current states and trend of applicable material technology for aerospace structure. J. JILM, 1(7), 302-309.

5. Paton, B.E., Nazarenko, O.K., Nesterenkov, V.M. et al. (2004) Computer control of electron beam welding with multi-coordinate displacements of the gun and workpiece. The Paton Welding J., 5, 2-5.

6. Kravchuk, L.A. (2010) Elimination of undercuts in EBW with complete and incomplete penetration. Ibid., 6, 22-25.

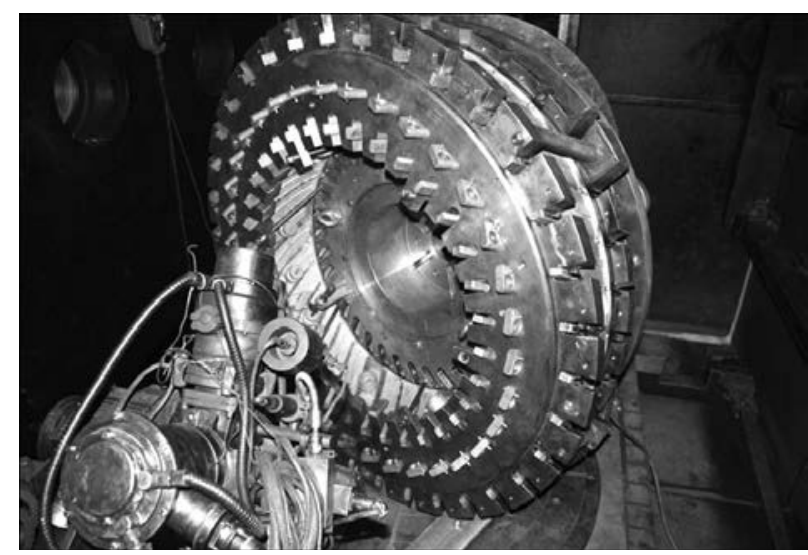

Figure 7. Appearance of outer part of MPC front case placed onto rotator with horizontal axis of rotation for EBW of post inner butt welds by electron beam gun positioned at $V G=35^{\circ}$

7. Nesterenkov, V.M. (2003) Special features of capillary waves in the vapour-gas channel in electron beam welding of thick metal. Ibid., 4, 7-12.

8. Nazarenko, O.K., Kajdalov, A.A., Kovbasenko, S.N. et al. (1987) Electron beam welding. Kiev: Naukova Dumka.

9. Blakely, P.Y., Sanderson, A. (1984) The origin and effect of magnetic fields in electron beam welding. Welding J., 1, 42-49.

10. Frits, D. (1988) Electron beam welding today. In: Proc. of Int. Conf. on Electron Beam Technologies (Varna, 31 May-4 June, 1988), 1048-1063.

11. Sayegh, G. (1986) State of the art of high energy density beam welding: Houdremont lecture. Tokyo: IIW.

12. Shida, T., Kita, H., Okamura, H. et al. Effects of welding parameters and prevention of defects in deep penetration EBW of heavy section steel. IIW Doc. $I V, 239-78$.

13. Stocker, G. (1974) Erfahrungen beim Elektronenstrahlschweissen dick wandiger Bauteile aus der Titanlegierung $\mathrm{Ti}_{6} \mathrm{Al}_{4} \mathrm{~V}$ gegliht. Schweissen und Schneiden, 3, 91-93.

14. Nudelman, Ya.B., Zadery, B.A. (1988) Weld formation in electron beam welding of titanium alloy of up to $25 \mathrm{~mm}$ thickness. Avtomatich. Svarka, 5, 29-30.

15. Anderl, P., Scheffels, W (1992) Process control for electron beam welding. Welding in the World, 5/6, $138-144$

Received 13.07.2015 


\title{
DEVELOPMENT OF NEW EMISSION SYSTEMS OF ELECTRON BEAM GUNS FOR PROCESS OPERATIONS UNDER SPACE CONDITIONS*
}

\author{
Yu.V. ZUBCHENKO and E.G. TERNOVOJ \\ E.O. Paton Electric Welding Institute, NASU \\ 11 Bozhenko Str., 03680, Kiev, Ukraine. E-mail: office@paton.kiev.ua
}

\begin{abstract}
Development of a new system, in contrast to diode emission systems with filamentary cathode being earlier applied in space guns, is based on triode emission system with cathode preheating by electron bombardment. New emission system is designed using a procedure based on simultaneous solution of problems of analysis and synthesis applying an apparatus for trajectory analysis of electron beams. The proposed emission system is designed in two variants, i.e. manual and automated types of electron beam tools. An electron beam with phase characteristic close to linear one is formed in each of calculated variants, that provides for high specific power of the beam in place of welding (to $9 \mathrm{~kW} / \mathrm{mm}^{2}$ ) at total beam capacity to $2.5 \mathrm{~kW}$ and, as a result, allows carrying out welding and cutting of aluminum and titanium alloys, as well as stainless steels, of up to $5 \mathrm{~mm}$ thickness in continuous and pulsed modes under open space conditions. 10 Ref., 1 Table, 7 Figures.
\end{abstract}

$\boldsymbol{K} \boldsymbol{e} \boldsymbol{y} \boldsymbol{w} \boldsymbol{o} \boldsymbol{r} \boldsymbol{d} \boldsymbol{s}:$ emission system, electron beam, triode system, crossover, focal plane, trajectory analysis, perveance, operating distance, manual and automated tool, welding, cutting, brazing, heating, aluminum and titanium alloys, stainless steels

At present time the E.O. Paton Electric Welding Institute carries out works on development of a new generation EB tool for performance of erection and repair works in open space [1]. The developed tool provides for two design variants, namely manual and automated one being part of a robot or precision manipulator.

Task of the present work lies in development of emission systems of EB gun for two variants of the developed tool, which will provide increase of general (to $2.5 \mathrm{~kW}$ ) and specific (to $9 \mathrm{~kW} / \mathrm{mm}^{2}$ ) beam power in continuous pulsed mode as well as rise of service reliability of the equipment.

In contrast to EB guns with diode emission systems and filamentary cathodes [2-5] being earlier applied for work under space conditions, current problem statement requires application of triode emission system. In it the cathode is heated up by electron bombardment and operates in a mode of emission current limitation by electron beam space charge, and beam power is varied by supply of cathode, negative controlled potential, to modulated (focusing) electrode at fixed accelerating voltage and constant cathode temperature.

Let us consider general and distinctive features of beam formation in guns for manual and automated variants.

Maximum attainable current density in a crossover (minimum section of beam formed only by emission system, i.e. electrostatic part of electron-optical system of the gun) is only caused by heat velocities of the electrons and evaluated by Langmuir dependence, which for paraxial beams is reduced to [6]

$$
J_{\mathrm{CR}}=j_{\mathrm{C}} \frac{e U_{\mathrm{acc}}}{k T_{\mathrm{C}}} \gamma_{1}^{2},
$$

where $j_{\mathrm{C}}$ is the density of current emission, A $/ \mathrm{mm}^{2} ; e=1.6 \cdot 10^{-19}$ is the electron charge, C; $U_{\text {acc }}$ is the accelerating voltage, $\mathrm{V} ; k$ is the Boltzmann constant; $T_{\mathrm{C}}$ is the absolute cathode temperature, $\mathrm{K} ; \gamma_{1}$ is the beam convergence angle in the crossover, rad.

Let us analyze the ways of possible increase of current density in the crossover applicable to conditions of gun operation in space.

Reduction of cathode operating temperature $T_{\mathrm{C}}$ and increase of density of emission current from cathode $j_{\mathrm{C}}$ are virtually impossible due to limited selection of cathode materials (tantal, tungsten, lanthanum hexaboride) related with For the first time works on synthesis of emission systems of power electron beam welding guns were carried out in the PWI Department
by Drs K.S. Akopiants, Yu.V. Zunchenko and V.E. Lokshin under the leadership of Prof. O.K. Nazarenko, Corr. Member of the NASU. 
heavy operating conditions of the cathode in welding guns.

Increase of accelerating voltage more than $10 \mathrm{kV}$ is also unallowable due to danger of X-ray irradiation of operator. Rise of convergence angle $\gamma_{1}$ for increase of current density in crossover can be efficient, but practically applied only in the guns for automated variant, where final focusing of the beam on part being welded is carried out by additional electromagnetic lens transmitting crossover image in a focal plane (Figure 1, I). For manual gun variant the conditions are necessary, at which final beam focusing on the part is performed only by emission system, i.e. crossover of the beam is located in the focal plane (Figure 1, II). In this situation, increase of convergence angle is related with reduction of gun operating distance (from anode to part), that limits line-of-sight coverage of a weld pool as well as promotes increase of possibility of breakdown in welding or brazing of the materials with high vapor pressure and reduction of electric strength of gun isolating gaps.

Thus, any of the conditions, given in expression (1), cannot be used for direct increase of current density in the crossover in manual variant of the gun. In automated variant, vice versa, increase of beam convergence angle in the crossover is reasonable and efficient, since in this case the emission system shall form short-focus electron beam converging in the crossover before electromagnetic lens.

It should be noted that expression (1) is true only for idealized conditions of beam formation in the emission system (absence of aberrations, absence of influence of beam space charge, uniformity of field intensity near the cathode, constant density of emission current on cathode surface etc.). Only under these conditions, due to the fact that thermal rates of electrons are distributed by Maxwell law, distributions of current density in the crossover obey normal Gaussian law, and crossover radius acquires the minimum possible value. Therefore, measures on further improvement of structure and parameters of the emission systems in development of close to ideal conditions of the electron beam formation are efficient for rise of current density in the crossover.

Analysis of the conditions of beam formation in the emission systems was carried out using trajectory analysis apparatus from package of application programs ERA designed for automation of electron-optical calculations [7]. According to this apparatus the beam is represented in form of finite number of fine coaxial current tubes, which are displayed on longitudinal beam section
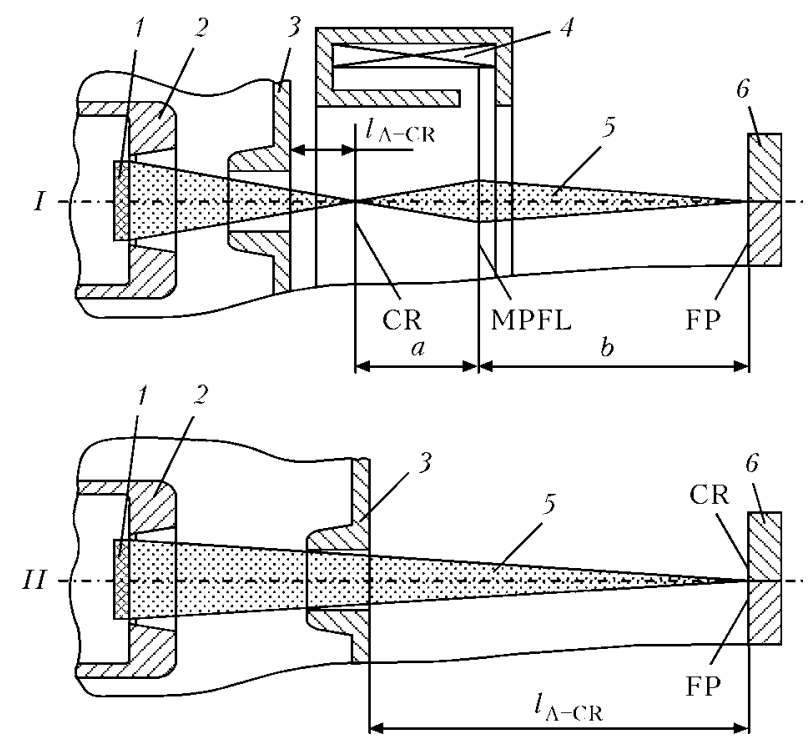

Figure 1. Schemes of emission systems of guns for EBW in space: $I$ - for automated variant; $I I$ - for manual variant; 1 - cathode; 2 - focusing electrode; 3 - anode; 4 electromagnetic focusing lens; 5 - electron beam; 6 part being welded; CR - crossover; MPFL - mean plane of focusing lens; FP - focal plane; $l_{\mathrm{A}-\mathrm{CR}}-$ anode-crossover distance; $a$ - distance along CR-MPFL system axis; $b$ - distance along MPFL-CR system axis

by corresponding number of trajectories. Spherical aberrations of analyzed emission system can be considered by means of development of phase characteristic of a beam formed in this system according to the results of trajectory analysis. Phase characteristic of the beam is represented as dependence of inclination angle $r_{i}{ }^{\prime}$ of trajectories on their radial coordinate $r_{i}$ derived for any cross-section of the beam. $r^{\prime}-r$ variables range is called phase plane [8]. If thermal rates of electrons are not considered and emission system does not have spherical aberrations, phase characteristic of the beam is linear in such a system and inclination of trajectories $r_{i}^{\prime}$ is proportional to radiuses of their location $r_{i}$, i.e.

$$
r_{1}{ }^{\prime} / r_{1}=r_{2}{ }^{\prime} / r_{2}=\ldots=r_{n}{ }^{\prime} / r_{n}=\text { const }=c,
$$

where $c$ is the inclination of phase characteristic.

Only in this ideal case all trajectories of the beam, converging after cathode, will concur in one point of the crossover at its radius $r^{*}=0$, and phase characteristic is expressed by linear dependence $r^{\prime}=c r$, where $1 / c=l_{c}$ is the distance from plane $z_{\text {ph.ch }}$, in which phase characteristic is determined, to crossover position plane $z_{\mathrm{CR}}$ (Figure 2).

In general case the following dependence is received considering $c$ sign:

$$
z_{\mathrm{CR}}=z_{\mathrm{ph} . \mathrm{ch}}-1 / c,
$$

where $c<0$ and $l_{c}=1 / c<0$ at $z_{\mathrm{ph} . \mathrm{ch}}<z_{\mathrm{CR}} ; c>$ $>0$ and $l_{c}=1 / c>0$ at $z_{\text {ph.ch }}>z_{\mathrm{CR}}$. 


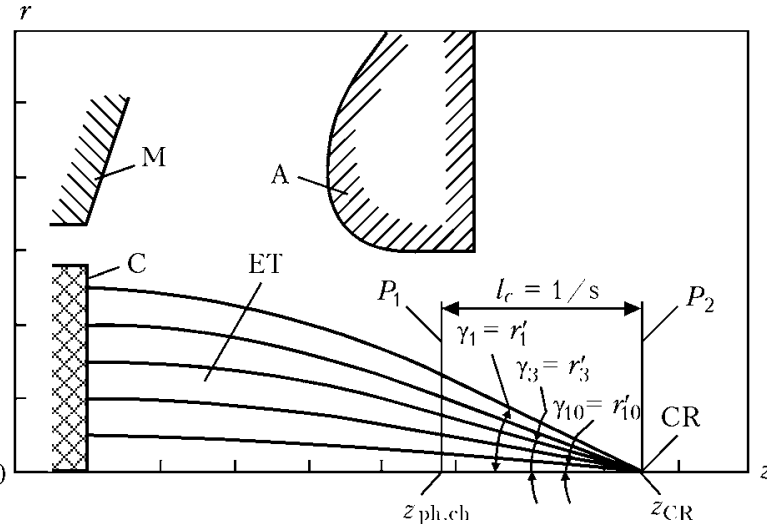

Figure 2. Image of electron trajectories of ideally formed beam: $\mathrm{C}$ - cathode; $\mathrm{M}$ - modulating (focusing) electrode; A - anode; ET - electron trajectory; $r$ - radial coordinate; $z$ - longitudinal coordinate of emission system (system axis); CR - beam crossover; $z_{\mathrm{CR}}-P_{2}$-plane $z$-coordinate (crossover position); $z_{\text {ph.ch }}-P_{1}$-plane coordinate in which beam phase characteristic is plotted; $\gamma$ - inclination angles of trajectory to $z$-axis (for paraxial beam $\gamma \approx$ $\left.\approx \operatorname{tg} \approx \gamma \approx r^{\prime}\right) ; c-$ inclination of phase characteristic of beam in $P_{1}$-plane

In general case, due to spherical aberrations of the emission systems, electron beams are nonlaminar to that or another degree, and their phase characteristics are nonlinear, respectively. Nonlinear phase characteristic in any beam section can be represented in form of

$$
r^{\prime}=c r+\varepsilon(r) .
$$

Here $c$ is the average inclination of phase characteristic; $\varepsilon(r)$ is the deviation of phase characteristic from linear one.

Analysis of phase characteristics of the beams can be significantly simplified with the help of method of phase parallelogram [9], which is plotted on phase plane $r^{\prime}-r$, in such a way as to include considered phase characteristic in its minimum area (Figure 3).

According to Liouville theory [8], phase parallelogram, plotted for any $z_{\text {ph.ch }}$ section in beyond anode area, intercept segment $r$ being equal

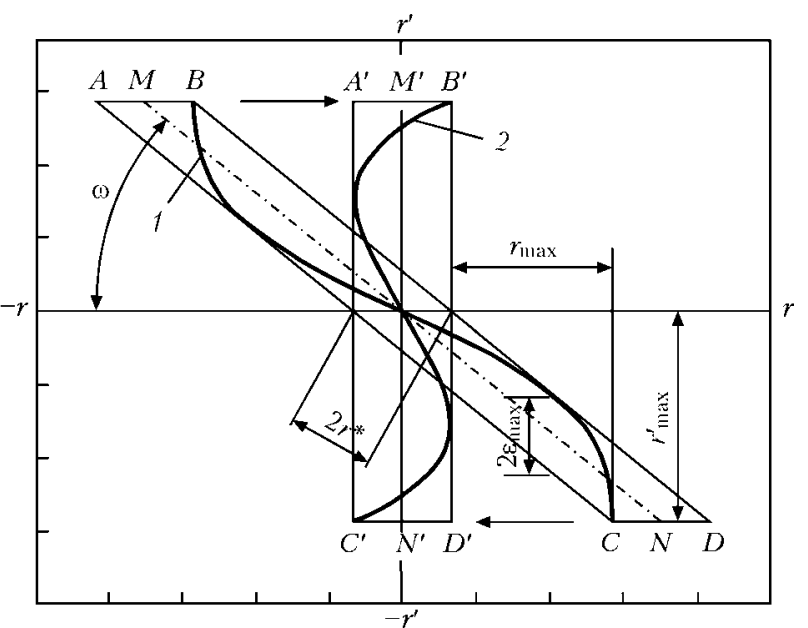

Figure 3. Plotting of phase parallelogram: 1 - phase characteristic for beam section in area before crossover; $2-$ the same in crossover (arrows show directions of parallelogram deformation in movement of investigated beam section to crossover); $A, B, C, D, M, N, A^{\prime}, B^{\prime}, C^{\prime}, D^{\prime}, M^{\prime}, N^{\prime}-$ points of parallelograms plotting; $\omega$ - inclination angle of median line of phase parallelogram to $r$-axis; $2 \varepsilon_{\max }-$ maximum deviation of phase characteristic from linear one; $2 r^{*}-$ beam diameter in crossover; $r_{\max }-$ radius of extreme trajectory; $r_{\max }^{\prime}-$ inclination angle of extreme trajectories to crossover diameter $2 r^{*}$. Finite dimensions of the crossover equal $2 r^{*}$ are caused by nonlinear phase characteristic, i.e. finite value $\varepsilon_{\max }$ of deviation of phase characteristic from linear one. Based on parallelogram plotting the following relationship can be received:

$$
r^{*}=\varepsilon_{\max } / c ; \quad c=r_{\max }^{\prime} /\left(r_{\max }+r^{*}\right) .
$$

Construction of new emission system becomes laborious and time-consuming process if only analysis method (trial-and-error) and apparatus for trajectory analysis are used. In this connection for construction of such system we used a procedure based on simultaneous solution of synthesis and analysis problems [10]. Final aim of the calculation is attaining a beam phase characteristic close to linear one, formation of electron beam with set values of its angle of convergence and

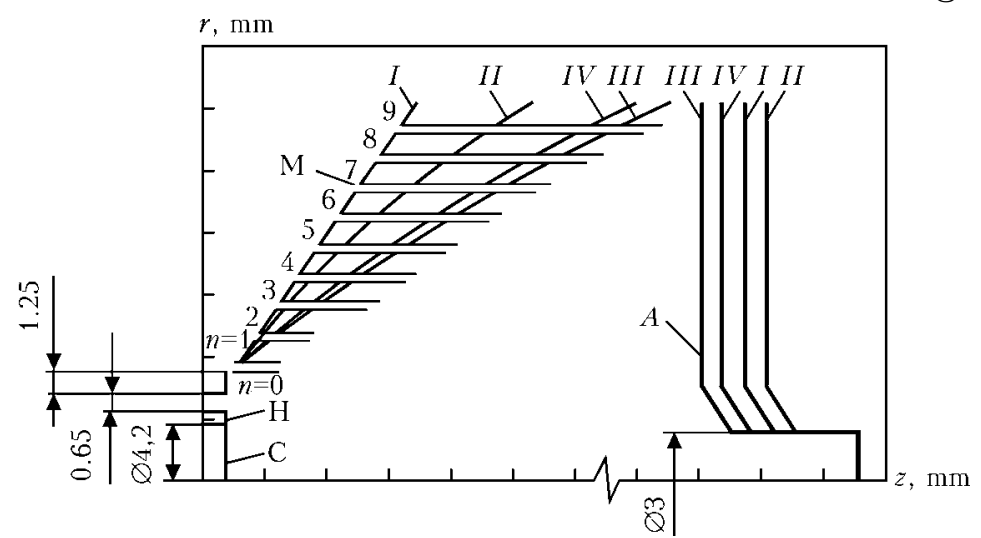

Figure 4. Development of emission system of EBW gun by means of trajectory analysis and synthesis: $H-$ electrode holder; $I-I V-$ successive steps of approximation to desired electrode shape; $n-$ areas for division of focusing electrode contour 


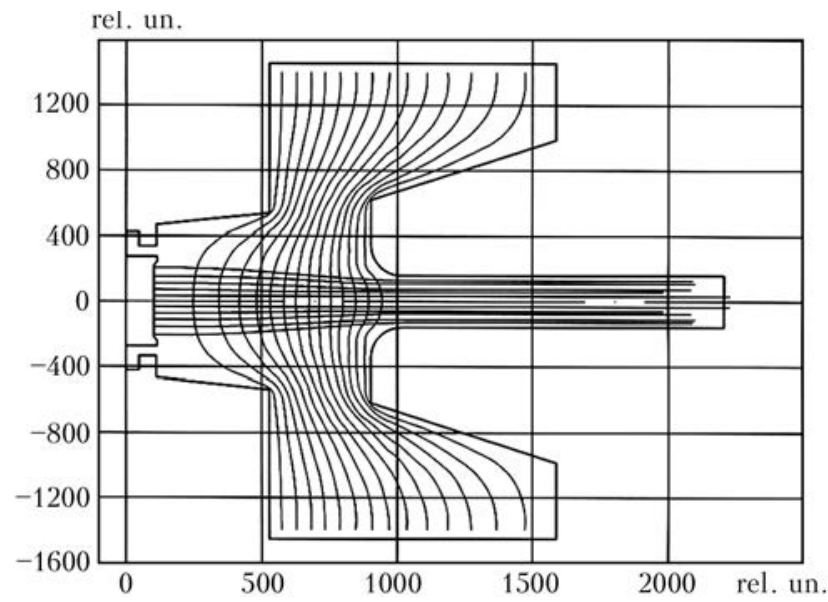

Figure 5. Trajectory analysis of optimized emission system for manual welding gun at $U_{\mathrm{m}}=-100 \mathrm{~V}$ and $I_{\mathrm{b}}=250 \mathrm{~mA}$

perveance at predetermined design-technological limitations on electrode geometry.

The procedure uses a supposition that in calculation focusing electrode can be replaced by composite one, each section of which receives such potentials that their joint effect results in formation of electron beam with set properties.

Required emission system is constructed step by step by means of successive approximation in accordance with algorithm given in the procedure. A sign of finishing convergence processes of the required emission system of construction is close location of resulting contours of focusing electrode and anode after four-five stages of calculation. Thus, for example, in calculation of gun emission system for manual tool the process has converged at stage $I V$ (Figure 4).

Received calculation contour of the focusing electrode is approximated by complex of easy-tomanufacture surfaces (cones, chamfering etc.), and peripheral part of the focusing electrode is taken away from anode in order to increase electric strength of accelerating gap. At the end trajectory analysis of approximated emission system

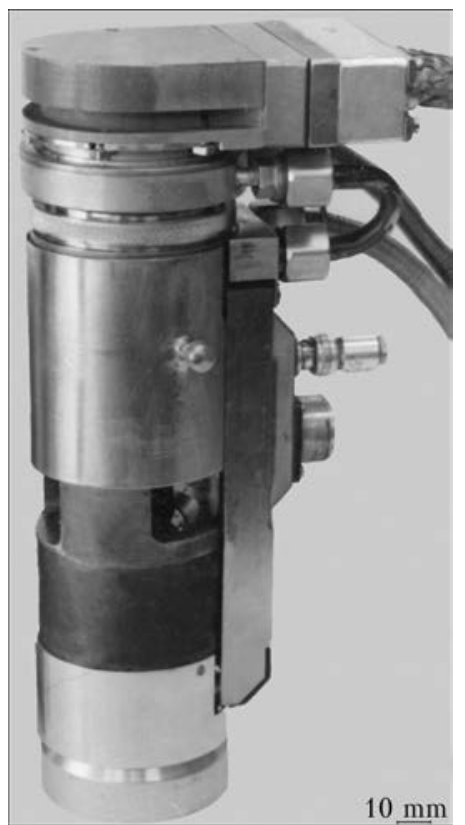

Figure 7. EBW gun used for experimental check-up of optimized emission system

is carried out (beam current $I_{\mathrm{b}}=250 \mathrm{~mA}$ is obtained at cut-off voltage $U_{\mathrm{m}}=-100 \mathrm{~V}\left(\mathrm{Fi}^{-}\right.$ gure 5)). Phase parallelogram is plotted for determination of final parameters of this system (Figure 6).

Thus, for example, length of segment $r$, intercepted by parallelogram sloping sides, is the diameter of beam in crossover $2 r^{*}=0.6 \mathrm{~mm}$. Inclination of median line of the parallelogram helps to evaluate crossover position on system axis relatively to cathode:

$$
\begin{gathered}
c=\frac{r_{\max }^{\prime}}{r_{\max }}=\frac{-1.3 \cdot 10^{-2}}{1.1}=-1.18 \cdot 10^{-2}\left[\frac{1}{\mathrm{~mm}}\right] ; \\
l_{c}=\frac{1}{c}=-\frac{1}{1.18 \cdot 10^{-2}}=-85[\mathrm{~mm}] .
\end{gathered}
$$

Taking into account that phase parallelogram was plotted for section with coordinate $z_{\text {ph.ch }}=$

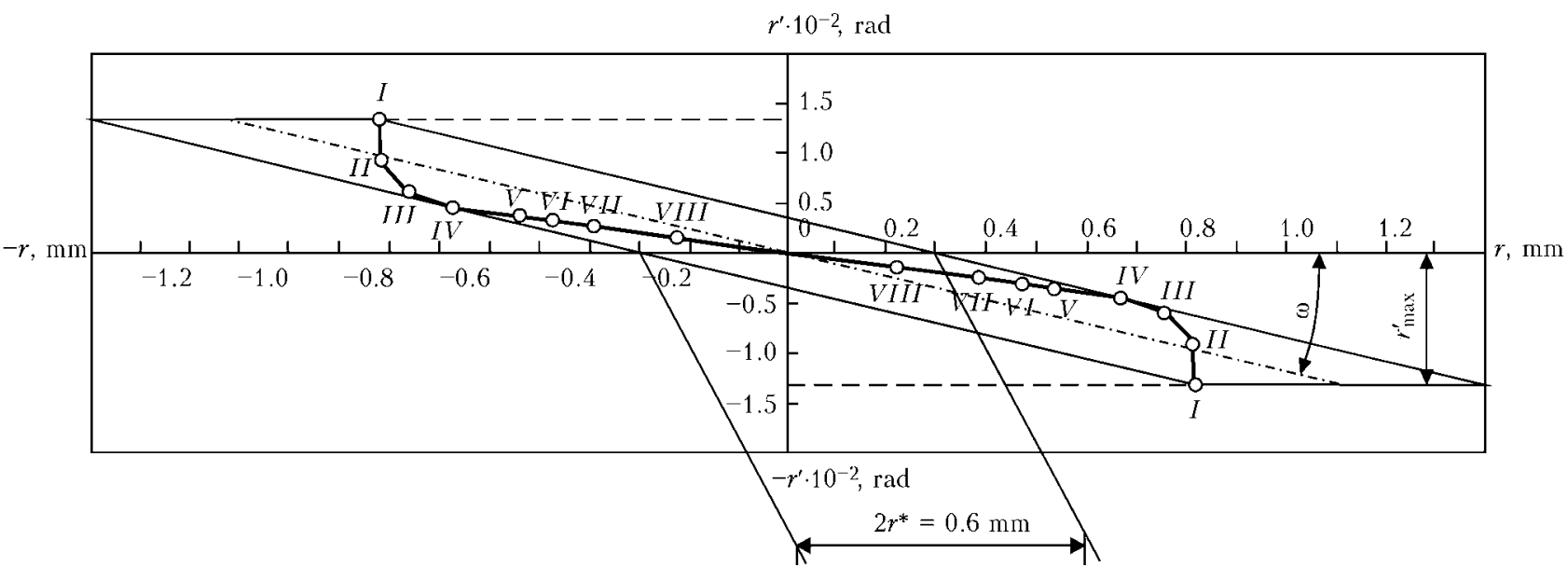

Figure 6. Phase parallelogram plotted on results of trajectory analysis of optimized emission system for longitudinal coordinate $z_{\text {ph.ch }}=19 \mathrm{~mm}$ for manual welding gun 
Parameters of emission systems for manual and automated guns obtained as a results of calculation

\begin{tabular}{|c|c|c|c|c|}
\hline \multirow{2}{*}{ Parameter } & \multicolumn{2}{|c|}{ Manual welding } & \multicolumn{2}{|c|}{ Automated welding } \\
\hline & Set value & Received value & Set value & Received value \\
\hline Perveance, $\mathrm{A} / \mathrm{B}^{3 / 2}$ & $\geq 0.2 \cdot 10^{-6}$ & $0.2 \cdot 10^{-6}$ & $0.2 \cdot 10^{-6}$ & $0.25 \cdot 10^{-6}$ \\
\hline Power beam, kW & $\geq 2.0$ & 2.5 & $\geq 2.0$ & 2.5 \\
\hline Power density in crossover, $\mathrm{kW} / \mathrm{mm}^{2}$ & $\geq 6.0$ & 7.1 & $\geq 7.5$ & 8.8 \\
\hline Half-angle of beam convergence in crossover, rad & $\leq 2 \cdot 10^{-2}$ & $1.32 \cdot 10^{-2}$ & $\geq 10^{-1}$ & $10.3 \cdot 10^{-2}$ \\
\hline Anode-crossover distance, $\mathrm{mm}$ & $\geq 70$ & 85 & $\leq 15$ & 12.7 \\
\hline
\end{tabular}

$=19 \mathrm{~mm}$ (distance from cathode on axis $z$, coordinate $z_{\mathrm{CR}}$ (from cathode) is received: $z_{\mathrm{CR}}=$ $=z_{\text {ph.ch }}-1 / c=19+85=104 \mathrm{~mm}$.

Considering assumed in calculation position of anode inlet $z_{\mathrm{A}}=9 \mathrm{~mm}$ and anode height $\sim 10 \mathrm{~mm}$, gun operating distance $l_{\mathrm{op}}=85 \mathrm{~mm}$ (from anode beam outlet to place of welding) is received. Half-angle of beam convergence, evaluated by extreme trajectory, equals $\sim 1.3 \cdot 10^{-2} \mathrm{rad}$.

The following design-process parameters were set for both variants in development of the emission systems for manual and automated variants of guns (see Figure 4):

- plate cathode of $4.2 \mathrm{~mm}$ diameter;

- ring surface in cathode holder of $0.05^{-}$ $0.1 \mathrm{~mm}$ width;

- annular gap between cathode holder and wall of hole in focusing electrode of $0.65 \mathrm{~mm}$ width;

- flat ring surface in the center of focusing electrode of $1.25 \mathrm{~mm}$ width;

- plate anode with flattened edges of $3 \mathrm{~mm}$ diameter central hole.

The Table provides for set and received calculated parameters of the emission systems for manual and automated guns.

Obtained calculation results were experimentally verified on vacuum unit OB1469M using PL101M gun (Figure 7), which was equipped with developed emission systems for manual and automated welding. Matching on beam current (at cut-off voltage $U_{\mathrm{m}}=-100 \mathrm{~V}$ ) at least $10 \%$, on beam convergence angle at least 5-7\%, on position of beam focal plane at least $15 \%$ were obtained in gun operation (evaluation was made based on penetration of $1 \mathrm{~mm}$ thin inclined plates from stainless steel). Penetration depth of specimens from titanium alloy VT1-0 and aluminum alloy 1201 at $75 \mathrm{~mm}$ working distance in manual variant of gun assembly (without focusing lens) achieved $5 \mathrm{~mm}$ at $2 \mathrm{~kW}$ power in beam and welding speed $25 \mathrm{~m} / \mathrm{h}$. Penetration depth achieved
$6 \mathrm{~mm}$ using additional electromagnetic focusing lens and emission system for automated welding and other conditions being equal.

Thus, the emission systems, developed by methods of trajectory analysis and synthesis, form electron beams sufficient for EBW of metals of up to $4-5 \mathrm{~mm}$ thickness and can be applied in electron gun of a new design for manual and automated welding in space.

Authors express thanks to Prof. V.M. Nesterenkov, Corr. Member of the NASU, Dr. V.E. Lokshin and Eng. V.A. Matvejchuk for useful critical remarks on paper material.

1. Ternovoj, E.G., Shulym, V.F., Lankin, Yu.N. (2013) Repair of fragments of International Space Station using electron beam welding. In: Abstr. of Int. Conf. on Welding and Related Technologies: Present and Future. Kiev: PWI.

2. Paton, B.E., Kubasov, V.N. (1970) Experiment on welding of metals in space. Avtomatich. Svarka, 5, $7-12$.

3. Paton, B.E., Nazarenko, O.K., Chalov, V.I. et al. (1971) Specifics of equipment and technologies of electron beam welding and cutting under space conditions. Ibid., 3, 3-8.

4. (2000) Space: Technologies, materials science, structures: Coll. Ed. by B.E. Paton. Kiev: PWI.

5. Bondarev, A.A., Ternovoj, E.G. (2010) Features of weld formation and properties of aluminium and magnesium alloy joints under simulated space conditions. The Paton Welding J., 11, 16-20.

6. Langmuir, D.B. (1973) Theoretical limitations of cathode-ray tubes. In: Proc. of IRE, 25, 977-991.

7. Gorbenko, N.I., Iliin, V.P., Popova, G.S et al. (1979) Program package ERA for automation of electron-optical calculations. In: Numerical methods of solution of electron optics problems, 31-60. Novosibirsk.

8. Molokovsky, S.I., Sushkov, A.D. (1972) Intensive and ion beams. Leningrad: Energiya.

9. Molokovsky, S.I., Akopiants, K.S., Zubchenko, Yu.V. et al. (1979) Effect of nonlinearity of phase characteristic on focusing of electron beam in welding guns. Avtomatich. Svarka, 9, 14-17.

10. Akopiants, K.S., Zubchenko, Yu.V. (1979) Method of calculation of electron-optical system of welding gun. Ibid., 11, 33-36. 


\title{
COMPARATIVE HYGIENIC EVALUATION OF ARC WELDING PROCESS AT CONSTANT AND PULSED ELECTRODE WIRE FEED
}

\author{
O.G. LEVCHENKO, S.Yu. MAKSIMOV, A.O. LUKIANENKO and I.V. LENDEL \\ E.O. Paton Electric Welding Institute, NASU \\ 11 Bozhenko Str., 03680, Kiev, Ukraine. E-mail: office@paton.kiev.ua
}

\begin{abstract}
The problem of improving the sanitary-hygienic characteristics in welding zone is solved by designing and equipping the welder workplace with a local exhaust, completing of welding heads and holders for mechanized welding with nozzles of special design which provide suction of welding fume or application of a protective mask with a system of forced purified air supply. All this additionally complicates and increases the cost of welding equipment. Therefore, the investigations are carried out aimed at study of influence of power parameters (voltage and current) of welding process on the volume of welding fumes evolution and their harmful components. The hygienic characteristics of arc welding process in shielding gases at a constant electrode wire feed using circuits of electrical parameters control of welding power sources of serial production as well as pulsed control of electric parameters of arc for electrode metal transfer are well studied and presented in the technical literature. The possibilities of influence of welding process with a pulsed electrode wire feed on hygienic characteristics were studied not enough. Therefore, in this paper the results of comparative hygienic evaluation of arc welding at pulsed and constant feed of electrode wire of different grades are presented. The advantages and possibilities of reducing evolution of harmful substances in the air of working area are shown applying welding with pulsed wire feed and selecting the appropriate parameters of its feeding mode. 14 Ref., 3 Figures.
\end{abstract}

Key words: arc welding, mechanized equipment, electrode wire, pulsed feed, hygienic characteristics, reduction of fumes evolution

One of the ways to improve the sanitary-hygienic characteristics of arc welding is the use of pulsed power sources, allowing reducing the excessive power of the arc, control of electrode metal transfer, reducing its spattering and, therefore, reducing the evolution of harmful substances contained in welding fumes (WF) to the air of the working area [1-3]. Recently for arc welding in shielding gases the equipment of a new type, i.e. automatic and semiautomatic machines with a pulsed electrode wire feed, become ever more widespread [4]. Thus, on the basis of computerized brushless direct current electric drive with fully controllable parameters of pulsed electrode wire movement (values of speeds in the pulse and reverse, time of pulses and pauses action, pulse frequency, value of duty cycle) it is possible to improve the quality of welded joints, to control the geometry of the weld, decrease the power and resource consumption during welding process and, probably, to reduce the evolution of harmful substances into the air of the working area. The latter remains a very urgent task in solving the problems of welder and environment protection from harmful inevitable evolutions of WF, especially when using alloyed electrode wires [5-7].

The aim of this work is to determine the possibilities of influencing the method of arc welding with a controllable pulsed electrode wire feed on hygienic characteristics of welding process and selection of modes providing decrease in evolution of harmful substances.

To find the ways of reducing the evolution of harmful substances contaminating the air of industrial environment during mechanized welding, the effect of pulsed electrode wire feed and welding mode on indicators of evolution of WF formed while performing the process in the mixture of shielding gases $\left(\mathrm{Ar}+18 \% \mathrm{CO}_{2}\right)$ using solid wires of grades $\mathrm{Sv}-08 \mathrm{G} 2 \mathrm{~S}, \mathrm{~Sv}$ 01Kh19N18G10AM4 (EP-690) of $1.2 \mathrm{~mm}$ diameter, and in $\mathrm{CO}_{2}$ with flux-cored wire Veltek-N320 of $1.6 \mathrm{~mm}$ diameter, containing chromium, nickel, manganese, fluorines and other components, was investigated. The dependencies of intensity of WF formation and their main toxic components on welding mode with electrode wire pulsed feed were investigated. Welding was applied with a pulsed electrode wire feed and (for comparison) with a continuous feed of solid wire at $160 \mathrm{~A}$ and $21-22 \mathrm{~V}$ mode and of flux-cored wire at $230 \mathrm{~A}$ and $26-27 \mathrm{~V}$. In the investigations 
the pulse frequency of electrode wire feed aquired $f=20,40,60 \mathrm{~Hz}$, and the relative pulse duration $s=2,3$ and 5 . The constant electrode wire feed was set by the frequency of $1 \mathrm{~Hz}$ at the pulse duration of 1 unit [8]. The shielding gases were selected according to the recommendations of electrode wire manufacturers, and welding modes were selected from the recommended ranges of current and voltage depending on the type of electrode wire and its diameter [9].

The determination of hygienic indicators of WF evolution was carried out in accordance with the standard [10]. The investigations of intensity of WF evolution were carried out using the method of «full capture». To determine the chemical composition of WF the methods of sanitary-chemical analysis were used [11].

Welding using wire Sv-08G2S in $\mathrm{Ar}+\mathrm{CO}_{2}$ mixture. The results of investigations (Figure 1, a) showed that in welding with a constant feed of electrode wire Sv-08G2S the maximum intensity of WF formation is observed. When applying all other modes of welding with a pulsed feed it is $1.2-2$ times decreased.

The investigation of dependencies of intensity of WF formation on the frequency and duration of pulses in welding using wire Sv-08G2S in the mixture of shielding gases $\mathrm{Ar}+\mathrm{CO}_{2}$ (see Figure $1, a$ ) determined that they have a complex form. Thus, in welding at $f=20 \mathrm{~Hz}$ the intensity of WF formation decreases with increase in pulse duration, and at $f=40 \mathrm{~Hz}$, on the contrary, it is increased, and at $f=60 \mathrm{~Hz}$ this dependence is ambiguous.

The complex view of the obtained dependencies can be explained as follows. It is known that in welding with constant electrode wire feed in shielding gas the level of WF evolution is determined not only by the arc power, but also

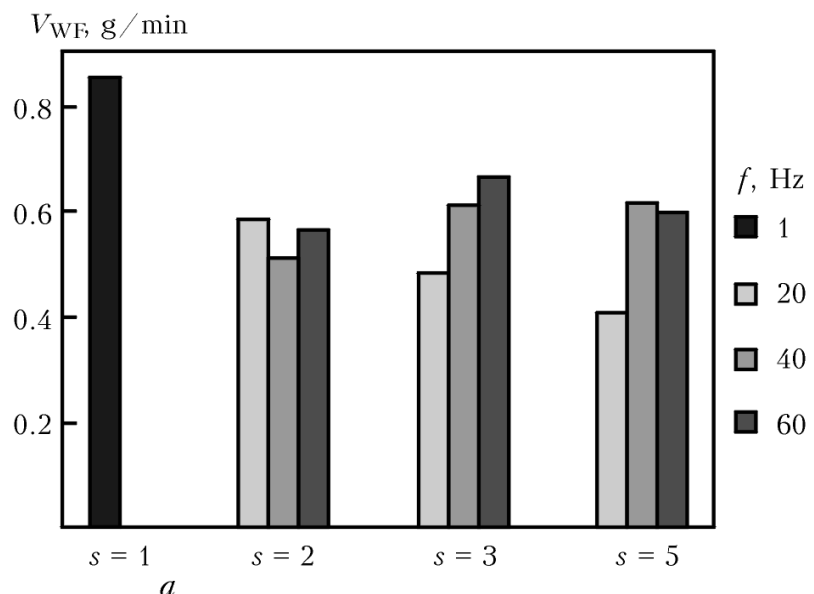

by the character of electrode metal transfer [12]. The dependence of intensity of WF formation on welding current bears an extreme character: at first, it is increased and, then, decreased and has a maximum corresponding to the greatest spattering of electrode metal and a minimum, characteristic for fine-drop transfer without short circuits with immersion of arc into the base metal [13]. In its turn, it is known [14] that in pulsed electrode wire feed depending on feed step the following three variants of electrode metal transfer are possible:

- feed step is equal or somewhat larger than the arc length, and the drop is dipped into the molten pool during movement of the electrode;

- feed step is somewhat smaller than the arc length and the electrode metal drop without its detachment comes into contact with weld pool after depay under the forces of inertia;

- feed step is smaller than the arc length and the drop detaches under the action of inertia forces and flies over the arc gap without a short circuit.

Therefore, the view of the diagram (see Figure 1, $a$ ) depends on the certain area of dependencies of intensity of WF formation on welding current and the available variant of electrode metal transfer considered at the moment.

As is known, welding using modulated pulsed current allows reducing the intensity of WF evolution (as compared to welding using continuous current) without reducing the labor efficeincy and melting coefficient $[1,3]$. The reduction of total arc power due to the pauses during application of pulsed current reduces the excess of energy occured in welding using continuous current and is spent for evaporation of fusible materials. The intensity of WF formation decreases with decrease in currents in the pulse, pause,

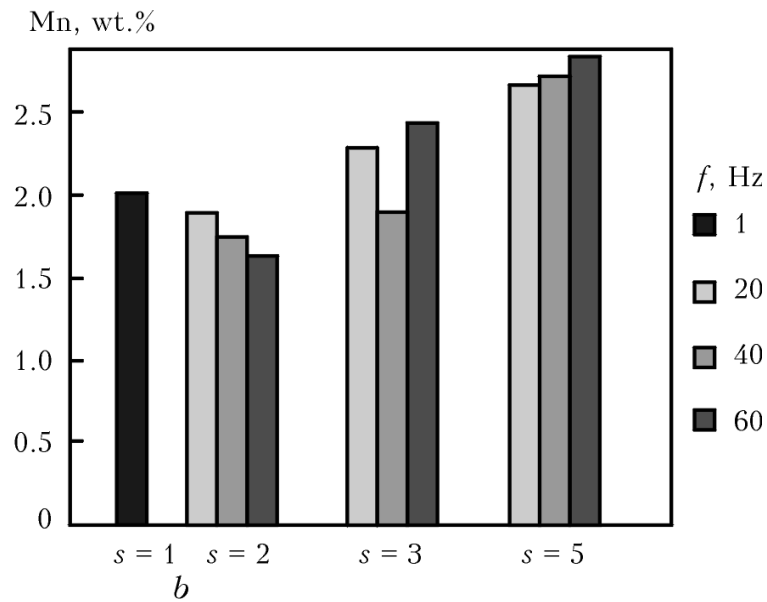

Figure 1. WF evolution in welding using wire Sv-08G2S at average current of $160 \mathrm{~A}$ and voltage of 21-22 V with constant electrode wire feed $(f=1 \mathrm{~Hz}, s=1)$ and with pulsed wire feed $(f=20,40,60 \mathrm{~Hz}, s=2,3,5): a-$ intensity of WF formation $V_{\mathrm{WF}} ; b-$ content of manganese in WF composition 


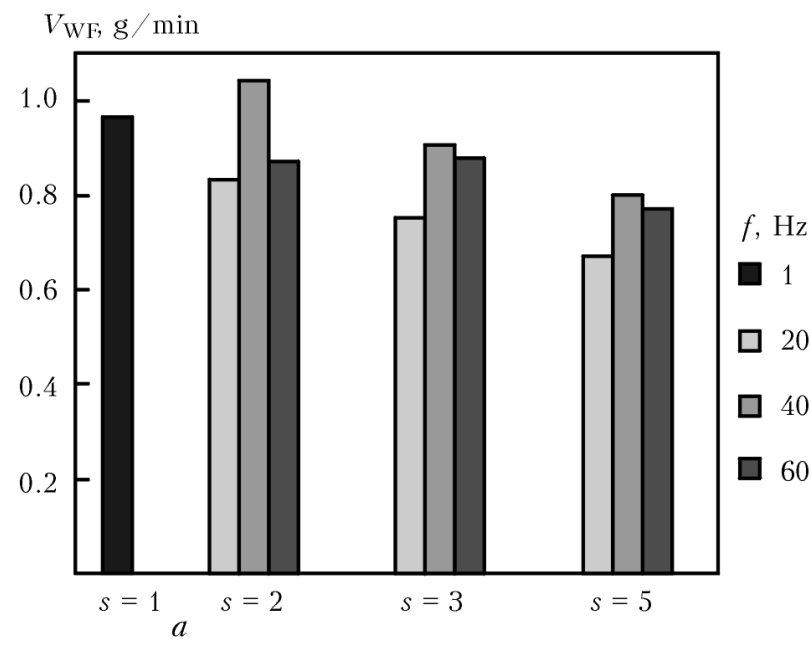

C, wt.\%

$V_{\mathrm{Cr}^{6+}}, \mathrm{g} / \mathrm{min}$
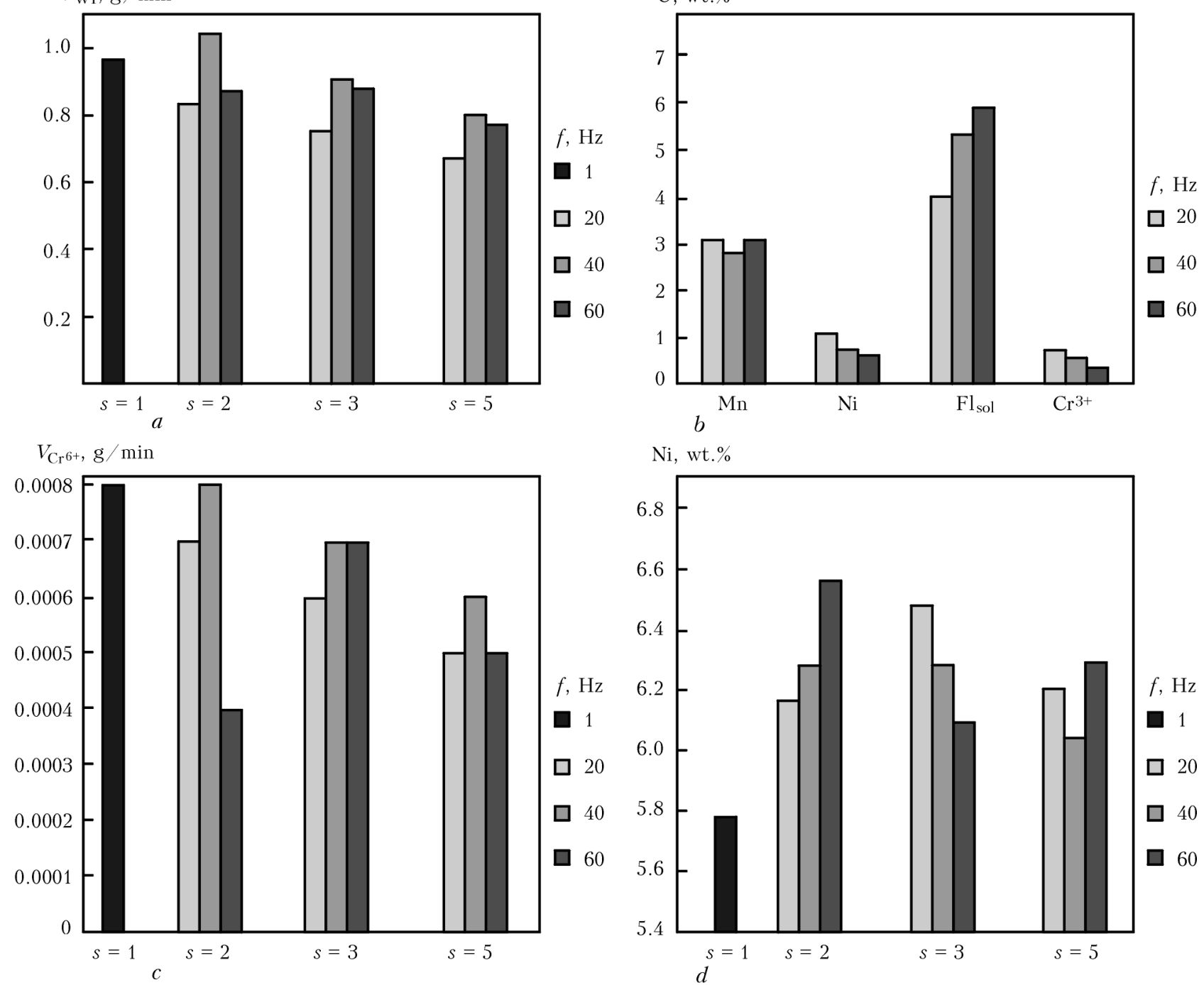

$\mathrm{Ni}, \mathrm{wt} . \%$

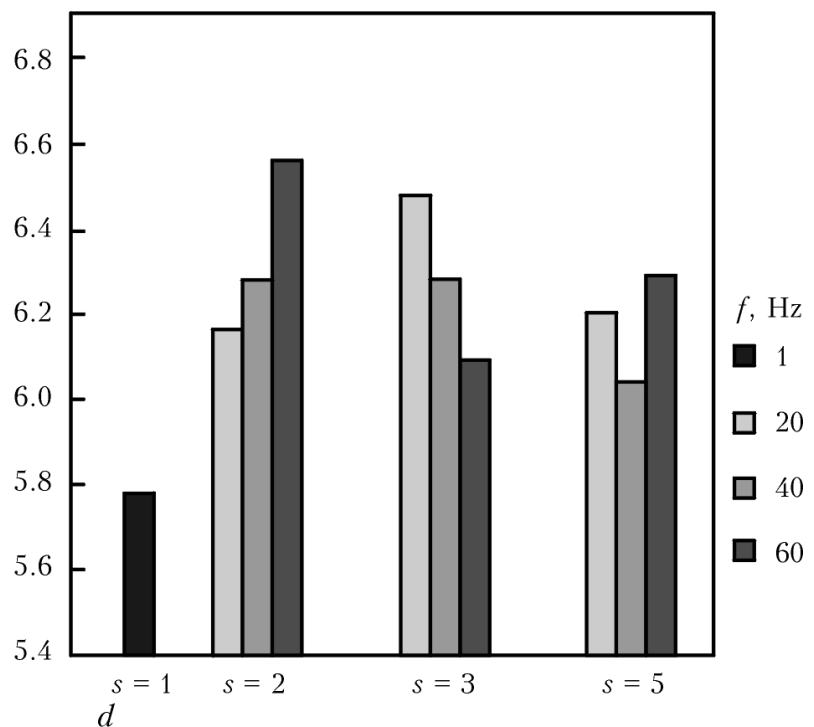

Figure 2. WF evolution in welding using wire EP-690 at $160 \mathrm{~A}$ average current and $21-22 \mathrm{~V}$ voltage with constant $(f=$ $=1 \mathrm{~Hz}, s=1)$ and with pulsed wire feed $(f=20,40,60 \mathrm{~Hz}, s=2,3,5): a$ - intensity of WF evolution; $b-$ mass fraction of $\mathrm{Mn}, \mathrm{Cr}^{3+}, \mathrm{Fl}_{\text {sol }}$ and $\mathrm{Ni}$ in the WF composition $(s=5) ; c-$ intensity of $V_{\mathrm{Cr}^{6+}}$ formation; $d-\mathrm{Ni}$ mass fraction

with pulse duration and with increase in the pause duration. Mechanized welding using pulsed current can reduce the intensity of WF evolution as compared to conventional mechanized arc welding due to decreaase in the volume of heat generated in welding zone.

Furthermore, the use of welding at pulsed current provides a significant decrease in evolution of manganese in the composition of WF [12] providing the process with a controllable forced short circuits, increasing frequency of circuits, arc length and reducing the droplet size. It is possible to reduce the manganese content in WF by adjusting the frequency of current pulses promoting the better drop detachment from the electrode and increase in frequency of their transition into the pool. The results of investigations, obtained in this work correlate well with the results of other works, on the subject of mechanized welding using modulated pulse current [2, 3, 12, 14].
The results of comparative investigations of toxic manganese content in WF, formed in welding using wire Sv-08G2S at constant and pulsed feed (Figure 1, $b$ ), show that its minimum content occurs at the pulsed electrode wire feed at $f=$ $=20,40,60 \mathrm{~Hz}$ and $s=2$ modes. The rest welding modes $f=20,40,60 \mathrm{~Hz}$ and $s=3,5$ result in somewhat increased manganese content in the composition of WF as compared to welding using continuous wire feed.

The investigation of dependencies of manganese content in the composition of WF (see Figure $1, b)$ and the intensity of its evolution on frequency and duration of pulses of electrode wire feed showed that increase in pulse duration contributes to increase in the concentration of manganese in WF and the intensity of its evolution, and the influence of pulse frequency is ambiguous. In welding with pulsed feed of electrode wire with $f=40-60 \mathrm{~Hz}$ the decrease in the value 
of pulse duration from 5 to 2 units allows reducing the content of toxic manganese in the WF composition and almost twice decreasing the intensity of its evolution.

Thus, the results of investigations of dependencies of intensity of manganese evolution, as a leading toxic component in welding using wire Sv-08G2S allow selecting the welding mode, which provides the minimum evolution of manganese to the working area air. This is the welding mode with pulsed electrode wire feed with $40-60 \mathrm{~Hz}$ frequency and pulse duration of 2 units.

Welding using wire EP-690 in $\mathrm{Ar}+\mathrm{CO}_{2}$ mixture. Applying wire EP-690 for welding with its pulsed feeding the intensity of WF formation is lower than during welding with constant wire feed, except of $f=40 \mathrm{~Hz}, s=2$ mode (Figure 2, $a)$. The use of wire EP-690 leads to release of such harmful components into the working area air as manganese, trivalent chromium, nickel (Figure 2, b), as well as hexavalent chromium. In the composition of WF the highest content has manganese, the lower belongs to trivalent chromium and nickel, and the minimum has hexavalent chromium. In this case, the most toxic component of WF is hexavalent chromium, whose results of investigated intensity of evolution are shown in Figure 2, c. From the Figure it is seen that during welding with pulsed electrode wire feed (except of $f=40 \mathrm{~Hz}, s=2$ mode) the intensity of evolution of hexavalent chromium is lower than at constant wire feed. The maximum intensity of hexavalent chromium evolution is noted in welding mode with $f=40 \mathrm{~Hz}$ and $s=2$ as compared to other welding modes with the pulsed and constant wire feed. The most acceptable mode, providing the minimum evolution of hexavalent chromium (twice lower than in welding with constant wire feed) is the mode with pulsed wire feed with $60 \mathrm{~Hz}$ frequency and pulse duration of 2 units.

Regarding nickel (the second largest toxic carcinogenic component of WF), then from the results of investigations (Figure 2, d) it is seen that its content in WF during welding using wire EP-690, on the contrary, has a minimum value at mode with constant wire feed as compared to welding with pulsed wire feed at all the investigated modes. The results of investigations of dependencies of intensity of nickel evolution at welding mode with pulsed wire feed showed that it is minimal at $f=20 \mathrm{~Hz}$ and $s=5$, and the maximum is at $f=40 \mathrm{~Hz}$ and $s=2$. It is recommended to consider this peculiarity during selection of the optimal welding mode, when the in- tensity of evolution of all the WF components in the working area is taken into account. Here it should be remembered that according to the value of the maximum permissible concentration (MPC) the toxicity of hexavalent chromium is 5 times higher than the toxicity of nickel, and many times exceeds the MPC of other components in the composition of WF.

Welding using flux-cored wire Veltek-N320 in $\mathbf{C O}_{2}$. In welding using Veltek-N320 flux-cored wiire, the composition of which besides the above-mentioned components includes also fluorines, the application of pulse mode, in most cases, allows improving the hygienic characteristics as compared to welding with constant wire feed, particularly, at modes with $20 \mathrm{~Hz}$ frequency at any pulse duration (Figure $3, a$ ).

The results of investigations of dependencies of intensity of WF formation on frequency and pulse duratione (see Figure 3,a) showed that at $s=2,3$ and 5 and $f=20 \mathrm{~Hz}$, it has a minimum value, and further at $40 \mathrm{~Hz}$ frequency it reaches the maximum and then decreases up to $60 \mathrm{~Hz}$, except of mode with $s=2$, where after the pulse frequency of $40 \mathrm{~Hz}$, the intensity of WF formation continues to grow. The determination of chemical composition of WF (Figure $3, b$ ) revealed that it contains the greatest amount of insoluble fluorines $(61.4 \%)$, followed by soluble fluorines $(18.0 \%)$, then manganese $(13.9 \%)$, nickel $(5.0 \%)$, and the lowest content of trivalent chromium (3.4\%). Remarkably that hexavalent chromium in this case is absent. The minimum content of toxic manganese in the composition of WF was observed during welding with pulsed wire feed at $f=40 \mathrm{~Hz}, s=2$, and the maximum one occured during welding with constant feed (Figure 3,c).

The investigations of intensity of dependencies of manganese evolution on frequency and pulse duration showed that they bear a complex character: at pulse frequencies of 20 and $60 \mathrm{~Hz}$ they have almost the the same values; at $f=40 \mathrm{~Hz}$ and $s=5$ the intensity of manganese evolution has the maximum value, and at $s=2$ it is the minimum. The latter confirms the previous obtained data [2] that welding with pulse current can reduce the manganese content in WF due to the control of electrode metal transfer.

The determination of soluble fluorines evolution (2nd class of hazard) shows that its maximum content was in WF formed in welding with pulsed wire feed at $f=40$ and $60 \mathrm{~Hz}$ and $s=2$, 3,5 ; the lower was in welding with constant and pulsed wire feed at $f=20 \mathrm{~Hz}$ and $s=2,3,5$ (Figure 3,d). The investigations of dependencies 

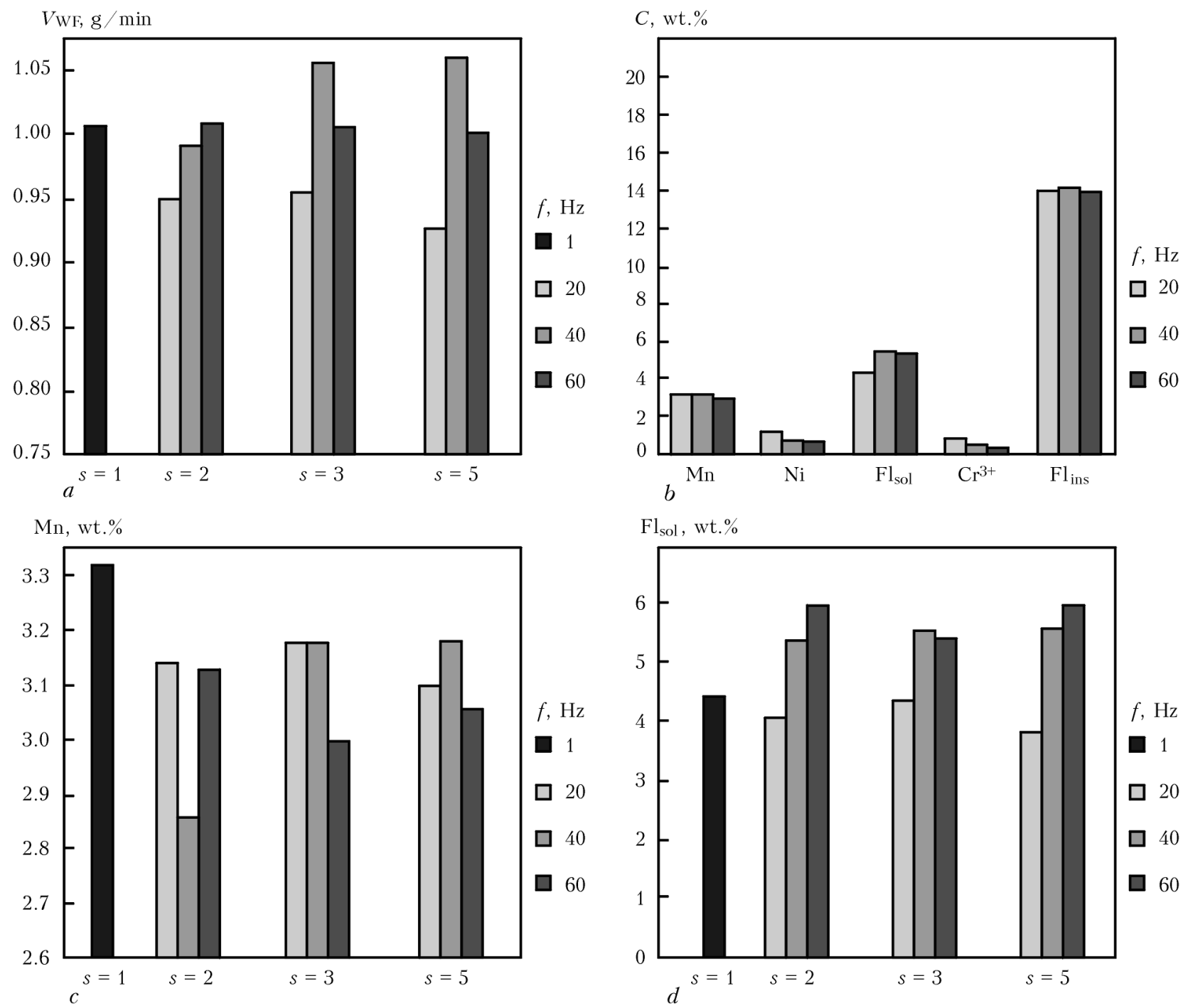

$\mathrm{Fl}_{\mathrm{sol}}$, wt.\%
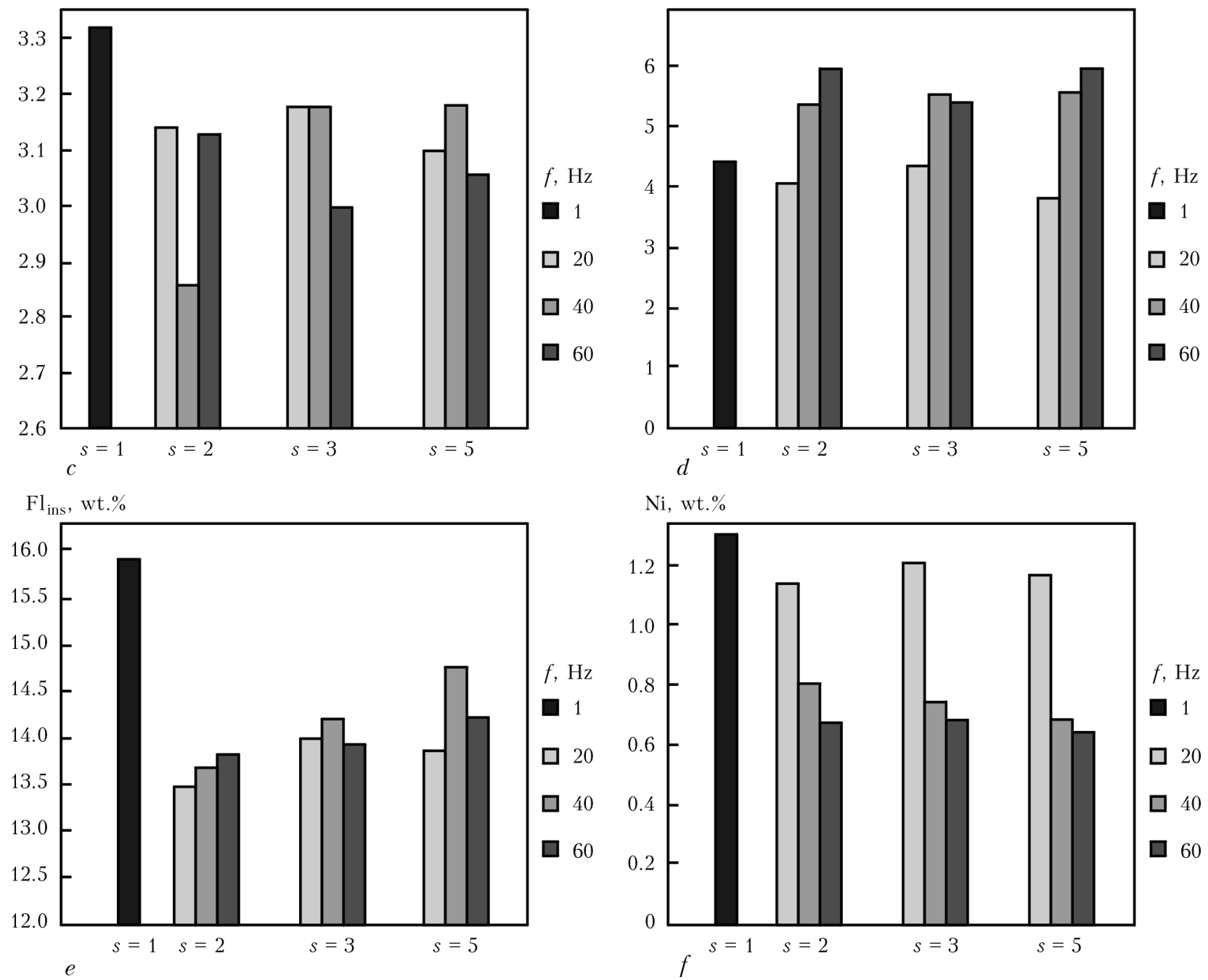

Figure 3. WF evolution in welding using wire Veltek-N320 at 230 A average current and 26-27 V voltage with constant $(f=1 \mathrm{~Hz}, s=1)$ and with pulsed wire feed $(f=20,40,60 \mathrm{~Hz}, s=2,3,5): a-$ intensity of WF formation; $b-$ mass fraction of harmful substances in WF $(s=3) ; c-$ Mn mass fraction; $d-$ mass fraction of soluble fluorine; $e-$ mass fraction of insoluble fluorine; $f-\mathrm{Ni}$ mass fraction in WF

of intensity of soluble fluorine formation on the frequency and duration of pulse showed that in welding with $s=3$ and 5 at $f=20-40 \mathrm{~Hz}$ it is increased, and from 40 to $60 \mathrm{~Hz}$ it is reduced, except of pulse duratioon of 2 units, where the intensity of soluble fluorine formation constantly grows. The insoluble fluorine (3rd class of hazard) is present in WF in the maximum volume 
in case of welding at constant electrode wire feed and in much smaller volumes in welding with pulsed wire feed at all the modes (Figure 3,e).

The investigation of nickel content (1st class of hazard) in WF (Figure 3,f), as the leading toxic component in this case, showed that its minimum volume was observed in welding with pulsed flux-cored wire feed at $f=40$ and $60 \mathrm{~Hz}$ and $s=2,3$ and 5, and the maximum was in welding with constant pulsed wire feed and also on modes with pulsed wire feed at $20 \mathrm{~Hz}$ and 2 , 3,5 units. The dependencies of intensity of nickel evolution on pulse frequency are reduced with its increase. Therefore, in this case (in the absence of hexavalent chromium in WF) during selection of welding modes providing the minimal influence of WF on the body of welder, it is necessary to focus on nickel.

Thus, from the obtained data it was revealed that the intensity of WF formation, volume of evolved impurities and their mass fraction in the WF composition are rather sensitive to changes in voltage in the range of $\pm(1.5-2) \mathrm{V}$, which occurs at the pulse electrode wire feed. It depends on the type of electrode metal transfer, type of electrode wire and level of its alloying. The application of pulsed electrode wire feed provides not only the control of the size of molten droplet through a feed step, but also presets the type of electrode metal transfer. Thus, when using fluxcored wire Veltek-N320 at $f=40$ and $60 \mathrm{~Hz}$ and $s=2,3$ and 5 the spray transfer with a frequent modulation of arc length was observed and, consequently, its voltage, that eventually resulted in reduction of nickel vapors content (the lowest evolution of nickel is provided at modes with pulsed wire feed at $f=40$ and $60 \mathrm{~Hz}$ ). The transition to globular metal transfer with short circuits at $f=20 \mathrm{~Hz}$ did not change significantly the level of nickel content as compared to the constant electrode wire feed, but influenced the rate of WF formation and content of vapors of other compounds in it. Whereas in case with solid electrode wire EP-690 its capability of pulsed feeding influences the type of electrode metal transfer and allows obtaining the stable process with short circuits at $s=5$ and $f=20 \mathrm{~Hz}$, that, as a result, has a positive effect on the intensity of WF formation, and almost twice reduction of intensity of hexavalent chromium evolution. The same regularities, associated with the influence of pulsed electrode wire feed parameters on the volume of drop, duration of its staying at the end of electrode wire, duration of drop transfer to the weld pool, are observed in case of welding with electrode wire Sv-08G2S. In welding with pulsed feed using this wire in the mixture of shielding gases $\mathrm{Ar}+\mathrm{CO}_{2}$, the intensity of $\mathrm{WF}$ evolution decreases from 1.2 to 2 times as compared to welding using continuous wire feed.

From all the mentioned above, it follows that welding with a controllable pulsed electrode wire feed improves hygienic characteristics of this process as compared to welding using continuous feed and to some extent provides their control at accurate presetting of pulsed electrode wire feed parameters and the whole complex of welding equipment. It is recommended to use the obtained results of investigations when selecting the welding modes with a controllable pulsed electrode wire feed.

1. Golovatyuk, A.P., Sidoruk, V.S., Levchenko, O.G. et al. (1985) Intensity of aerosol formation in manual modulated-current welding. Avtomatich. Svarka, 2, 39-40.

2. Levchenko, O.G. (2000) Formation of aerosols in $\mathrm{CO}_{2}$ modulated-current welding. The Paton Welding J., 8, 47-49.

3. Castner, H.R. (1995) Gas metal arc welding using pulsed fume generation current. Welding Res. Suppl., February, 59-68.

4. Lebedev, V.A. (2014) Specifics of control of consumable electrode welding process with pulsed electrode wire feed. Svarka i Diagnostika, 1, 16-18.

5. Palmer, W.G., Eaton, J.C. (2007) Effects of welding on health: AWS Int. Standard Book 978-0-87171067-3.

6. Antonini, J.M. (2003) Health effects of welding. Critical Rev. in Toxicology, 33(1), 61-103.

7. ANSI Z49.1-2005: Safety in welding, cutting and allied processes, Sect. E5.4, 12. AWS.

8. Lebedev, V.A., Lendel, I.V. (2013) Control of pulsed movement of electrode wire in mechanized welding due to change of feed pitch. Zagotovitel. Proizv. v Mashinostroenii, 3, 10-14.

9. Potapievsky, A.G., Saraev, Yu.N., Chinakhov, D.A. (2012) Consumable-electrode shielded-gas welding of steels. Technique and technology of future. Tomsk: TPU.

10. DSTU ISO 15011-1:2008: Occupational health and safety in welding and allied processes. Laboratory method of aerosol and gas extraction formed in arc welding. Pt 1: Determination of emission level and sampling for analysis of aerosol microparticles. Valid from 2008-8-15. Kyiv: Derzhstandart Ukrainy.

11. (1990) 4945-88: Guidelines for determination of harmful substances in welding aerosol (solid phase and gases). Moscow: Minzdrav SSSR.

12. Levchenko, O.G. (1986) Influence of shielded gas composition and welding parameters on bulk emissions of welding aerosol. Avtomatich. Svarka, 1, 73-74.

13. Voropaj, N.M., Benidze, Z.D., Buchinsky, V.N. (1989) Peculiarities of $\mathrm{CO}_{2}$ welding process with pulsed electrode wire feed. Ibid., 2, 23-26, 36.

14. Levchenko, O.G. (1992) Influence of technological parameters of $\mathrm{CO}_{2}$ welding of structural steels on aerosol emission. Ibid., 9/10, 31-33. 


\title{
COMPARATIVE ANALYSIS OF MODELS OF DYNAMIC WELDING ARC ${ }^{*}$
}

\author{
I.V. PENTEGOV and V.N. SYDORETS \\ E.O. Paton Electric Welding Institute, NASU \\ 11 Bozhenko Str., 03680, Kiev, Ukraine. E-mail: office@paton.kiev.ua
}

Keywords: gas-shielded arc welding using consumable and non-consumable electrode, dynamic arc, mathematical model, power balance, investigations

There are number of dynamic arc models at present time. Therefore, the researchers when solving the specific tasks on investigation of processes in power source-welding arc system face with the problem of selection of a model providing complete description of the main arc peculiarities in each specific case. This paper is dedicated to objective estimation and comparison of models of dynamic arc and elaboration of recommendations for model selection on this basis.

Some progress in description of welding arc of constant length (non-consumable electrode) as part of electric circuit was achieved using mathematical model of dynamic arc, developed at the E.O. Paton Electric Welding Institute (PWI-MA) [1]. PWI-MA was further developed in works [2, 3]. Arc column in PWI-MA has been phenomenological considered as heat inertial macroobject, for which the following power balance is valid:

$$
\frac{d Q}{d t}=P-P_{\theta},
$$

where $Q$ is the internal energy of arc column; $P$ and $P_{\theta}$ is the input and output power, respectively. All isoenergetic identical states in PWIMA are characterized by one parameter, i.e. arc state current $i_{\theta}[1,3]$. It determines such characteristics of the arc column as static resistance

$$
R_{\mathrm{st}}\left(i_{\theta}\right)=\frac{U_{\mathrm{col}}\left(i_{\theta}\right)}{i_{\theta}}
$$

and output power

$$
P_{\theta}=U_{\text {col }}\left(i_{\theta}\right) i_{\theta},
$$

where $U_{\text {col }}$ is the function defining static voltampere characteristic (SVAC) of the arc column.

Input power is determined by arc column resistance as well as value of its transitional current:

$$
P=R_{\mathrm{st}}\left(i_{\theta}\right) i^{2}=\frac{U_{\mathrm{col}}\left(i_{\theta}\right)}{i_{\theta}} i^{2} .
$$

Voltage on the arc column in dynamic is found from expression

$$
u_{\mathrm{col}}=\frac{U_{\mathrm{col}}\left(i_{\theta}\right)}{i_{\theta}} i .
$$

State current $i_{\theta}$ for any representative point on plane, corresponding to arc column dynamic states in the coordinates of arc column voltage arc current $\left(u_{\mathrm{col}}, i\right)$, is determined as $x$-coordinate of cross point of beam from the origin, passing through this point, with arc column SVAC. Work [3] shows that PWI-MA equation in differential form [2] corresponds to energy balance equation (1):

$$
\theta \frac{d i_{\theta}^{2}}{d t}=i^{2}-i_{\theta}^{2}
$$

which is electroengineering analog of equation (1). At that internal energy of arc column equals [3]

$$
Q=2 \theta \int_{0}^{i_{\theta}} U_{\operatorname{col}}\left(i_{\theta}\right) d i_{\theta},
$$

where $\theta$ is the time constant of arc column.

Since all other models use such a value as arc column conductivity $g$ [4], PWI-MA equation

\footnotetext{
*Translation of paper from «Avtomaticheskaya Svarka» Journal, 1989, No. 2, pp. 33-36. Monitoring of references to the papers, published in this Journal, showed that paper of I.V. Pentegov and V.N. Sydorets is one of the most cited in area of welding arc modelling. It is dedicated to comparison of dynamic model of arc, being developed at the E.O. Paton Electric Welding Institute, with other models and is still of high interest up to the present moment. Unfortunately, «Avtomaticheskaya Svarka» Journal was not translated in English in 1989. However, current reality of the world scientific community necessitates publications in English. Therefore, the Editorial Board of the Journal has made a decision to publish this paper in «The Paton Welding Journal» in order to make it more accessible to wider
} audience of researchers, post-graduate students and students. 
(7) is transferred in conductivity terms using formula (2), from which

$$
g=\frac{i_{\theta}}{U_{\operatorname{col}\left(i_{\theta}\right)}} .
$$

PWI-MA equation is converted in $g$-form by differentiation of expression (8) by time and substituting found $d i_{\theta} / d t$ value in equation (6):

$$
\left[\frac{2 \theta}{1-\frac{g}{G_{\mathrm{dif}}(g)}}\right] \frac{1}{g} \frac{d g}{d t}+1=\frac{i^{2}}{g^{2} U_{\mathrm{col}}^{2}(g)}=\frac{i^{2}}{g P_{\theta}},
$$

where $G_{\mathrm{dif}}=\left(d U_{\mathrm{col}} / d i_{\theta}\right)^{-1}$ is the differential conductivity. For making a comparison let us provide equations of arc column dynamic of all widespread models.

Cassie's model [5]:

$$
\frac{\theta_{\mathrm{C}}}{g} \frac{d g}{d t}+1=\left(\frac{i}{g U_{\mathrm{C}}}\right)^{2}
$$

where $\theta_{\mathrm{C}}$ is the arc time constant in Cassie's model; $U_{\mathrm{C}}$ is the static voltage on the arc column, which is constant in Cassie's model.

Mayr's model [6]:

$$
\frac{\theta_{\mathrm{M}}}{g} \frac{d g}{d t}+1=\frac{i^{2}}{g P_{\mathrm{M}}}
$$

where $\theta_{\mathrm{M}}$ is the time constant in Mayr's model; $P_{\mathrm{M}}$ is the output power, which is constant in Mayr's model.

Zarudi's model [7, 8]:

$$
\frac{\theta \mathrm{z}}{g} \frac{d g}{d t}+1=\frac{i^{2}}{g^{k+1} X_{k}},
$$

where $\theta_{Z}=(1+k) \theta$ is the value, which can be considered as time constant in Zarudi's model; $k$ is the index of plasma non-linearity depending on gas nature, in which arc burns; $X_{k}$ is the constant at fixed $k$.

Schellhase's model [9]:

$$
\frac{\theta_{\mathrm{S}}}{g} \frac{d g}{d t}+1=\frac{1}{g U_{\mathrm{col}}(i)},
$$

where $\theta_{\mathrm{S}}$ is the time constant in Schellhase's model.

Comparison of the models show that the time constants are different in all models. Let us consider what are the conditions when expression

$$
\tau=\frac{2 \theta}{1-\frac{g}{G_{\operatorname{dif}}(g)}}
$$

in equation (9) is the constant.

Obviously, for this it is necessary that

$$
\frac{g}{G_{\mathrm{dif}}(g)}=\frac{i_{\theta}}{U_{\mathrm{col}}\left(i_{\theta}\right)} \frac{d U_{\mathrm{col}}}{d i_{\theta}}=n=\text { const. }
$$

Separating the variables and integrating the latter equation the following is received:

$$
U_{\text {col }}\left(i_{\theta}\right)=U_{0}\left(\frac{i_{\theta}}{I_{0}}\right)^{n},
$$

where $U_{0}$ and $I_{0}$ are the coordinates of one of SVAC fixed points.

Thus, Cassies's, Mayr's and Zarudi's models follow from PWI-MA (9) in a special case, when SVAC has power form with index of power $n$, and equation (9) is written as

$$
\frac{2 \theta}{1-n} \frac{1}{g} \frac{d g}{d t}+1=\left(\frac{I_{0}^{n}}{U_{0}}\right)^{\frac{2}{1-n}} \frac{i^{2}}{g^{\frac{2}{1-n}}} .
$$

Cassie's model (10) is received at $n=0$. Then $U_{\mathrm{C}}=U_{0}$ and $\theta_{\mathrm{C}}=2 \theta$. Mayr's model (11) takes place at $n=-1$. In this case $P_{\mathrm{M}}=U_{0} I_{0}$ and $\theta_{\mathrm{M}}=$ $=\theta$. Zarudi's model (12) is realized at $n=-(1-$ $-k) /(1+k)$. Then

$$
X_{k}=I_{0}^{2}\left(\frac{U_{0}}{I_{0}}\right)^{1+k} \text { and } \theta_{\mathrm{Z}}=(1+k) \theta=\frac{2 \theta}{1-n} .
$$

Schellhase's model (13) can not be received from PWI-MA (9) under any conditions. It can be superposed neither with Cassie's models no with Zarudi's model. Obviously, it is explained by the fact that Schellhase's model [9] was built on concepts, which did not use power balance equation (1).

Specific attention is to be given to interpretation of coefficient $\tau$ from formula (14). It was mentioned above that this coefficient remains constant in the case of SVAC power function (15). Therefore, it is called an arc time constant in different models. In general case $\tau$ value depends on conductivity and can not be interpreted as arc time constant. Moreover, as it is shown in work [3], the transfer processes in the circuit with arc generally can not be characterized by process time constant. This conclusion matches with the results of experimental investigations in works [10, 11]. Thus, PWI-MA eliminates existing contradiction on variability of arc time constant. The arc time constant $\theta$ in PWI-MA is the invariable value, but it is not time constant of the process. And generally coefficient $\tau$ is the variable value. 
It follows from mentioned above that PWIMA applicable to welding arc has series of advantages in comparison with other methods. PWI-MA is the most general of all models. It can use SVAC of any type (including areas with independent and growing SVAC), that is very important in welding arc modelling. PWI-MA, in terms of electric engineering, uses a value of state current, that has apparent advantages in comparison with other models, which use values of conductivity or arc column resistance. PWIMA allows easily determining such important energy parameters of the arc column as output power and internal energy of the arc column. Formula (7) for internal energy of the arc column, obtained with the help of PWI-MA, allows expanding sphere of application of dynamic arc equations, including for the cases of arcs with varying in time arc length $l_{\mathrm{a}}(t)$ as well as moving and blown arcs, that is in principle inaccessible for alternative arc models.

Using equality

$$
U_{\text {col }}\left(i_{\theta}\right)=l_{\mathrm{a}}(t) E_{\text {col }}\left(i_{\theta}\right),
$$

where $E_{\mathrm{col}}\left(i_{\theta}\right)$ is the average value of electric field intensity in the arc column (SVAC of the arc is determined particularly for this value of intensity, in the case of cylindrical arc, $E_{\text {col }}\left(i_{\theta}\right)$ agrees with real electric field intensity in the arc column). Let us transfer equation (7) in the following form:

$$
Q=2 \theta l_{\mathrm{a}}(t) \int_{0}^{i_{\theta}(i)} E_{\mathrm{col}}\left(i_{\theta}\right) d i_{\theta} .
$$

Here out

$$
\begin{gathered}
\frac{d Q}{d t}=\frac{\partial Q}{\partial i_{\theta}} \frac{d i_{\theta}}{d t}+\frac{\partial Q}{\partial l_{\mathrm{a}}} \frac{d l_{\mathrm{a}}}{d t}= \\
=2 \theta l_{\mathrm{a}} E_{\mathrm{col}}\left(i_{\theta}\right) \frac{d t_{\theta}}{d t}+2 \theta \frac{d l_{\mathrm{a}}}{d t} \int_{0}^{i_{\theta}} E_{\mathrm{col}}\left(i_{\theta}\right) d i_{\theta} .
\end{gathered}
$$

Substituting this expression together with (3) and (4) in equation (1), PWI-MA equation for changing arc length is received in general case:

$$
\theta \frac{d i_{\theta}^{2}}{d t}=i^{2}-i_{\theta}^{2}\left[1+\frac{2 \theta v_{1}}{l_{\mathrm{a}}}\left[\frac{\int_{i_{\mathrm{col}}}^{i_{\theta}} E_{\left.i_{\theta}\right) d i_{\theta}}}{E_{\mathrm{col}}\left(i_{\theta}\right) i_{\theta}}\right]\right\} \text {, }
$$

where $v_{1}=d l_{\mathrm{a}} / d t$ is the rate of arc length change.

The latter equation assumes the following form of record for general case

$$
\theta \frac{d i_{\theta}^{2}}{d t}=i^{2}-i_{\theta}^{2}\left(1+\frac{v_{1}}{l_{\mathrm{a}}} \frac{Q}{P_{\theta}}\right)
$$

and for particular case of power approximation of SVAC curve (15)

$$
\theta \frac{d i_{\theta}^{2}}{d t}=i^{2}-i_{\theta}^{2}\left(1+\frac{2 \theta v_{1}}{(1+n) l_{\mathrm{a}}}\right) .
$$

In the latter formula $n \neq 1$ since SVAC can not be hyperbola at all integration interval [3] due to inversion into infinity of value of arc internal energy $Q$. Generally, SVAC is not approximated by power function, and it is necessary to use common equation (19). Expression in square brackets is easily calculated at any form of arc SVAC.

Obtained equation reveals more perspectives in solving the problems relating with consumable electrode welding, since this method of welding is the most widespread.

Gas blowing of welding arc provides for additional mechanism of energy output, power of which at longitudinal blowing

$$
P_{v}=\frac{V_{\mathrm{sp}}}{V_{\mathrm{a}}} Q=\frac{\left|v_{\mathrm{bl}}\right|}{l_{\mathrm{a}}} Q,
$$

at transverse blowing

$$
P_{v}=\frac{V_{\mathrm{sp}}}{V_{\mathrm{a}}} Q=\frac{2 l_{\mathrm{e}}\left|v_{\mathrm{bl}}\right|}{\pi l_{\mathrm{a}} r_{\mathrm{a}}} Q,
$$

where $V_{\mathrm{sp}}$ is the volume of plasma being blown per unit of time.

For longitudinal blowing

$$
V_{\mathrm{sp}}=\pi r_{\mathrm{a}}^{2}\left|v_{\mathrm{bl}}\right|,
$$

for transverse blowing

$$
V_{\mathrm{sp}}=2 r_{\mathrm{a}} l_{\mathrm{e}}\left|v_{\mathrm{bl}}\right| .
$$

Here $v_{\mathrm{bl}}$ is the blowing rate; $r_{\mathrm{a}}$ is the arc column radius; $l_{\mathrm{e}}$ is the distance between the electrodes, in general case $l_{\mathrm{e}} \leq l_{\mathrm{a}} ; V_{\mathrm{a}}$ is the arc volume.

Equation of power balance in this case has a form of

$$
\frac{d Q}{d t}=P-P_{\theta}-P_{v}
$$

PWI-MA equation for longitudinal blow is

$$
\theta \frac{d i_{\theta}^{2}}{d t}=i^{2}-i_{\theta}^{2}\left(1+\frac{\left|v_{\mathrm{bl}}\right|}{l_{\mathrm{a}}} \frac{Q}{P_{\theta}}\right),
$$

and for transverse blow

$$
\theta \frac{d i_{\theta}^{2}}{d t}=i^{2}-i_{\theta}^{2}\left(1+\frac{2}{\pi} \frac{l_{\mathrm{e}}}{l_{\mathrm{a}}} \frac{\left|v_{\mathrm{bl}}\right|}{r_{\mathrm{a}}} \frac{Q}{P_{\theta}}\right) .
$$


Equation (25) is expedient to be used for description of processes with plasma arc application, when longitudinal gas blow is inseparable part of the process. Equation (26) shall be used in transverse blowing as well as for different cases of arc movement, including arc movement in magnetic field, at that $v_{\mathrm{bl}}$ is considered as arc movement rate. It should be noted that different combinations of equations (19), (24) and (25) are possible. For example PWI-MA equation

$$
\theta \frac{d i_{\theta}^{2}}{d t}=i^{2}-i_{\theta}^{2}\left(1+\frac{\left|v_{\mathrm{bl}}\right|+v_{1}}{l_{\mathrm{a}}} \frac{Q}{P_{\theta}}\right)
$$

is valid in arc length change and longitudinal arc blow.

\section{Conclusions}

1. Mathematical model of dynamic arc is valid for any types of SVAC and allows solving the problems in the electroengineering terms. It can be used in the cases of varying length arcs (including the consumable electrode arc), moving arcs and gas blown arcs, and provides the method for determination of internal energy and output power, that is impossible in alternative models.

2 . Obtained results are valid not only for welding, but for plasma arcs and rupturing arcs in electric apparatuses.

3. Using the computer PWI-MA equations allows investigating evolutionary processes in power source-arc system for various cases of gas- shielded welding, namely consumable-electrode in inert gases and mixture of active gases and tungsten-electrode in inert gases welding.

1. Pentegov, I.V. (1976) Mathematical model of column of electric dynamic arc. Avtomatich. Svarka, 6, $8-12$

2. Pentegov, I.V., Sydorets, V.N., Genis, I.A. (1984) Problems of modelling of welding arc dynamics as part of electric circuit. Ibid., 10, 18-23.

3. Pentegov, I.V., Sydorets, V.N. (1988) Energy parameters in mathematical model of dynamic welding arc. Ibid., 11, 36-40."

4. Novikov, O.Ya. (1987) Electric arc stability. Leningrad: Energiya.

5. Cassie, A.M. (1939) A new theory of arc rupture and circuit severity. CIGRE, 102, 1-10.

6. Mayr, O. (1943) Beitrage zur Theorie des statischen und des dynamischen Lichtbogens. Arch. fuer Elektr., 38, 588-608.

7. Zarudi, M.E. (1971) On effect of non-linear properties of plasma on character of non-stationary processes in column of channel arc (Problems of theory and calculation). Zhurnal Tekhn. Fiziki, 41(4), 734743 .

8. Zarudi, M.E. (1977) Criteria of existence and stability of stationary modes in alternating current inductive circuit with arc. Elektrichestvo, 4, 53-60.

9. Schellhase, M. (1971) Mathematical model of transfer processes in welding arc and its investigations. Avtomatich. Svarka, 7, 13-16.

10. Kruchinin, A.M., Peshekhonov, V.I., Lazutkin, Yu.V. et. al. (1983) Calculation of arc time constant on computer. In: Mathematical modelling and disign of electric arc and plasma steel furnaces: Transact. of VNIIETO, 46-49. Moscow: Energoatomizdat.

11. (1981) Current interruption in high-voltage mains. Moscow: Energoizdat.

Received 04.11.2015

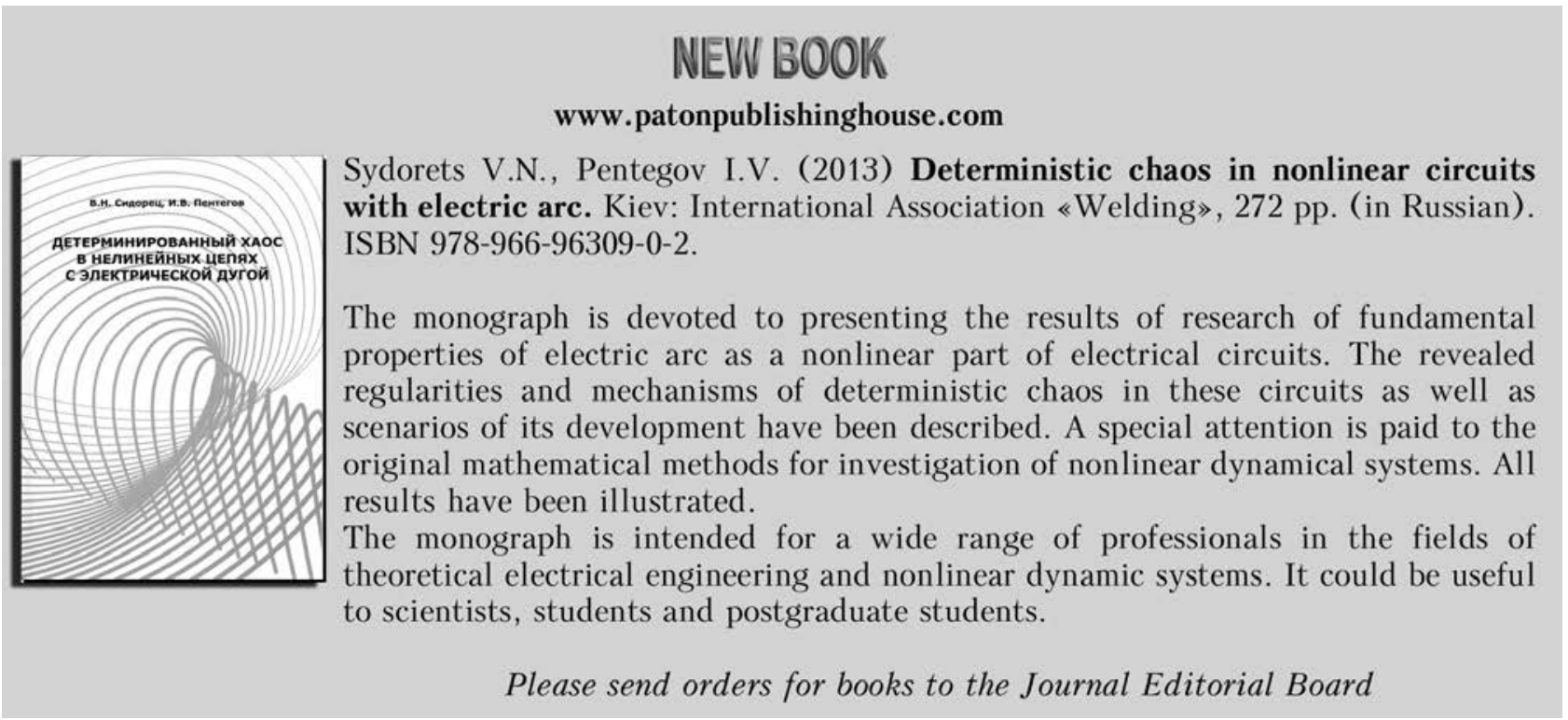

*Pentegov, I.V., Sidorets, V.N. (1990) Energy parameters in a mathematical model of a dynamic welding arc. Welding Int., 4 (4), $272-275$. 


\section{MACHINES FOR FLASH-BUTT WELDING OF BAND SAWS, RODS, WIRES AND BARS}

Flash-butt welding of band saws has its own features associated with geometrical shape of crosssection of the saw (width is much larger than thickness). During resistance welding the random character of contacting areas location in the butt and, as a result of that, the non-uniformity of heating of these areas is a great problem. The heat, generated at the contacting areas, causes a rapid growth in temperature, which is maintained even after the disappearing of contact resistance up to the welding cycle end. This leads to the overheating the metal at the mentioned areas with all the coming consequences like grain growth, accumulation of impurities along the grain boundaries, etc. The ductile and strength properties of metal of this area are reduced, and it is impossible to improve them by high tempering used in FBW. Furthermore, a high current density necessary for resistance heating (much higher than in flash heating) leads to splashes of metal during heating and oxides formation in the joint zone. Therefore, welded joints of band saws produced using resistance welding do not have a high and, most important, stable quality. In FBW of band saws the single contacts are uniformly distributed in the flashing area over the entire cross-section of the butt, which provides its uniform heating and obtaining the more stable properties of the welded joints.

For joining the band saws the world industry produces machines both for resistance as well as FBW.

The machines for resistance welding of all the manufacturers (FULGOR, GRIGGIO, IDEAL) are designed almost identically and adequately handle welding of saws of up to $20 \mathrm{~mm}$ width. In order to increase the demand their technological capabilities were expanded by modification with clamps for mounting the band of $40 \mathrm{~mm}$ width, and in some machines of up to $60 \mathrm{~mm}$ width. In such a situation a stable and reliable welding cannot be even a question.

Machines for FBW of band saws offered in the market, like IDEAL BAS-050 or IDEAL BAS060 (Germany), FULGOR FW400 (Italy), FL50 (China) are produced according to the traditional scheme of the same type and are differed from each other mainly by capacity and appearance. Machines of Ukrainian manufacturers G-22 and its copy MS4 with improved appearance but deteriorated as to the components and rigidity of its design are heavy, unreliable and out-of-date designs.

The most successful and, therefore, popular are the machines of IDEAL company. These machines can be equipped with pyrometers and allow obtaining a stable quality of welding. For this purpose the manufacturer recommends to remove the current-carrying jaws from the machine and perform their grinding every $10-20$ welds (depending on width of bands to be welded). This requires the availability of grinding machine, which, for obvious reasons, is expensive.

The flashing process is accompanied with release of a large number of metal particles in the form of splashes and aerosol. Therefore, in all the welding machines the bearings of carriage of a moving clamp and the contact surfaces of clamps are extremely vulnerable.

The essential resource in improving the quality of welded joints of band saws in FBW is the increase in speed of closing of the spark gap. The increase in speed will reduce the oxidation of molten metal, increase the deformation rate of joint area and provide the finer grain structure of weld metal. However, the significant increase in the upsetting rate during welding in the existing equipment is complicated because the great upsetting forces result in loss of stability of the band ends, and large inertial masses of mobile clamps are determined by the design of machines and cannot be changed. A particularly low upsetting rate is observed in welding of sections, which are minimum for welding machine, traditionally evidenced by a poor quality of produced welded joints. In welding of spring and highspeed cutting steels, of which the bimetallic saw blades are manufactured, the increase in upsetting rate is also very desirable, as far as it is known that obtaining a stable quality of welding of bimetallic saw blades in the available machines is a difficult task.

In FBW to provide a stable flashing the transformers with 3 or 5 times power margin is used. At high power even a short break in flashing with transition to resistance heating (short-period short circuit) leads to a sharp increase in current in the parts to be welded and overheating of 
metal in the joining zone. This is caused by the peculiarity that the voltages required for stable flashing are approximately 1.5 times higher than the voltages required for resistance heating. Therefore, designing of new welding machines with a lower electric power margin, providing high and stable quality of joints, is very relevant.

The main drawback in the design of almost all manual clamps of FBW machines is that they are not fully opened after each welding for cleaning of current-carrying electrodes, and the clamping force is not controlled in them. The clamping force of thin and narrow bands should be reduced as far as clamping of narrow bands the saw can deform the current-carrying electrode. Moreover, there is no need in a strong clamping, since the upsetting force is low and the probability of saw slipping in the clamps of the machine is also low. In connection with that, the rational is such design of clamps, where the above-mentioned problems will be solved.

The quality control of joints of band saws, rods and wires is an important part of welding technology. The control is carried out mainly by visual inspection and testing for number of bends at $180^{\circ}$. The tests for number of bends allow evaluating both strength as well as ductile properties of welded joints, but they provide only consulting information. Such tests are carried out after each readjustment of the machine to the other welding mode. Therefore, it is highly desirable to have a parameter, according to which the quality of the produced joint can be evaluated without its destruction. Such a parameter may be the amount of butt deformation during upsetting. At a low upsetting value in the joint area the oxide films and lacks of penetration are observed, a large value may indicate the overheating of metal. Therefore, the development of a method for control of the upsetting value represents the interest.

To achieve the put aim , i.e. the development of new welding machines, deprived of the abovementioned disadvantages, the following tasks were solved:

- reduction of weight of moving parts of the machine, that improved the quality of welding the sections, which are minimal for the welding machine;

- moving carriage is designed so that it has no friction parts like guides, bearings and other traditional elements and connections. It is suspended in the space on springs, which provide rigidity in vertical and flexibility in horizontal directions during movement of the carriage. Due to such a design, the maintenance of the carriage during operation of the machine is no longer required;

- transformer is designed to provide stable flashing at the minimum power margin, the power losses from magnetic currents are minimized;

- approach to evaluation of quality of the produced welded joints as to the upsetting value was offered. In the version of the machine with microprocessor control the actual value of the obtained upsetting is measured and appears on the display;

- clamps with symmetrical arrangement of bands are designed in relation to the axis of welding transformer (they provide uniform heating of bands, since electromagnetic field of the transformer does not displace the current line). The design of clamps provides access to the currentcarrying electrodes after each welding, the controlled compressing force is proportional to its thickness, the easy and comprehensible adjustment of uniform distribution of clamping force (and correspondingly uniform heating) across the width of the band. The grinding of electrodes is carried out without their removal from the welding machine.

The technical data of FBW machines CHAJKA are given below.

The designed equipment is patented, has a high reliability and provides a stable quality of welded joints of both saw bands as well as rods and wires.

Today the two new models of welding machines are produced. The first machine is with a manual start, and the second one is a fully automatic with electric flashing drive controlled by a microcontroller. The machine is controlled by a single lever or a joystick (there are no control buttons).

In the first model the designed hydraulic drive of flashing with self-regulation of flashing rate is applied. The self-regulation is performed as follows. At the break of flashing at any reason (oxidized ends, mains voltage drop, etc.) the bands heating is transferred from flashing process to the process of resistance heating. At the same time, the solid layers of metal of the flashed ends contact each other (lean against each other) and the fluid pressure in the hydraulic cylinder decreases. The speed of piston movement is reduced and, accordingly, the rate of flashing is automatically reduced. The machine comes out of the crisis (flashing is stabilized) without loss of quality of the welded joint. The peculiarity of the machine is that welding time is not constant due 
Technical characteristics of FBW machines CHAJKA

\begin{tabular}{|c|c|c|}
\hline Parameters & MKSSO-40 & MKSSO-60 \\
\hline Primary mains voltage, $\mathrm{V}$ & 380 & 380 \\
\hline Maximum primary current (in welding), A & 10 & 15 \\
\hline Width/thickness of bands to be welded, $\mathrm{mm}$ & $10-40 / 0.6-1.3$ & $20-60 / 0.7-1.3$ \\
\hline Diameters of low-carbon steel wires and bars to be welded, mm & $1.0-8.0$ & $1.5-9.0$ \\
\hline Number of welds (bands) per hour & $30-40$ & $30-40$ \\
\hline Welding time, $\mathrm{s}$ & $0.9-2$ & $1-2$ \\
\hline Welding voltage, $\mathrm{V}$ & $2.8-3.2$ & $2.8-3.4$ \\
\hline Cooling & \multicolumn{2}{|c|}{ Water, autonomous } \\
\hline Upsetting force, $\mathrm{N}$ & $200-400$ & $200-800$ \\
\hline Heat treatment regulation & Manual & Manual/Automatic \\
\hline Dimensions, $\mathrm{mm}$ & $250 \times 500 \times 400$ & $250 \times 500 \times 400$ \\
\hline Weight, kg & 85 & 85 \\
\hline
\end{tabular}

to self-regulation of flashing rate. To control the welding time the indication is provided.

The second model of welding machine is automatic and controlled by a microcontroller. This peculiarity simplified the design of mechanical part of the machine and the choice of optimal acceleration during flashing, welding time and accurate dosing of heat generation during upsetting. The latter is provided by a rough dosing of number of current pulses and their power passing through the butt after upsetting is switched-on. To evaluate the quality of the produced joints after each welding the measurement of the actual upsetting value is performed and this value is shown on the display.

On the machine the designed clamps are installed, which are fully opened after each welding for cleaning the contact surfaces of the upper jaws and the current-carrying electrodes ( $\mathrm{Fi}^{-}$ gure 1). In these clamps, regardless of force on the cam closing the clamp, the pressing force of the upper jaw band against the electrode is proportional to the thickness of the clamped band.

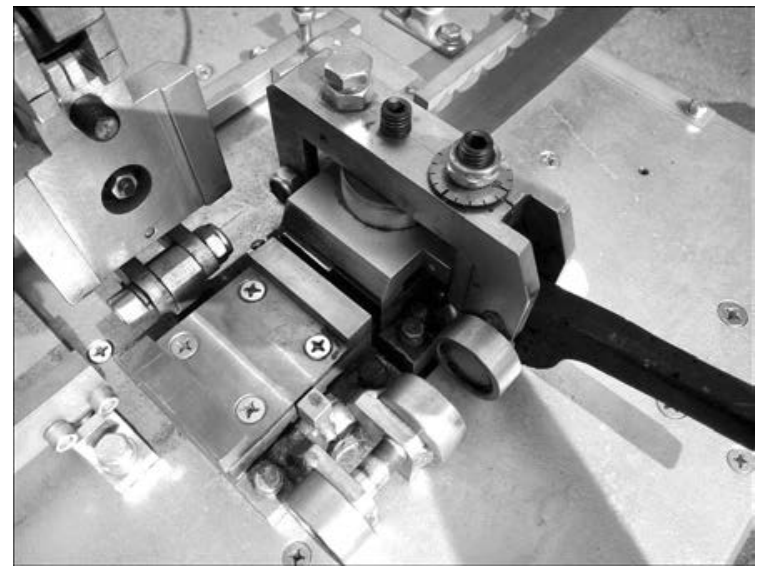

Figure 1. Clamps of FBW machine
The uniform distribution of clamping force across the width of the band and, accordingly, the uniform heating are provided by a preliminary presetting the value of welded band thickness on the clamping scale.

Due to the specially developed algorithm the control of welding machine is performed by a one four-position joystick, by which both the selection of preliminary presetting of welding, as well as start of welding itself and heat treatment are carried out. The support frame regulating the protrusion of the tooth from the clamps of the machine providing rectilinear welding of bands, is made common for both clamps, has a facilitated setting and can provide supporting of the saw both along the tooth, as well as along the «back» (Figure 2).

The software of the welding device allows updating the built-in program by the user himself, which allows reacting promptly to the requests of the operator for adjustment of the operation algorithm. The multilingual interface facilitates the use of the machine in different countries. The

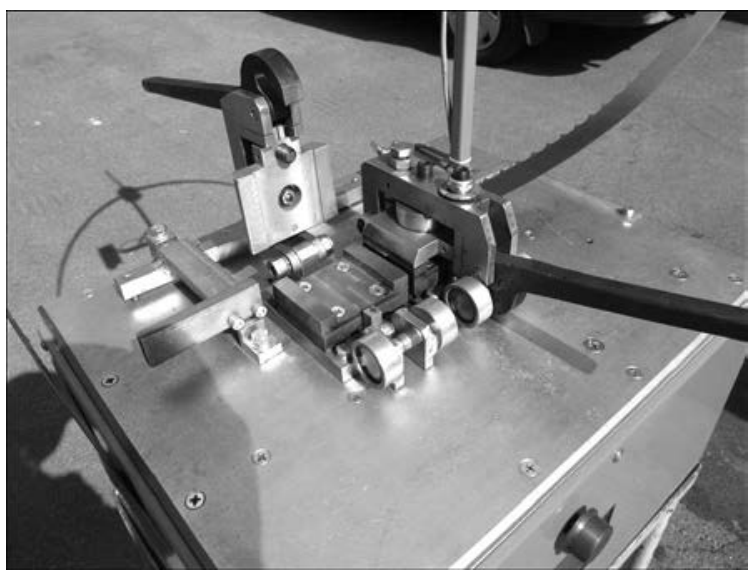

Figure 2. Saw support frame 


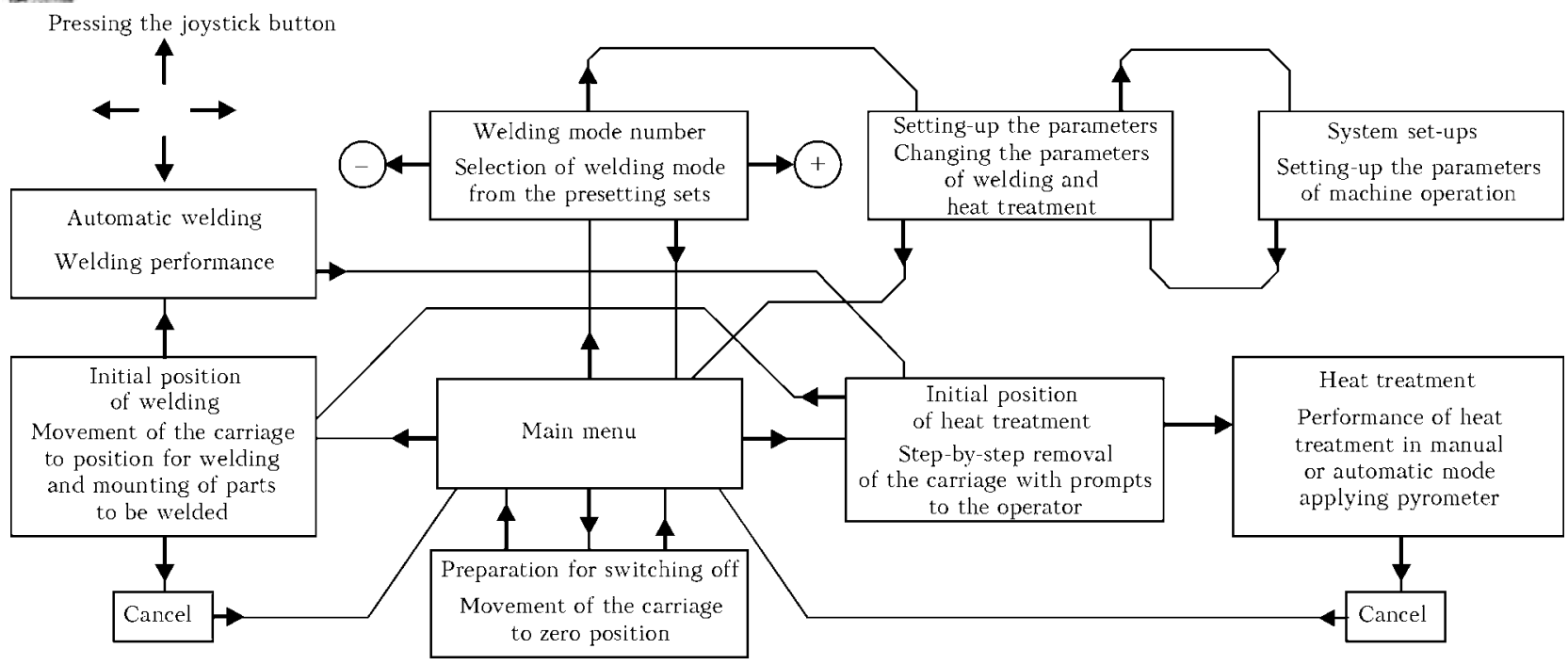

Figure 3. Block-diagram of the machine with microcontroller control system

block diagram of the machine with electronic control is shown in Figure 3.

The microcontroller control system allows facilitating the operation due to step-by-step prompts, appearing on the display. It remains for the operator only to select the type of a saw to be welded according to the program, mount it to the clamps and tilt the joystick to «Welding» position. Then the machine will perform the welding process automatically. After welding is performed, the measurement of upsetting value of the produced welded joint is automatically performed. The measured value is shown on the display. After the welding according to step-bystep instructions, on the display the heat treatment of the weld is carried out. The automatic heat treatment process runs without operator. The temperature of the weld is controlled by a pyrometer according to the program of the $\mathrm{mi}^{-}$ crocontroller of the welding machine. In case of using manual mode of heat treatment the operator needs to regulate the heating of butt himself using joystick being visually oriented by the brightness of incandescent metal. There are 20 preset modes of welding and heat treatment offered for different saws, knives and jigsaws.
The machine with microcontroller control system is characterized by very broad capabilities as to installation, adjustment and fulfillment of welding parameters with stabilization of heat generation in the butt during upsetting. For its use the special training of welding operator is not required.

In conclusion it should be noted that the presented FBW machines have the following operational advantages: the carriage has no friction parts (no bearings) and does not require maintenance during operation process, the controlled pressing force of bands, uniform heating across the width, stabilization of heat generation in the butt during upsetting, automatic heat treatment, full access to the electrodes after each welding, high and stable quality of welding including that of small sections and evaluation of quality of welded joints, produced without their destruction, are provided.

\author{
D.V. Chajka, NTUU «KPI» \\ V.G. Chajka, PWI \\ S.P. Krushnevich, Gas Institute \\ B.I. Volokhatyuk, PWI \\ A.A. Hatayan, RELEMA, Lithuania
}




\section{INDEX OF ARTICLES FOR TPWJ'2015, Nos. 1-12}

Company «Plasma-Master Ltd.» is on the way of innovation development

Evgeny O. Paton, the outstanding scientist in the field of welding and bridge construction (on the occasion of the 145th birthday anniversary)

Interview with Prof. L.M. Lobanov, the Deputy Director of the E.O. Paton Electric Welding Institute

Interview with Prof. S.I. Kuchuk-Yatsenko, the Deputy Director of the E.O. Paton Electric Welding Institute

\section{INTERNATIONAL CONFERENCE «SURFACING - SCIENCE. PRODUCTION. PROSPECTS»}

«TM. VELTEK Ltd.»: Strategy of development

APPLICATION OF MATHEMATICAL METHODS IN INVESTIGATIONS OF SURFACING PROCESSES

Calculation of fatigue life of cylindrical parts at multilayer surfacing and service cyclic thermomechanical loading (Senchenkov I.K., Chervinko O.P. and Ryabtsev I.A.)

Effect of surfacing on stress-strain state of rollers of machines for continuous casting of billets (Gopkalo A.P. and Klipachevsky V.V.)

Modeling of process of melting of electrodes with exothermal mixture in coating during repair welding and surfacing (Kushchy A.M. and Vlasov A.F.)

Structural scheme of procedure for calculation of stressstrain state of parts during surfacing and further service (Senchenkov I.K., Ryabtsev I.A. and Turyk E.)

MODERN METHODS OF SURFACING,

TECHNOLOGIES OF SURFACING

AND THEIR APPLICATION

Application of friction stir welding method for repair and restoration of worn-out copper plates of MCCB moulds (Grigorenko G.M., Adeeva L.I., Tunik A.Yu., Poleshchuk M.A., Zelenin E.V., Zelenin V.I., Nikityuk Yu.N. and Lukash V.A.)

Effect of pulsed electrode wire feeding on formation and wear resistance of deposited bead and losses of electrode metal in $\mathrm{CO}_{2}$ arc surfacing (Lendel I.V., Maksimov S.Yu., Lebedev V.A. and Kozyrko O.A.)

Effect of scheme of powder feeding into arc on its losses and efficiency of plasma-powder surfacing process (Som A.I.)

Electroslag surfacing using discrete materials of different methods of manufacture (Kuskov Yu.M., Gordan G.N., Bogajchuk I.L. and Kajda T.V.)

Energy approach in analysis of microplasma powder surfacing modes (Yarovitsyn A.V.)

Experience in application of the European standards for qualification of surfacing procedures (Turyk E. and Rybtsev I.A.)

Improvement of bimetal joint quality in submerged arc surfacing of high-tin bronze on steel (Majdanchuk T.B., Ilyushenko V.M. and Bondarenko A.N.) 7
Modern state and challenges for development of laser and hybrid surfacing technologies (Review) (Khaskin V.Yu. Shelyagin V.D. and Bernatsky A.V.)

Optimization of modes of submerged arc surfacing over the layer of alloying charge of caterpillar machine running gear parts (Peremitko V.V. and Nosov D.G.)

Peculiarities of fire-cracker plate electrode arc surfacing over alloying charge (Bartenev I.A.)

Peculiarities of heating of stamped billets in non-consumable electrode electroslag surfacing (Kuzmenko O.G.)

Plasma-powder surfacing of nickel and cobalt alloys on copper and its alloys (Pereplyotchikov E.F.)

Ways of updating the technology of induction surfacing of thin steel discs (Pulka Ch.V., Shably O.N., Baranovsky V.N., Senchishin V.S. and Gavrilyuk V.Ya.)

Wear-resistant surfacing with feeding of nanopowders to weld pool (Kuznetsov V.D. and Stepanov D.V.)

5/6 SURFACING MATERIALS, DEPOSITED METAL. COMPOSITION, STRUCTURE, PROPERTIES

Capabilities of laser radiation for improvement of electrode wire quality (Shevchenko S.B., Krivtsun I.V., Golovko L.F., Lutaj A.N. and Slobodyanyuk V.P.)

Cobalt-based alloys for surfacing (Rosert R.)

5/6 Double-layer surfacing compositions based on filling material of $\mathrm{Cr}-\mathrm{Ti}-\mathrm{C}$ alloying system (Sukhovaya E.V.)

Effect of alloying on physico-mechanical properties of fused tungsten carbides (Bely A.I., Zhudra A.P., Roslyakov A.I., Petrov V.V. and Loboda P.I.)

Effect of magnetic-pulsed treatment of filler materials on deposited metal structure (Kuskov Yu.M., Gordan G.N., Eremeeva L.T., Bogajchuk I.L. and Kajda T.V.)

Effect of technological parameters of laser and laser-plasma alloying on properties of 38KhN3MFA steel layers (Markashova L.I., Shelyagin V.D., Kushnaryova O.S. and Bernatsky A.V.)

Flux-cored wires at the world and regional markets of welding consumables (Review) (Mazur A.A., Makovetskaya O.K., Pustovojt S.V. and Brovchenko N.S.)

Flux-cored wires providing deposited metal with high resistance to adhesion wear (Osin V.V.)

Materials and equipment for surfacing of metal hot cutting knives (Zhudra A.P., Voronchuk A.P., Fomakin A.A. and Veliky S.I.)

New electrodes for repair surfacing of damaged lining of impeller chamber of HES hydropower units (Yushchenko K.A., Kakhovsky Yu.N., Bulat A.V., Samojlenko V.I. and Kakhovsky N.Yu.)

Peculiarities of technology of manufacture and application of flux-cored strips for surfacing (Voronchuk A.P., Zhudra A.P., Kochura V.O., Petrov A.V. and Fedosenko V.V.)

Structure and abrasive wear resistance of deposited metal hardened with carbides of different types (Ryabtsev I.A., Panfilov A.I., Babinets A.A., Ryabtsev I.I., Gordan G.N. and Babijchuk I.L.) 
Structure and properties of metal deposited by flux-cored wire with charge of used metal-abrasive wastes (Lentyugov I.P. and Ryabtsev I.A.)

\section{$5 / 6$}

Structure and properties of railway wheel surface after restoration surfacing and service loading (Markashova L.I., Poznyakov V.D., Gajvoronsky A.A., Berdnikova E.N. and Alekseenko T.A.)

\section{INDUSTRIAL}

Application of pulse welding power sources in electrochemical processes (Zhernosekov A.M. and Kislitsyn V.M.)

Application of welded studs for fastening of railway bridge deck (Knysh V.V., Solovej S.A., Grishanov A.A., Linnik G.O. and Malgin M.G.)

Autovacuum brazing in repair of copper panels of MCCB moulds (Grigorenko G.M., Puzrin A.L., Atroshenko M.G., Poleshchuk M.A., Shevtsov A.V. and Mossokovskaya I.A.)

Comparative analysis of models of dynamic welding arc (Pentegov I.V. and Sydorets V.N.)

Comparative hygienic evaluation of arc welding process at constant and pulsed electrode wire feed (Levchenko O.G., Maksimov S.Yu., Lukianenko A.O. and Lendel I.V.)

Contribution of Professor Evgeny O. Paton to the development of welding materials science and production of highquality steel (Lyuty A.P.)

Converter of frequency and number of phases for flash-butt welding of rails (Kuchuk-Yatsenko S.I., Rudenko P.M., Gavrish V.S., Didkovsky A.V. and Antipin E.V.)

Determination of force caused by heating of ring-type products in flash-butt welding (Moltasov A.V., Gushchin K.V., Klochkov I.N., Tkach P.N. and Tarasenko A.I.)

Development of new emission systems of electron beam guns for process operations under space conditions (Zubchenko Yu.V. and Ternovoj E.G.)

Electron beam welding of medium-pressure chamber of gas turbine engine (Nesterenkov V.M., Kravchuk L.A., Arkhangelsky Yu.A., Petrik I.A. and Marchenko Yu.A.)

Equipment for preparation of pipe ends to welding of position butt joints of pipeline (Lobanov L.M., Makhlin N.M., Smolyakov V.K., Vodolazsky V.E., Popov V.E. and Sviridenko A.A.)

Erosion resistance of $\mathrm{Cr}-\mathrm{Ni}-\mathrm{Si}$ metal in surfacing in different shielding environments (Lopukhov Yu.I.)

Evaluation of operability of WWR-M reactor primary circuit piping with welded joint defects (Makhnenko O.V., Milenin A.S. and Saprykina G.Yu.)

Evaluation of strength of joints produced using welding with concurrent brazing (Savulyak V.I., Zabolotny S.A. and Bakalets D.V.)

Evaluation of stress-strain state of gas pipeline section with local stability loss (Rybakov A.A., Garf E.F., Yakimkin A.V., Lokhman I.V. and Burak I.Z.)

Evaluation of thermal stressed state in welded joint of alloy Inconel 690 (Chervyakov N.O.)

Experience of introduction of the technology of reconditioning microplasma powder surfacing at repair of highpressure turbine blades in batch production (Zhemanyuk P.D., Petrik I.A. and Chigilejchik S.L.)

Inductor for continuous heating in hardening of railway rail head (Pantelejmonov E.A. and Pismenny A.A.)

2
Industrial application of hybrid laser-arc welding (Review) (Krivtsun I.V., Khaskin V.Yu., Korzhik V.N. and Luo Ziyi)

Influence of abrasive mass fractional composition on deposited metal wear resistance (Peremitko V.V. and Kuznetsov V.D.)

5 / 6 Influence of metal shrinkage in longitudinal welds of sleeves on contact pressure in main gas pipeline repair (Olejnik O.I.)

8 Manufacture of coaxial copper-aluminium rods using explosion welding and drawing (Bryzgalin A.G., Dobrushin L.D., Shlensky P.S., Lavrenko I.G. and Romashko I.M.)

Manufacture of long-length semi-products from sintered titanium alloys using friction welding (Kapustyan A.E.)

Manufacture of rods of sintered titanium alloys by using different methods of welding (Review) (Ovchinnikov A.V.)

Manufacturing large-sized beds by consumable-nozzle electroslag welding (Shapovalov K.P., Belinsky V.A., Kosinov S.N., Litvinenko S.N., Yushchenko K.A., Lychko I.I. and Kozulin S.M.)

Method of evaluation of thermal resistance of multilayer deposited metal (Babinets A.A.)

3/4 Modern composite materials for switching and welding equipment. Information 1. Powdered composite materials (Khomenko E.V., Grechanyuk N.I. and Zatovsky V.Z.)

Multilayer structures of increased crack resistance formed by explosion welding (Didyk R.P. and Kozechko V.A.)

New possibilities of radiation control of quality of welded joints (Troitsky V.A.)

Noise characteristics during welding in argon-containing shielding gases (Levchenko O.G., Kuleshov V.A. and Arlamov A.Yu.)

Peculiarities of contactless ignitions of alternating current arc (Makhlin N.M.)

Peculiarities in manufacture of thin-walled welded transformable-volume structures for space application (Lobanov L.M. and Volkov V.S.)

9 Peculiarities of restoration of working parts of drilling bit matrix bodies (Stefaniv B.V., Khorunov V.F., Sabodash O.M., Maksymova S.V. and Voronov V.V.)

8 Peculiarities of welding and control in manufacture of heatexchange modules of exhaust-heat boiler of steam-gas electric plant of $150 \mathrm{MW}$ capacity (Tsaryuk A.K., Elagin V.P.,

1 Davydov E.A., Gavrik A.R., Pasechnik A.I., Polonets S.A., Dedov V.G. and Gorelov V.P.)

Physical and mechanical properties of transition zone of bimetal produced by autonomous vacuum brazing of copper on steel (Atroshenko M.G., Poleshchuk M.A., Shevtsov A.V., Puzrin A.L., Mishchenko D.D., Serebryanik I.P. and Borodin A.I.)

State-of-the-art and tendencies of development of European market of joining technologies (Review of materials of eco11 nomical-statistical data collection on welding production SVESTA-2014) (Makovetskaya O.K.)

State-of-the-art and tendencies of development of world market of the main structural materials and welding equipment (Makovetskaya O.K.)

2

Structural superlight porous metals (Review) (Khokhlov M.A. and Ishchenko D.A.)

(1)


Technology of manufacturing high-quality welded tubes from corrosion-resistant steel in Ukraine (Buryak T.N., Katsaj I.A., Kuznetsov V.G., Novikov A.I., Taranenko A.A. and Yaroshenko N.V.)

Thermal protection tile structures of shuttle craft with different external load-carrying elements (Tikhy V.G., Gusev V.V., Potapov A.M., Shevtsov E.I., Gusarova I.A., Manko T.A. and Falchenko Yu.V.)

\section{INFORMATION}

Machines for flash-butt welding of band saws, rods, wires and bars

Welding units A1569M (M1) for automatic submerged-arc welding of circumferential rotatable joints in deep groove

\section{NEWS}

International Conference on Laser Technologies was held in Ukraine

International Conference «Surfacing - Science, Production, Prospects»

Meeting of Boris E. Paton, President of the NAS of Ukraine, with Carlos Moedas, EU Commissioner

New welding wire manufacturer in Ukraine

\section{SCIENTIFIC AND TECHNICAL}

Analysis of process of bead shaping in cladding on narrow substrate (Yushchenko K.A., Yarovitsyn A.V., Khrushchov G.D., Fomakin A.A. and Olejnik Yu.V.)

Analysis of the copper-chromium based electrode deformation during resistance spot welding process (Nachimani C.)

Asynchronous exciters and stabilizers of arc. Analysis and calculation procedure. Part 2 (Makhlin N.M. and Korotynsky A.E.)

Asynchronous exciters and stabilizers of welding arc. Analysis and design procedure.Part 1 (Makhlin N.M. and Korotynsky A.E.)

Calculation of size of structural constituents of metal deposited by induction method with application of mechanical vibration (Senchishin V.S. and Pulka Ch.V.)

Comparative evaluation of power and technological characteristics in continuous flash-butt welding of thick-walled parts at direct and alternating current (Kuchuk-Yatsenko S.I., Rudenko P.M., Gavrish V.S. and Gushchin K.V.)

Computer information-and-measuring system for investigation of arc surfacing processes (Ryabtsev I.A., Lankin Yu.N., Soloviov V.G., Osechkov P.P., Tishchenko V.A. and Tikhomirov A.G.)

Concerning requirements to impact toughness of joints of pipelines produced using flash butt welding (Kyrian V.I., Kuchuk-Yatsenko S.I. and Kazymov B.I.)

Development of technology of combined joining of position butts of thick-walled pipes of high-strength steels (KuchukYatsenko S.I., Kazymov B.I., Zagadarchuk V.F. and Didkovsky A.V.)

Diffusion welding of steel to tin bronze through porous interlayers of nickel and copper (Ustinov A.I., Falchenko Yu.V., Melnichenko T.V., Petrushinets L.V., Lyapina K.V., Shishkin A.E. and Gurienko V.P.)

Effect of depressants and base metal on microstructure of brazed seams in joints of Ni3Al-based alloys with Inconel 718 alloy (Maksymova S.V., Khorunov V.F. and Myasoedov V.V.)
Effect of titanium-containing inoculants on structure and properties of weld metal of high-strength low-alloy steels (Golovko V.V., Stepanyuk S.N. and Ermolenko D.Yu.)

Effect of welding thermal cycle on structure-phase transformations and properties of HAZ metal of alloyed 30Kh2N2MF type medium-carbon steel (Poznyakov V.D. Kostin V.A., Gajvoronsky A.A., Mossokovskaya I.A., 3/4 Zhukov V.V. and Klapatyuk A.V.)

Evaluation of operability of the main pipeline with local wall thinning at repair by arc surfacing (Velikoivanenko 12 E.A., Rozynka G.F., Milenin A.S. and Pivtorak N.I.)

Evaluation of shape and sizes of weld pool in surfacing using combined strip electrode (Matvienko V.N., Mazur V.A. and Leshchinsky L.K.)

Experimental investigation of process of plasma-arc wire spraying (Gulyaev I.P., Gulyaev P.Yu., Korzhik V.N., Dolmatov A.V., Iordan V.I., Krivtsun I.V., Kharlamov M.Yu. and Demianov A.I.)

Features of chromium filler melting depending on laser radiation pulse shape in welding and surfacing processes (Baevich G.A., Myshkovets V.N. and Maksimenko A.V.)

Flash butt welding of railway frogs through cast austenitic insert (Kuchuk-Yatsenko S.I., Shvets Yu.V., Kavunichenko A.V., Shvets V.I., Taranenko S.D. and Proshchenko V.A.)

9

Improving the efficiency of hybrid welding of aluminum alloys (Khaskin V.Yu., Korzik V.N., Sidorets V.N., 8 Bushma A.I., Wu Boyi and Luo Ziyi)

Influence of thermodynamic and structural parameters of multilayer foils on SHS process characteristics (Kravchuk M.V. and Ustinov A.I.)

Interaction of $\mathrm{CO}_{2}$-laser radiation beam with electric arc plasma in hybrid (laser + TIG) welding (Krivstun I.V., Krikent I.V., Demchenko V.F., Reisgen U., Zabirov A.F. and Mokrov O.A.)

8 Investigation of structure and properties of thermal coatings of $\mathrm{WC}-\mathrm{Co}-\mathrm{Cr}$ system produced by high-velocity methods of spraying (Borisov Yu.S., Astakhov E.A., Murashov A.P., Grishchenko A.P., Vigilyanskaya N.V. and Kolomytsev M.V.)

Laser-arc welding of high-strength steels with yield strength of more than $700 \mathrm{MPa}$ (Poznyakov V.D., Shelyagin V.D., Zhdanov S.L., Maksimenko A.A., Zavdoveev A.V. and Bernatsky A.V.)

Laser welding of commercial arc slag remelted titanium VT1-0 hardened by nitrogen (Shelyagin V.D., Saenko V.Ya., Polishko A.A., Ryabinin V.A., Bernatsky A.V., Stepanyuk S.N. and Klochkov I.N.)

Modeling of heat processes for improvement of structure of metals and alloys by friction stir method (Majstrenko A.L., Nesterenkov V.M., Dutka V.A., Lukash V.A., Zabolotny S.V. and Tkach V.N.)

Modelling the characteristics of constricted-arc plasma in straight and reverse polarity air-plasma cutting (Kharlamov

$9 \quad$ M.Yu., Krivtsun I.V., Korzhik V.N., Tkachuk V.I., Shevchenko V.E., Yulyugin V.K., Wu Boyi, Sitko A.I. and Yarosh V.E.)

On the influence of capacitance in the welding circuit on 12 stability of arc welding mode (Tsybulkin G.A.) 
Peculiarities of degradation of metal in welded joints of steam pipelines (Dmitrik V.V., Sobol O.V., Pogrebnoj M.A. and Syrenko T.A.)

Peculiarities of microstructure and impact toughness of metal of welded joints of pipes of high-strength steel with niobium and molybdenum (Rybakov A.A., Filipchuk T.N. and Kostin V.A.)

Prediction of thermodynamic properties of $\mathrm{Al}_{2} \mathrm{O}_{3}-\mathrm{SiO}_{2}$ system melts (Goncharov I.A., Galinich V.I., Mishchenko D.D. and Sudavtsova V.S.)

Resistance welding of shape-memory copper-aluminium alloy (Paton B.E., Kaleko D.M., Kedrovsky S.N., Koval Yu.N., Krivtsun I.V. and Slepchenko V.N.)

Some advantages of butt joints of thin wrought aluminium alloys AMg5M and AMg6M produced by FSW, compared to TIG-welded joints (Poklyatsky A.G., Klochkov I.N. and Motrunich S.I.)

State-of-the-art of hybrid laser-plasma welding (Review) (Bushma A.I.)

Structural changes in metal of welded joints of steam pipelines in operation (Dmitrik V.V., Sobol O.V., Pogrebnoj M.A., Glushko A.V. and Ishchenko G.I.)

Structure and properties of EB- and TIG-welded joints of high-strength two-phase titanium alloys (Akhonin S.V., Belous V.Yu., Selin R.V., Petrichenko I.K. and Vrzhizhevsky E.L.)

Structure of $\gamma$-TiAl joints in resistance butt welding with application of interlayers (Kuchuk-Yatsenko S.I., Zyakhor I.V., Chernobaj S.V., Nakonechny A.A. and Zavertanny M.S.)

Supersonic plasma gas air spraying of cermet coatings of the ( $\mathrm{Ti}, \mathrm{Cr}$ )C-NiCr system (Borisov Yu.S., Borisova A.L., Kolomytsev M.V. and Masyuchok O.P.)

Thermodynamic properties of melts of $\mathrm{CaO}_{2}-\mathrm{SiO}_{2}$ system (Goncharov I.A., Galinich V.I., Mishchenko D.D. and

\section{7}

Sudavtsova V.S.)

Thermodynamics of formation of chromium compounds in welding aerosols (Levchenko O.G. and Bezushko O.N.)

3/4 Vacuum diffusion welding of stainless steel through porous nickel interlayers (Ustinov A.I., Falchenko Yu.V., Melnichenko T.V., Petrushinets L.V., Lyapina K.V. and Shishkin A.E.)

1

\section{WELDING PRODUCTION CHAIR} OF NTUU «KPI» IS 80

12 Application of $\mathrm{N}-\mathrm{O}-\mathrm{C}-\mathrm{H}$ gas systems for synthesis of strengthening components in plasma coatings (Pashchenko V.N.)

Effect of cooling mode after diffusion welding and brazing 7 on residual stresses in graphite-copper edge joints (Kvasnitsky V.V., Ermolaev G.V. and Matvienko M.V.)

8 Main tendencies in development of plasma-arc welding of aluminium alloys (Grinyuk A.A., Korzhik V.N., Shevchenko V.E., Babich A.A., Peleshenko S.I., Chajka V.G., Tishchenko A.F. and Kovbasenko G.V.)

Structure and properties of weld metal modified by nanooxides (Kuznetsov V.D. and Stepanov D.V.)

8 The 80th anniversary of the Chair of Welding Production of NTUU «Kiev Polytechnic Institute»

Thermal-physical peculiarities of gas-shielded pulse-arc welding using non-consumable electrode (Review) (Slivin-

9 sky A.A., Zhdanov L.A. and Korotenko V.V.)

Index of articles for TPWJ'2015, Nos. 1-12

2 List of authors for TPWJ'2015, Nos. 1-12 


\section{LIST OF AUTHORS FOR TPWJ'2015, Nos. 1-12}

Adeeva L.I. No. $5 / 6$

Akhonin S.V. No. 8

Alekseenko T.A. No. 5/6

Alimov A.N. No. 11

Antipin E.V. No. 7

Arkhangelsky Yu.A. No. 12

Arlamov A.Yu. No. 9

Astakhov E.A. No. 10

Atroshenko M.G. No. 9, 11

Babich A.A. No. 11

Babijchuk I.L. No. 5/6

Babinets A.A. No. 5/6, 10

Baevich G.A. No. 2

Bakalets D.V. No. 7

Baranovsky V.N. No. 5/6

Bartenev I.A. No. 5/6

Belinsky V.A. No. 9

Belous V.Yu. No. 8

Bely A.I. No. $5 / 6$

Berdnikova E.N. No. 5/6

Bernatsky A.V. No. 3/4, 5/6(2), 10

Bezushko O.N. No. 7

Bogajchuk I.L. No. 5/6(2)

Bojko V.P. No. 11

Bondarenko A.N. No. 5/6

Borisov Yu.S. No. 2, 10

Borisova A.L. No. 2

Borodin A.I. No. 11

Brovchenko No. 5/6

Bryzgalin A.G. No. $3 / 4$

Bulat A.V. No. $5 / 6$

Burak I.Z. No. 2

Buryak T.N. No. 2

Bushma A.I. No. 8, 12

Chajka D.V. No. 12

Chajka V.G. No. 11, 12

Chernobaj S.V. No. 9

Chervinko O.P. No. 5/6

Chervyakov N.O. No. 11

Chigilejchik S.L. No. 8

Davydov E.A. No. 1

Dedov V.G. No. 1

Demchenko V.F. No. 3/4

Demianov A.I. No. $3 / 4$

Didkovsky A.V. No. 7, 10

Didyk R.P. No. 2

Dmitrik V.V. No. 7, 12

Dobrushin L.D. No. $3 / 4$

Dolmatov A.V. No. $3 / 4$

Dutka V.A. No. 1

Elagin V.P. No. 1
Eremeeva L.T. No. 5/6

Ermolaev G.V. No. 11

Ermolenko D.Yu. No. 2

Falchenko Yu.V. No. 3/4, 7, 9

Fedosenko V.V. No. $5 / 6$

Filipchuk T.N. No. $3 / 4$

Fomakin A.A. No. $5 / 6,9$

Fomichev S.K. No. 11

Gajvoronsky A.A. No. 2, 5/6

Galinich V.I. No. 1, 2

Garf E.F. No. 2

Gavrik A.R. No. 1

Gavrilyuk V.Ya. No. 5/6

Gavrish V.S. No. 1, 7

Glushko A.V. No. 12

Golovko L.F. No. $5 / 6$

Golovko V.V. No. 2

Goncharov I.A. No. 1, 2

Gopkalo A.P. No. 5/6

Gordan G.N. No. 5/6(3)

Gorelov V.P. No. 1

Grechanyuk N.I. No. 10

Grigorenko G.M. No. 5/6, 9

Grinyuk A.A. No. 11

Grishanov A.A. No. 1

Grishchenko A.P. No. 10

Gulyaev I.P. No. 3/4

Gulyaev P.Yu. No. 3/4

Gurienko V.P. No. 9

Gusarova I.A. No. $3 / 4$

Gusev V.V. No. $3 / 4$

Gushchin K.V. No. 1, 11

Hatayan A.A. No. 12

Ilyushenko V.M. No. 5/6

Iordan V.I. No. $3 / 4$

Ishchenko D.A. No. $3 / 4$

Ishchenko G.I. No. 12

Kajda T.V. No. 5/6(2)

Kakhovsky N.Yu. No. 5/6

Kakhovsky Yu.N. No. 5/6

Kaleko D.M. No. 12

Kapustyan A.E. No. 3/4

Katsaj I.A. No. 2

Kavunichenko A.V. No. 8

Kazymov B.I. No. 2, 10

Kedrovsky S.N. No. 12

Kharlamov M.Yu. No. 3/4, 10

Khaskin V.Yu. No. 7, 5/6, 12

Khokhlov M.A. No. $3 / 4$

Khomenko E.V. No. 10

Khorunov V.F. No. 8, 12 
Khrushchov G.D. No. 9

Kislitsyn V.M. No. 8

Klapatyuk A.V. No .2

Klipachevsky V.V. No. 5/6

Klochkov I.N. No. 3/4, 7, 11

Knysh V.V. No. 1

Kochura V.O. No. 5/6

Kolomytsev M.V. No. 2, 10

Kornienko A.N. No. $3 / 4$

Korotenko V.V. No. 11

Korotynsky A.E. No. 3/4, 7

Korzhik V.N. No. 3/4, 7, 10, 11, 12

Kosinov S.N. No. 9

Kostin V.A. No. 2, 3/4

Koval Yu.N. No. 12

Kovalenko V.L. No. 11

Kovbasenko G.V. No. 11

Kozechko V.A. No. 2

Kozulin S.M. No. 9

Kozyrko O.A. No. $5 / 6$

Kravchuk L.A. No. 12

Kravchuk M.V. No. 8

Krikent I.V. No. $3 / 4$

Krivtsun I.V. No. 3/4(2), 5/6, 7, 10, 12

Krushnevich S.P. No. 12

Kuchuk-Yatsenko S.I. No. 1, 2, 7, 8, 9, 10

Kuleshov V.A. No. 9

Kushchy A.M. No. 5/6

Kushnaryova O.S. No. $5 / 6$

Kuskov Yu.M. No. 5/6(2)

Kuzmenko O.G. No. $5 / 6$

Kuznetsov V.D. No. 5/6, 10, 11

Kuznetsov V.G. No. 2

Kvasnitsky V.V. No. 11(2)

Kyrian V.I. No. 2

Lankin Yu.N. No. 9

Lavrenko I.G. No. $3 / 4$

Lebedev V.A. No. $5 / 6$

Lendel I.V. No. 5/6, 12

Lentyugov I.P. No. $5 / 6$

Leshchinsky L.K. No. 9

Levchenko O.G. No. 7, 9, 12

Linnik G.O. No. 1

Lipodaev V. No. 5/6, 7(2)

Litvinenko S.N. No. 9

Lobanov L.M. No. 1, 9

Loboda P.I. No. $5 / 6$

Lokhman I.V. No. 2

Lopukhov Yu.I. No. 8

Lukash V.A. No. 1, 5/6

Lukianenko A.O. No. 12

Luo Ziyi No. 7, 12

Lutaj A.N. No. $5 / 6$

Lyapina K.V. No. 7, 9

Lychko I.I. No. 9

Lyuty A.P. No. $3 / 4$

Majdanchuk T.B. No. 5/6

Majstrenko A.L. No. 1
Makhlin N.M. No. 3/4, 7, 9, 10

Makhnenko O.V. No. 1

Makovetskaya O.K. No. 5/6, 8, 10

Maksimenko A.A. No. 10

Maksimenko A.V. No. 2

Maksimov S.Yu. No. 5/6, 12

Maksymova S.V. No. 8, 12

Malgin M.G. No. 1

Manko T.A. No. $3 / 4$

Marchenko Yu.A. No. 12

Markashova L.I. No. 5/6(2)

Masyuchok O.P. No. 2

Matvienko M.V. No. 11

Matvienko V.N. No. 9

Mazur A.A. No. 5/6

Mazur V.A. No. 9

Melnichenko T.V. No. 7, 9

Milenin A.S. No. 1(2)

Mishchenko D.D. No. 1, 2, 11

Mokrov O.A. No. $3 / 4$

Moltasov A.V. No. 11

Mossokovskaya I.A. No. 2, 9

Motrunich S.I. No. 7

Murashov A.P. No. 10

Myasoedov V.V. No. 12

Myshkovets V.N. No. 2

Nachimani C. No. 8

Nakonechny A.A. No. 9

Nesterenkov V.M. No. 1, 12

Nikityuk Yu.N. No. $5 / 6$

Nosov D.G. No. $5 / 6$

Novikov A.I. No. 2

Olejnik O.I. No. 11

Olejnik Yu.V. No. 9

Osechkov P.P. No. 9

Osin V.V. No. $5 / 6$

Ovchinnikov A.V. No. 2

Panfilov A.I. No. 5/6

Pantelejmonov E.A. No. 3/4

Pasechnik A.I. No. 1

Pashchenko V.N. No. 11

Paton B.E. No. 12

Peleshenko S.I. No. 11

Pentegov I.V. No. 12

Peremitko V.V. No. 5/6, 10

Pereplyotchikov E.F. No. 5/6

Petrichenko I.K. No. 8

Petrik I.A. No. 8, 12

Petrov A.V. No. $5 / 6$

Petrov V.V. No. 5/6

Petrushinets L.V. No. 7, 9

Pismenny A.A. No. $3 / 4$

Pivtorak N.I. No. 1

Pogrebnoj M.A. No. 7, 12

Poklyatsky A.G. No. 7

Poleshchuk M.A. No. 5/6, 9, 11

Polishchuk A.K. No. 2 
Polishko A.A. No. 3/4

Polonets S.A. No. 1

Popov V.E. No. 9

Potapov A.M. No. $3 / 4$

Poznyakov V.D. No. 2, 5/6, 10

Proshchenko V.A. No. 8

Pulka Ch.V. No. 5/6, 8

Pustovojt S.V. No. $5 / 6$

Puzrin A.L. No. 9, 11

Reisgen U. No. 3/4

Romanyuk V.S. No. 2

Romashko I.M. No. 3/4

Rosert R. No. $5 / 6$

Roslyakov A.I. No. 5/6

Rozynka G.F. No. 1

Rudenko P.M. No. 1, 7

Ryabinin V.A. No. $3 / 4$

Ryabtsev I.A. No. 5/6(4), 9

Ryabtsev I.I. No. 5/6(2)

Rybakov A.A. No. 2, 3/4

Sabodash O.M. No. 8

Saenko V.Ya. No. 3/4

Samojlenko V.I. No. 5/6

Saprykina G.Yu. No. 1

Savulyak V.I. No. 7

Selin R.V. No. 8

Semenenko A.V. No. 2

Senchenkov I.K. No. 5/6(2)

Senchishin V.S. No. 5/6, 8

Serebryanik I.P. No. 11

Shably O.N. No. $5 / 6$

Shapovalov K.P. No. 9

Shelyagin V.D. No. 3/4, 5/6(2), 10

Shevchenko S.B. No. $5 / 6$

Shevchenko V.E. No. 10, 11

Shevtsov A.V. No. 9, 11

Shevtsov E.I. No. $3 / 4$

Shishkin A.E. No. 7, 9

Shlensky P.S. No. 3/4

Shvets V.I. No. 8

Shvets Yu.V. No. 8

Sitko A.I. No. 10

Slepchenko V.N. No. 12

Slivinsky A.A. No. 11(2)

Slobodyanyuk No. 5/6

Smolyakov V.K. No. 9

Sobol O.V. No. 7, 12

Solovej S.A. No. 1

Soloviov V.G. No. 9

Som A.I. No. $5 / 6$

Stefaniv B.V. No. 8

Stepanov D.V. No. 5/6, 11

Stepanyuk S.N. No. 2, 3/4

Sudavtsova V.S. No. 1, 2

Sukhovaya E.V. No. 5/6

Sviridenko A.A. No. 9
Sydorets V.N. No. 12(2)

Syrenko T.A. No. 7

Taranenko A.A. No. 2

Taranenko S.D. No. 8

Tarasenko A.I. No. 11

Ternovoj E.G. No. 12

Tikhomirov A.G. No. 9

Tikhy V.G. No. $3 / 4$

Tishchenko A.F. No. 11

Tishchenko V.A. No. 9

Tkach P.N. No. 11

Tkach V.N. No. 1

Tkachuk V.I. No. 10

Troitsky V.A. No. 7

Tsaryuk A.K. No. 1

Tsybulkin G.A. No. 12

Tunik A.Yu. No. 5/6

Turyk E. No. 5/6(2)

Ustinov A.I. No. 7, 8, 9

Velikoivanenko E.A. No. 1

Veliky S.I. No. 2, 5/6

Vigilyanskaya N.V. No. 10

Vlasov A.F. No. $5 / 6$

Vodolazsky V.E. No. 9

Volkov V.S. No. 1

Volokhatyuk B.I. No. 12

Voronchuk A.P. No. 5/6(2)

Voronov V.V. No. 8

Vrzhizhevsky E.L. No. 8

$\mathbf{W}_{\mathrm{u}}$ Boyi No. 10, 12

Yakimkin A.V. No. 2

Yarosh V.E. No. 10

Yaroshenko N.V. No. 2

Yarovitsyn A.V. No. 5/6, 9

Yulyugin V.K. No. 10

Yushchenko K.A. No. 5/6, 9(2)

Zabirov A.F. No. 3/4

Zabolotny S.A. No. 7

Zabolotny S.V. No. 1

Zagadarchuk V.F. No. 10

Zatovsky V.Z. No.1 0

Zavdoveev A.V. No. 10

Zavertanny M.S. No. 9

Zelenin E.V. No. 5/6

Zelenin V.I. No. 5/6

Zelnichenko A. No. 5/6, 7(2), 10

Zhdanov L.A. No. 11(2)

Zhdanov S.L. No. 10

Zhemanyuk P.D. No. 8

Zhernosekov A.M. No. 8

Zhudra A.P. No. 5/6(3)

Zhukov V.V. No. 2

Zubchenko Yu.V. No. 12

Zyakhor I.V. No. 9 


\title{
PATON PUBLISHING HOUSE
}

\author{
www.patonpublishinghouse.com
}

SUBSCRIPTION

The Patgobormat

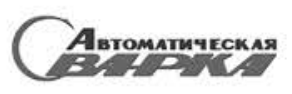

«The Paton Welding Journal» is Published Monthly Since 2000 in English, ISSN 0957-798X.

«Avtomaticheskaya Svarka» Journal (Automatic Welding) is Published

Monthly Since 1948 in Russian, ISSN 005-111X.

«The Paton Welding Journal» is Cover-to-Cover Translation of

Avtomaticheskaya Svarka» Journal into English.

If You are interested in making subscription directly via Editorial Board, fill, please, the coupon and send application by Fax or E-mail.

The cost of annual subscription via Editorial Board is $\$ 348$ for «The Paton Welding Journal» and $\$ 180$ for «Avtomaticheskaya Svarka» Journal.

«The Paton Welding Journal» can be also subscribed worldwide from catalogues subscription agency EBSO.

\author{
SUBSCRIPTION COUPON \\ Address for journal delivery \\ Term of subscription since \\ Name, initials \\ Affiliation \\ Position \\ Tel., Fax, E-mail
}

20

till

20

We offer the subscription all issues of the Journal in pdf format, starting from 2009.

The archives for 2009-2014 are free of charge on wrow.patonpublishinghouse.com site.
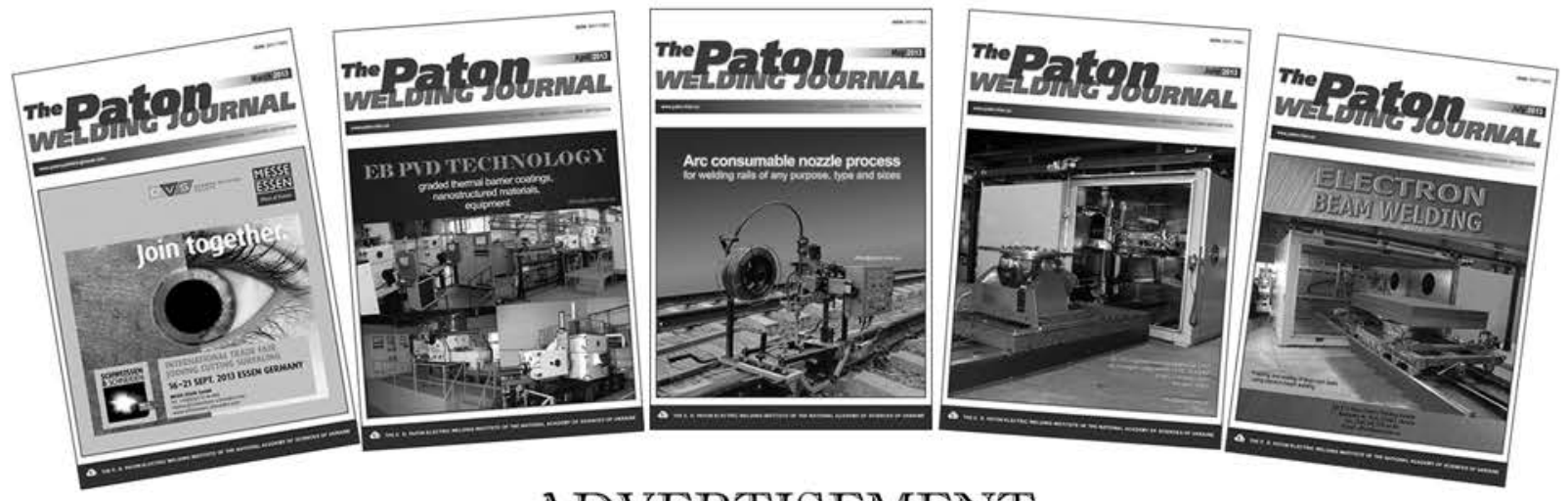

\section{ADVERTISEMENT}

in "Avtomaticheskaya Svarka" and "The Paton Welding Journal"

External cover, fully-colored:

First page of cover

$(190 \times 190 \mathrm{~mm})-\$ 700$

Second page of cover

$(200 \times 290 \mathrm{~mm})-\$ 550$

Third page of cover

$(200 \times 290 \mathrm{~mm})-\$ 500$

Fourth page of cover

$(200 \times 290 \mathrm{~mm})-\$ 600$

\author{
Internal cover, fully-colored: \\ First/second/third/fourth page \\ of cover $(200 \times 290 \mathrm{~mm})-\$ 400$ \\ Internal insert: \\ Fully-colored $(200 \times 290 \mathrm{~mm})-$ \\ $\$ 340$ \\ Fully-colored (double page A3) \\ $(400 \times 290 \mathrm{~mm})-\$ 500$
}

- Article in the form of advertising is $50 \%$ of the cost of advertising area

- When the sum of advertising contracts exceeds $\$ 1001$, a flexible system of discounts is envisaged

Size of journal after cutting is $200 \times 290 \mathrm{~mm}$

Editorial Board of Journal «Avtomaticheskaya Svarka» and «The Paton Welding Journal»

E.O. Paton Electric Welding Institute of the NAS of Ukraine

International Association «Welding

11, Bozhenko Str., 03680, Kyiv, Ukraine

Tel.: (38044) 20060 16, 20082 77; Fax: (38044) 20082 77, 2008145

E-mail: journal@paton.kiev.ua; www.patonpublishinghouse.com 